Manufacturıng

USA

\title{
HIGHLIGHTS $\begin{array}{lllllll}R & E & P & O & R & T\end{array}$
}

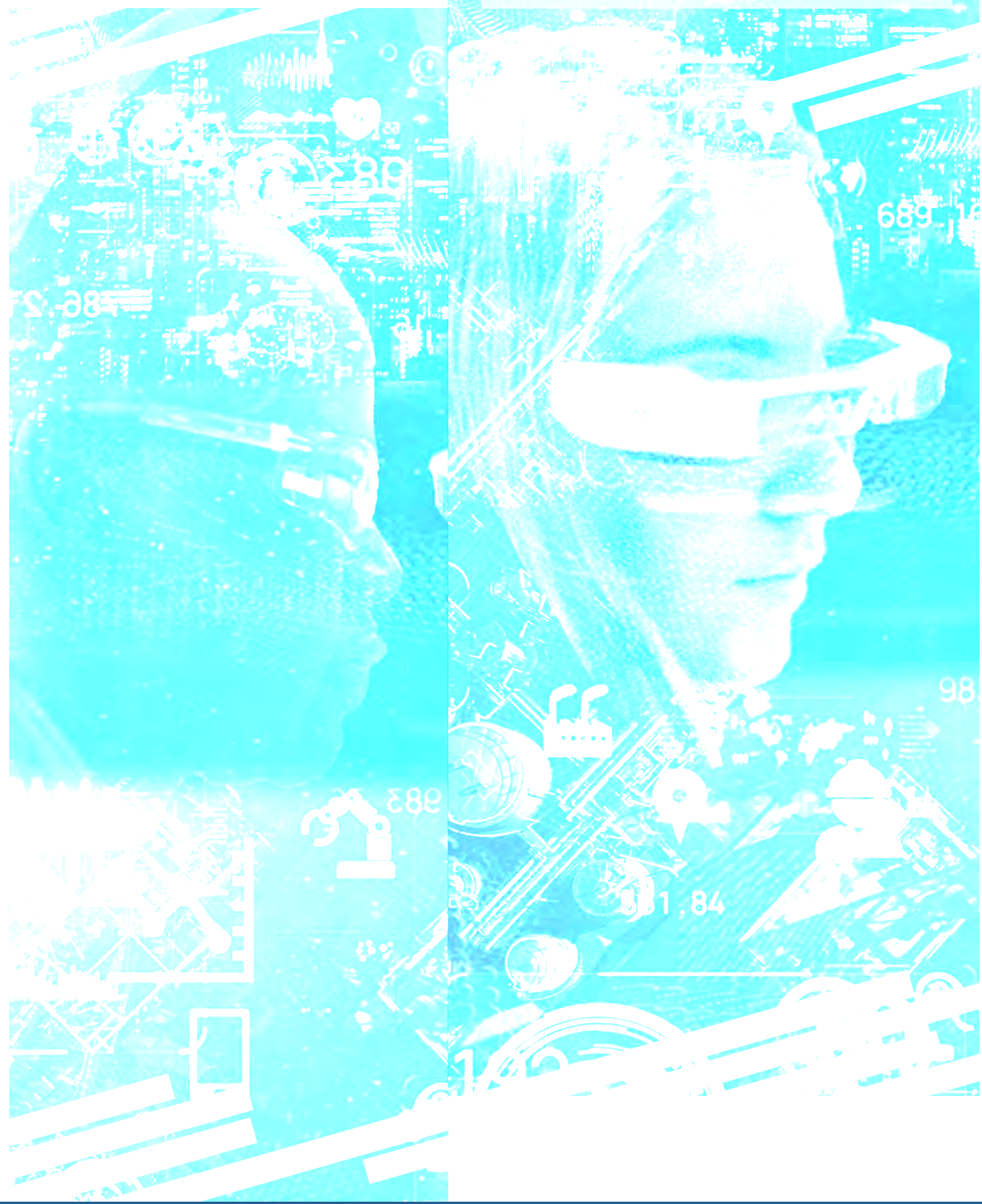




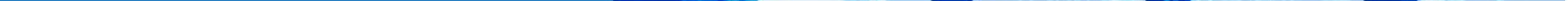




\section{MANUFACTURING USA HIGHLIGHTS REPORT}

\section{A summary of $\mathbf{2 0 2 0}$ Accomplishments and Impacts}

November 2021 


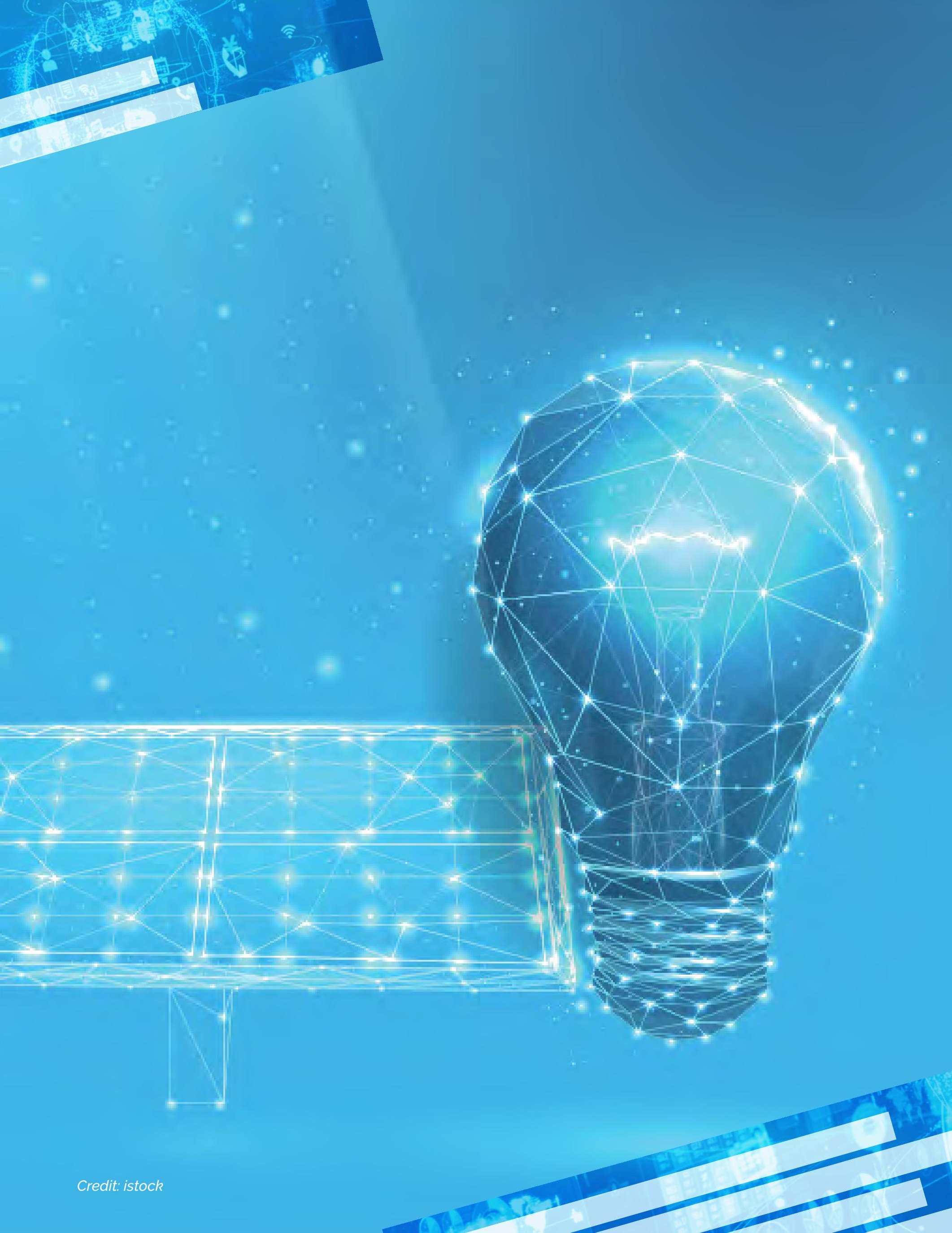




\section{TABLE OF CONTENTS}

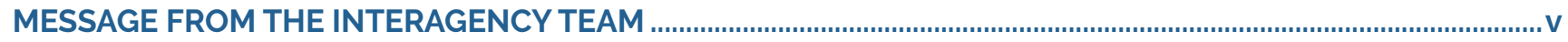

SECURING U.S. GLOBAL LEADERSHIP IN ADVANCED MANUFACTURING ...................................................

LARGE-SCALE PUBLIC-PRIVATE PARTNERSHIPS: THE MANUFACTURING USA NETWORK ........................... 1

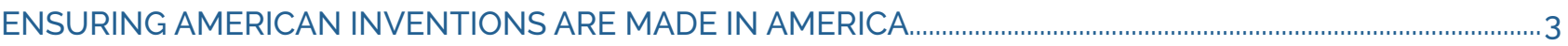

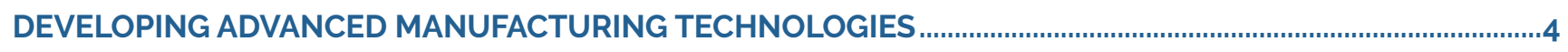

EMPOWERING THE ADVANCED MANUFACTURING WORKFORCE ..................................................................8

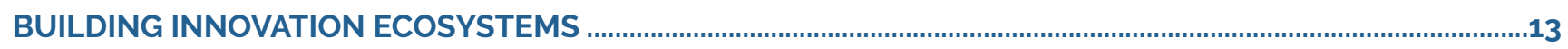

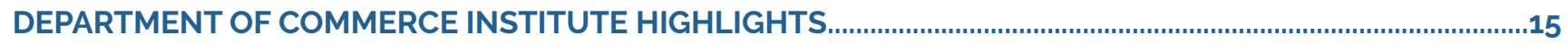

NIIMBL - THE NATIONAL INSTITUTE FOR INNOVATION IN MANUFACTURING

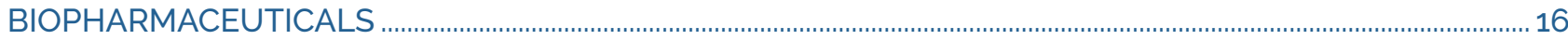

DEPARTMENT OF DEFENSE INSTITUTE HIGHLIGHTS .............................................................................. 24

AMERICA MAKES - THE NATIONAL ADDITIVE MANUFACTURING INNOVATION INSTITUTE .....................26

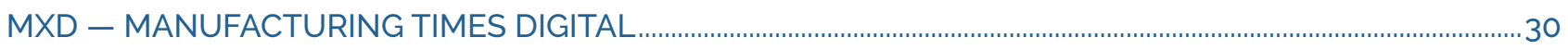

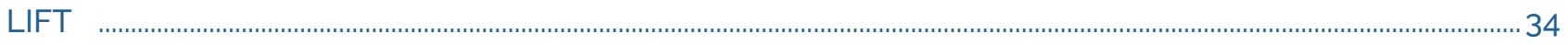

AIM PHOTONICS - AMERICAN INSTITUTE FOR MANUFACTURING INTEGRATED PHOTONICS .................38

NEXTFLEX - AMERICA'S FLEXIBLE HYBRID ELECTRONICS MANUFACTURING INSTITUTE .......................42 42

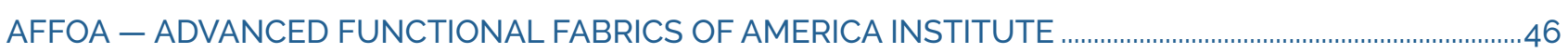

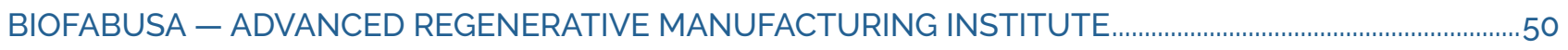

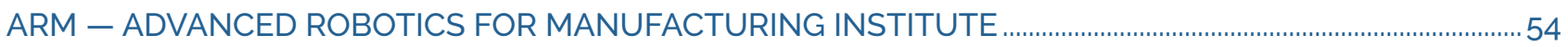

DEPARTMENT OF ENERGY INSTITUTE HIGHLIGHTS .............................................................................. 58

POWERAMERICA-THE NEXT GENERATION POWER ELECTRONICS MANUFACTURING

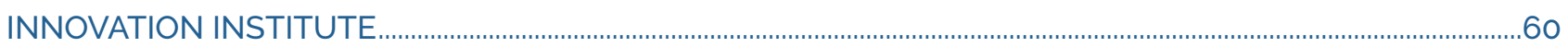

IACMI - INSTITUTE FOR ADVANCED COMPOSITES MANUFACTURING INNOVATION ..................................64

CESMII - CLEAN ENERGY SMART MANUFACTURING INNOVATION INSTITUTE .........................................68

RAPID — RAPID ADVANCEMENT IN PROCESS INTENSIFICATION DEPLOYMENT INSTITUTE ...................... 74

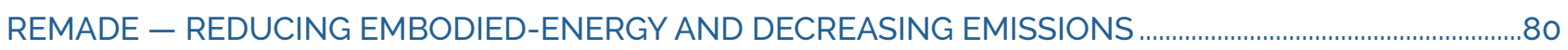

NEW: CYMANII- CYBERSECURITY MANUFACTURING INNOVATION INSTITUTE .........................................86

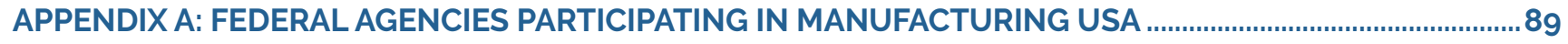

APPENDIX B: ADVANCED MANUFACTURING NATIONAL PROGRAM OFFICE INTERAGENCY WORKING TEAM PARTICIPANTS. 


\section{MESSAGE FROM THE INTERAGENCY TEAM}

This past year brought the country and our world unprecedented challenges, which now present opportunities to innovate and build a new path forward. Using lessons from this year, the manufacturing industry is poised to undergo a transformation.

Supporting this work are the institutes that are part of Manufacturing USA ${ }^{\circledR}$, a national network of publicprivate partnerships united to secure U.S. global leadership in advanced manufacturing through large scale collaboration on technology, supply chain, and workforce development. The network includes the U.S. Departments of Commerce (DOC), Defense (DoD), and Energy (DOE), their 16 sponsored manufacturing institutes, and six other federal partner agencies - the National Aeronautics and Space Administration (NASA), National Science Foundation (NSF), Health and Human Services (HHS), and the Departments of Agriculture, Education, and Labor.

The strong public-private partnerships built by the Manufacturing USA institutes enabled the network to respond rapidly to the COVID-19 pandemic. The institutes' early actions, along with $\$ 73 \mathrm{M}$ in Coronavirus Aid, Relief, and Economic Security (CARES) Act funds from DOC and DoD, propelled them to quickly work with $91^{+}$partners from industry, academia, and government on more than 36 rapid response projects to combat COVID-19 through manufacturing innovation. Earlier this year, we issued the Manufacturing USA Rapid Response to COVID-19 Special Report and held a briefing about these efforts. As of this writing, additional projects are underway and more will be launched as a result of additional funds from the American Rescue Plan to support high-impact projects for research, development, and testbeds to prevent, prepare for, and respond to coronavirus.

In addition to addressing the urgent issues associated with the pandemic, in FY 2020 the institutes conducted over 500 applied research and development projects of high priority for broad industry sectors and collaborated with more than 2,000 member organizations to execute them. Among the institutes' members, $62 \%$ are manufacturing firms and $72 \%$ of those are small manufacturers - critical components of the U.S. supply chain. More than 70,000 workers, students and educators were trained in advanced manufacturing through workforce efforts of the institutes and their partners-a noteworthy achievement considering many planned in-person programs were cancelled, shifted, or moved online due to the COVID-19 pandemic.

Finally, the institutes attracted \$262M in funds from state, federal, and private investment funds not part of the $\$ 163 \mathrm{M}$ in base federal funding. This 1.6 to 1 investment match exceeds the program design of a 1 to 1 match and represents the catalyzing effect of matching investment.

We are proud to share this report from Manufacturing USA highlighting our collective efforts to secure U.S. global leadership in advanced manufacturing.

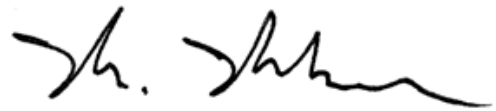

Michael F. Molnar

Department of Commerce

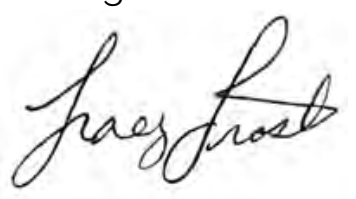

Tracy G. Frost

Department of Defense

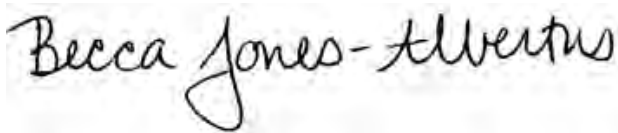

Becca Jones-Albertus

Department of Energy 



\section{ADVANCED MANUFACTURING}

Advanced manufacturing is essential to our economic and national security. American manufacturers contribute more than $\mathbf{\$ 2 . 3 5}$ trillion

to the U.S. economy which, taken alone, would represent theeighth-largesteconomyintheworld,1 Every dollar spent in manufacturing results in an additional \$2.79 added to the economy, making it the highest multiplier effect of any sector.2 This leads to jobs and economic opportunities in local and regional communities.

Manufacturing today employs over $\mathbf{1 2 . 2}$ million people and provides rewarding, living-wage jobs that pay $\$ 88,406$ annually on average, including wages and benefits. ${ }^{3}$ Advanced technology and automation are changing the nature of manufacturing work. While some traditional employee positions will be lost over the next decade, many more new, more technicallyskilled and higher-paying positions will be added. More than half of those new jobs-as many as two million-could go unfilled without training programs to prepare new graduates and current workers with the skills these roles will require.

There are countless benefits to embracing innovation and technology. The nation that capitalizes on these new manufacturing industries and develops the workforce first will dominate the global marketplace and lead the world. By leveraging more advanced manufacturing technologies, the U.S. can ensure that manufacturing remains a strong source of our economic and national security and solid middleclass careers.

\section{Large-scale Public-Private Partnerships: The Manufacturing USA Network}

Manufacturing USA exists to secure U.S. global leadership in advanced manufacturing. The nine federal agencies involved with Manufacturing USA establish and deploy a whole-of-government approach to innovation; one that springboards U.S.-based inventions to the forefront of advanced manufacturing technologies, made here by a skilled American workforce.

Sixteen institutes comprise the Manufacturing USA network: the Department of Commerce (DOC) sponsors one, the Department of Defense (DoD) sponsors nine, and the Department of Energy (DOE) sponsors six. In addition, six other federal agencies participate in key aspects of Manufacturing USA. This brings together vast resources and expertise from across the U.S. government to collaborate on supporting and strengthening U.S. manufacturing.

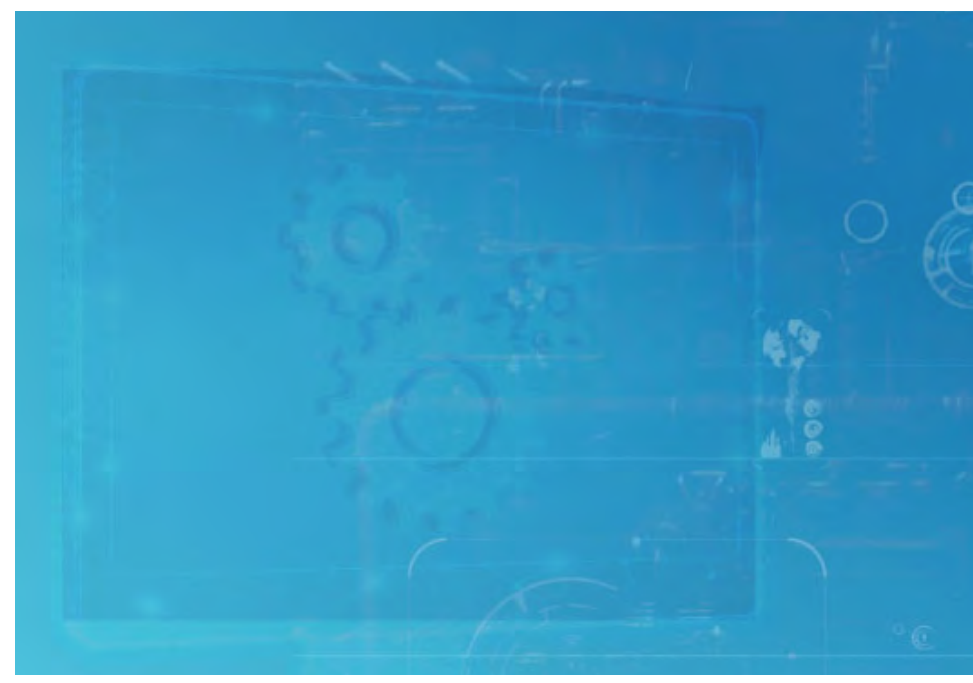




\section{MISSION: Connecting people, ideas, and technology to}

- solve industry-relevant advanced manufacturing challenges

- enhance industrial competitiveness and economic growth

- strengthen our national security

\section{VISION: U.S. global leadership in advanced manufacturing}

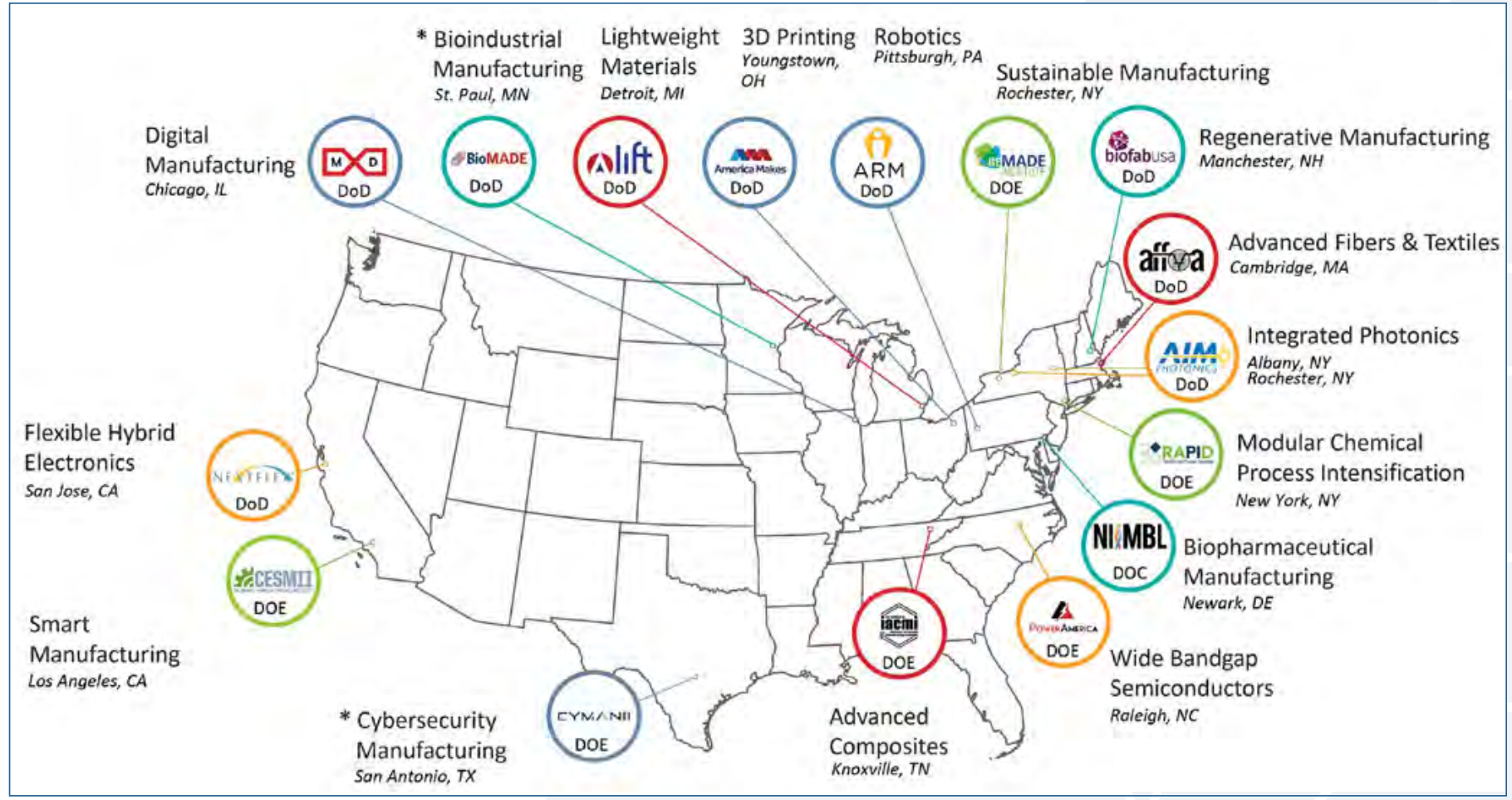

Credit: NIST

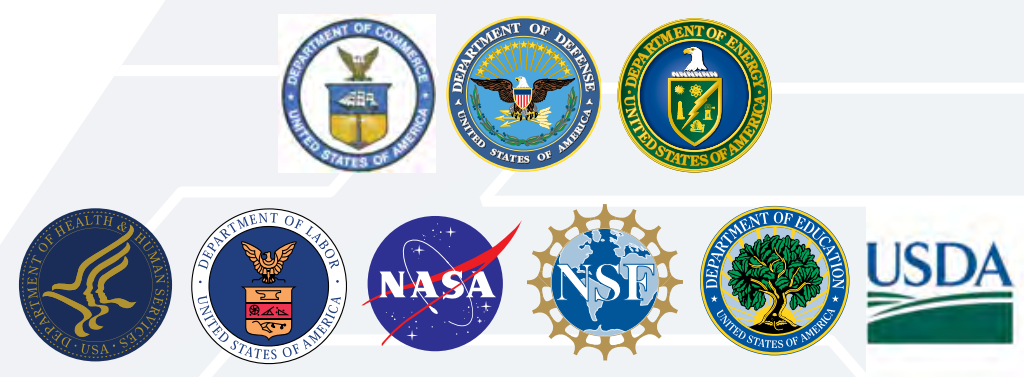


Ensuring American Inventions are Made in America

The members of each institute collaboratively engage in the pre-competitive development of technologies within their specific field of focus. They test applications for the technology, share capital-intensive infrastructure, and create training programs to develop a workforce with the skills needed for today's manufacturing. In addition, they answer the call to meet our country's most pressing challenges, such as the COVID-19 pandemic.

\section{FY 2020 NETWORK IMPACTS}

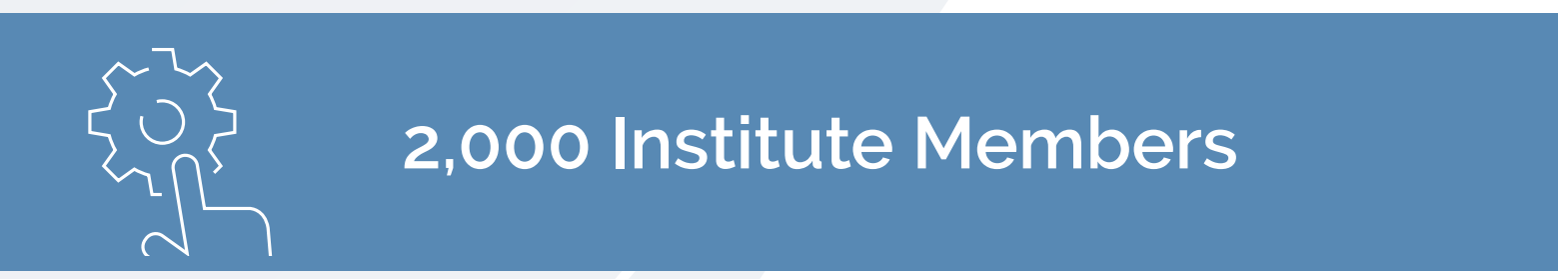

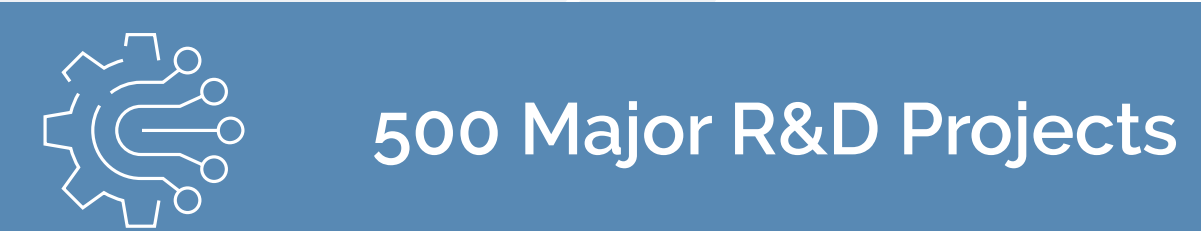
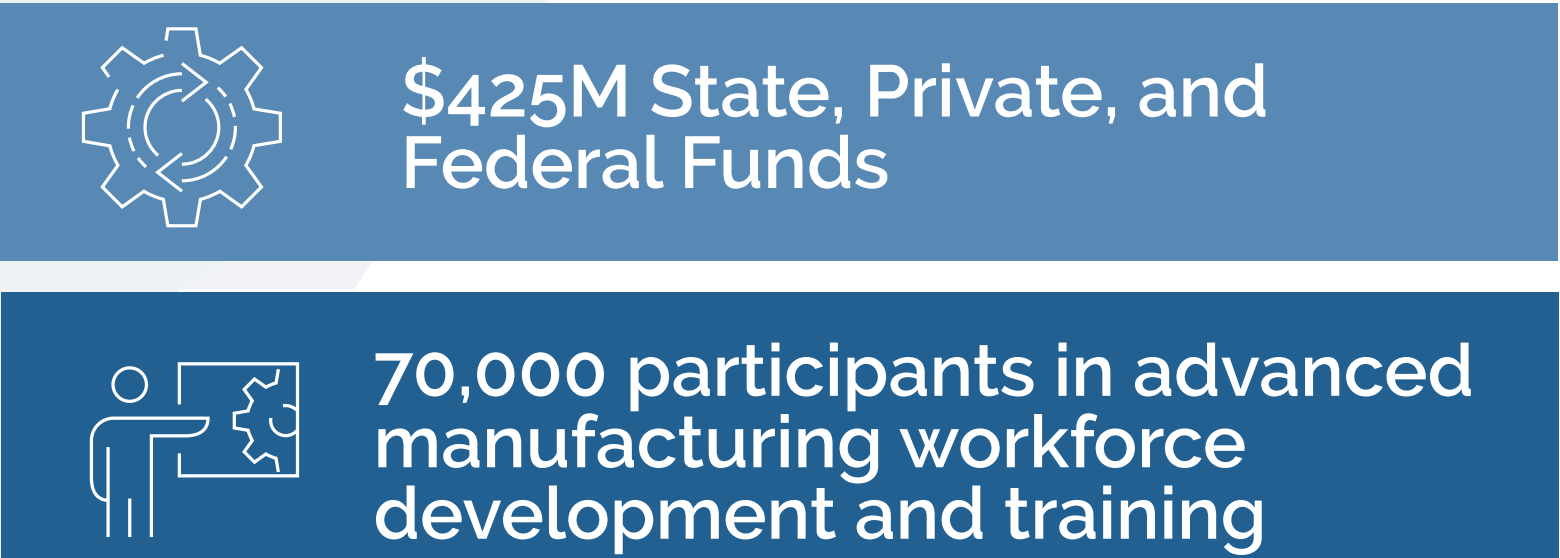

\section{0,000 participants in advanced manufacturing workforce development and training}

Credit: NIST 


\section{$>\quad \longrightarrow$}

TECHNOLOGIES

The institutes and their member organizations collaborate on applied research and development projects in their individual areas of advanced manufacturing technology. These projects lead to innovations in products and processes that have broad application potential throughout the industry. Collectively, this work helps propel the U.S. manufacturing industry forward in the global race to develop new advanced manufacturing technologies. Examples of the 532 R\&D technology advancement projects from the past year include:

\section{Commerce-Sponsored Institute}

\section{NIIMBL Targets Lowering Vaccine Cost}

NIIMBL brought together nearly 1,000 individuals from hundreds of organizations across the biopharmaceutical manufacturing ecosystem to collaborate on the innovations needed to strengthen domestic manufacturing for gene therapy, novel antibodies, and vaccines. Complementing this effort was the first NIIMBL collaborative project call for the Bill and Melinda Gates Foundation's Global Health Fund to lower costs and increase speed-to-market of vaccines.

\section{Defense-Sponsored Institutes}

\section{LIFT Strengthening Armored Vehicles}

LIFT supported the development of an ironmanganese-aluminum alloy for use as armor on military ground vehicles. The steel is expected to reduce armor weight by more than $10 \%$ while matching or exceeding the ballistic performance of rolled homogeneous armor. Through this project, LIFT is optimizing processing conditions to produce affordable, high-quality armor plate in large volumes.

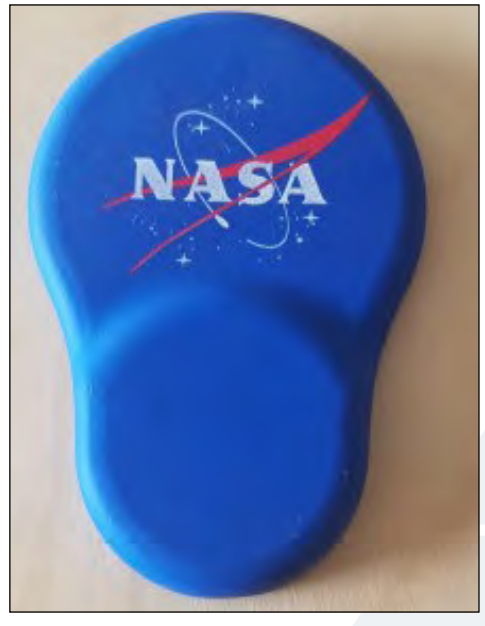

The wearable flexible sensor array for astronaut crew health monitoring. Photo credit: NASA

\section{NextFlex Printing NASA Cortisol Sensor Electrodes}

NextFlex has printed cortisol sensor electrode samples using commercially available graphene and silver-chloride inks on various commercially available substrates. This print capability is the first step in a National Aeronautics and Space Administration (NASA)-funded project that is developing a human-wearable sensing system to monitor multiple physiological markers such as cortisol. The intent is to test prototype devices in space flight by 2022 . 


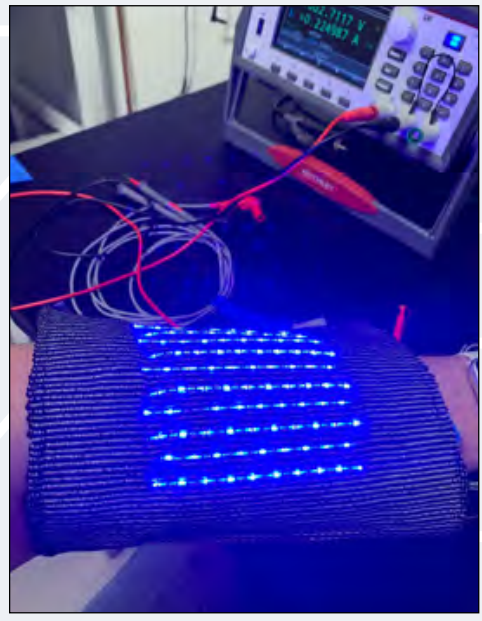

AFFOA blue LED fibers integrated into a conformal fabric for wound therapy; prototype can emit highintensity light. Credit: AFFOA

\section{AFFOA Advanced Blue Light Therapy Textiles}

AFFOA, in conjunction with Massachusetts General Hospital and the Massachusetts Institute of Technology Lincoln Laboratory, developed a blue light therapy textile for advanced wound treatment. The prototype contains nextgeneration light emitting fibers developed at AFFOA that are capable of delivering large doses of blue light into wounds in order to kill bacteria that are resistant to frontline antibiotic treatments. This work has generated interest from medical device companies and is expected to result in follow-on proprietary opportunities.

\section{MxD Manufacturing Readiness Assessment Tool}

Development work continues on Docent, an app for Manufacturing Readiness Level Assessment (MRA), a standardized process to help derisk and evaluate new defense acquisitions to improve outcomes and digitally provide flexibility, collaboration, and scalability across the enterprise. In FY 2020, MxD established a collaborative industry and government working group to help shape the future of the tool. $M \times D$ will launch a series of pilot programs with DoD contractors to enable full adoption of Docent by the Manufacturing Readiness Level Working Group.

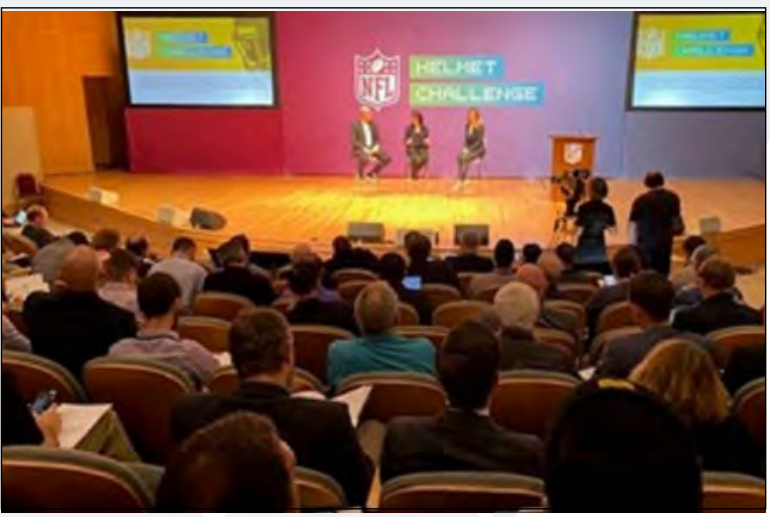

NFL Play Safe, Play Smart Helmet Challenge Kick Off Meeting. Credit: America Makes

\section{America Makes Safer Football Helmets}

For a second year, America Makes partnered with the National Football League (NFL) for the Play Safe, Play Smart Helmet Challenge. America Makes members collaborated with current helmet manufacturers and NFL health and safety scientists and engineers to leverage new technologies like additive manufacturing to produce and test a safer helmet. In FY 2020, the NFL Helmet Challenge announced the winning teams of the initial phase of the project, including multiple America Makes members who participated on the selected teams.

\section{BioFabUSA Deep Tissue Characterization}

As of 2020, BioFabUSA's Deep Tissue Characterization Center (DTCC), funded by the Defense Health Agency, is operational and houses sophisticated instrumentation needed for the multi-"omic" characterization of cells for Tissue Engineered Medical Products (TEMPs) developed by DoD investigators across the country. The DTCC informs the design of sensors specific to the monitoring of cells and tissues in-process on Tissue Foundry manufacturing lines. In FY 2020, BioFabUSA formalized a collaboration with the Cardiovascular Cell Therapy Research Network and the Texas Heart Institute to perform deep analysis of samples from 207 patients in two clinical trials to gain a deep understanding of the relationship between cell therapy manufacturing and efficacy of the therapy in patients. 


\section{AIM Photonics Multi-Project Wafer Run}

The AIM Photonics silicon photonics fabrication facility in Albany, NY has developed a costeffective way for organizations of any size to use the advanced node chip facility. AIM's silicon photonics Multi Project Wafer allows customers to use standard elements developed and optimized by AIM, shortening design time and improving first run success. This prototype vehicle is the most advanced integrated photonics wafer processing available today. AIM also offers access to its electronics and photonics Test, Assembly, and Packaging facility in Rochester, NY.

In addition, AIM offers indium phosphide Multi Project Wafer services through the Infinera Corporation. Infinera plans to send photonic integrated circuits and other photonic materials to the International Space Station, as part of the Materials International Space Station Experiment Program.

\section{ARM Advanced Robotics in Seafood Handing}

A great challenge of industrial robotics is the identification, handling, and manipulation of irregular slippery objects. ARM's FISH (Fostering Innovation in Seafood Handling) Project aimed to bring back to the U.S. processes in the fishing industry through the development of robotics that can reliably identify, grasp, and place seafood or other slippery, non-rigid items while working collaboratively with human workers in a factory environment.

New perception and gripping algorithms and other robotic technologies of the FISH Project could amount to $\$ 20 \mathrm{~B}$ in economic impact each year over the next five to ten years, with potential impact extending into numerous other defense applications such as explosive ordinance inspection, handling and logistics, and resupply. The ARM FISH project has received two additional grants from the National Science Foundation to study the adoption of new technology in the seafood industry while considering COVID-19's impact on worker and food safety concerns.

\section{Energy-Sponsored Institutes}

\section{IACMI Tools for High-Volume, High-Speed Inspection of Structures in Automotive Manufacturing}

Michigan State University established a nondestructive evaluation (NDE) cell to enable aircoupled ultrasound testing (ACUT) to efficiently evaluate composites components integrated into automotive structures. ACUT technology is currently used in the aerospace industry but has not yet been adapted to high-rate use of highvolume products, as in the automotive industry. The ability to inspect every part with NDE will enable increased use of carbon fiber reinforced polymer in auto body structures, leading to significant lightweighting and improved strength for fuel efficiency and crashworthiness. The other members of the project include American Chemistry Council and Vanderbilt University.

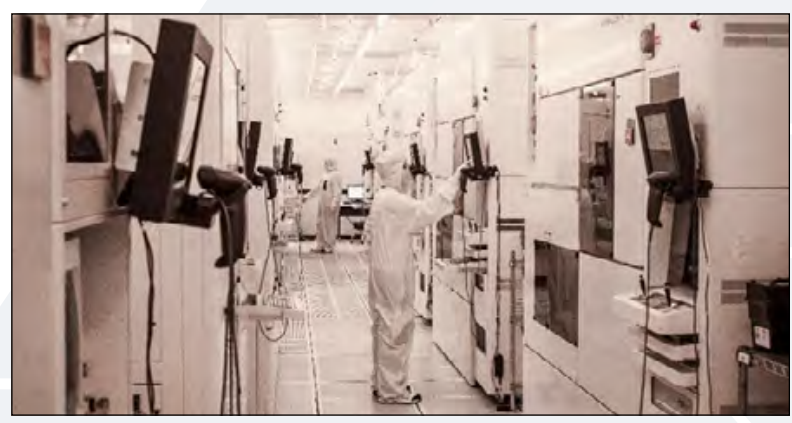

X-FAB Lab. Credit: Power America

\section{Power America Simplified Chip Production}

Silicon carbide is more efficient than standard silicon devices in today's power electronics systems, but it is more expensive to produce. PowerAmerica and X-FAB have standardized processes for customers of their silicon carbide foundry, eliminating technical and logistical complexities arising from different design processes. X-FAB can now fabricate silicon carbide power devices with economy of scale approaching that of silicon power devices. Five semiconductor companies who are PowerAmerica members are using X-FAB in FY 2020 to complement their internal manufacturing efforts. 


\section{CESMII Reducing Energy Consumption in Cement Manufacturing through Smart Manufacturing Technologies}

Researchers at the University of Louisville constructed a scale model of a rotary cement kiln. The lab-scale modelofacement clinker production kiln, equipped with sensors and a control system, combined with a multi-physics (flow, heat transfer) predictive model was developed to optimize operating parameters for reduced energy consumption. The project also validated multi-physics predictive models that will lead to optimized operating conditions, contributing to up to $15 \%$ reduction in energy usage in production kilns. This data analytics approach uses quality control and process operation information from the Argos Roberta Cement Plant to improve energy efficiency through the development of new machine learning tools.

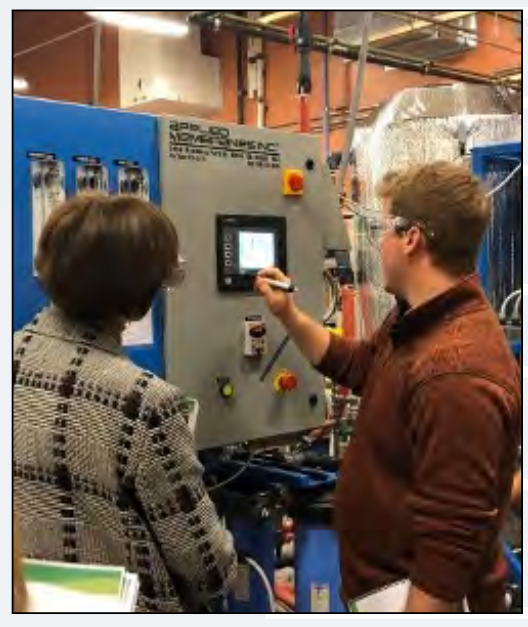

Course Participants. Credit: RAPID

\section{RAPID Conversion of Waste Biomass to Sugars}

lowa State University is partnering with Stine Seed to scale up a modular process for conversion of woody and agricultural biomass to fermentable sugars and other value-added products at or below current market prices. The new process uses less process heat than existing processes, is expected to double energy productivity, and is well suited for distributed processing in modular units designed to fit in standard shipping containers.

\section{REMADE Guiding the Plastics' Industry Transition} to a Circular Economy

A team from Michigan Technological University, Idaho National Laboratory, and their industrial trade association partner, the American Chemistry Council, have developed and validated a framework for systems analysis of polyethylene terephthalate (PET) and olefin polymers in a circular economy. The project was guided by an advisory board of experts from the plastics recycling value chain including Resource Recycling Systems, The Recycling Partnership, Titus MRF Services, Ravago, the Association of Plastics Recyclers, 4RSustainability, BASF Corporation, Dow Chemical Company, and Unilever. The model evaluated how the manufacturing and recycling processes can be configured to minimize energy consumption, reduce greenhouse gas emissions as much as $24 \%$, and provide the greatest benefits economically.

\section{Institutes and their}

\section{member organizations}

\section{collaborated on}

\section{2 technology}

\section{advancement projects.}




\section{EMPOWERING THE ADVANCED MANUFACTURING WORKFORCE}

The institutes and their member organizations partner within their communities and industries to train and develop the workforce needed to leverage advanced manufacturing technologies. They collaborate with the full range of educational entities to raise awareness about the rewards of manufacturing careers, provide a variety of workforce training, and equip current and nextgeneration manufacturing workers with the latest knowledge and skills the manufacturing industry needs for advanced technology processes.

Institutes and their workforce development partners are also developing curricula and certificate pathways in specific technology fields in response to and in collaboration with industry needs. More than 70,000 workers (including veterans and those impacted by the pandemic), students, and educators participated in institute workforce programs - either virtually or through a hybrid approach. Examples include:

\section{Commerce-Sponsored Institute}

\section{The NIIMBL eXperience}

NIIMBL continues to introduce talented African American/Black, Latinx, and Native American students to exciting careers in the biopharmaceutical industry and connects participating companies with prospects for internships and future recruitment. In-person or virtual host organizations include: Merck \& Co. Inc., AstraZeneca, Genentech, and United States Pharmacopeia.

\section{Defense-Sponsored Institutes}

\section{BioFabUSA's Online Gaming for BioFabrication}

BioFabUSA developed the "TEMPtation" game to introduce students in grades 7-12 to Tissue Engineered Medical Products (TEMPs) and biomanufacturing. The online competition, which featured 40 BioFabUsa member organizations, challenged students to learn about the TEMP industry while winning prizes. The goal was to expose students to careers in the industry while they are still choosing high school and college course work. This activity helps BioFabUSA close the skills gap in tissue and organ manufacturing by providing training opportunities to non-collegebound youth.

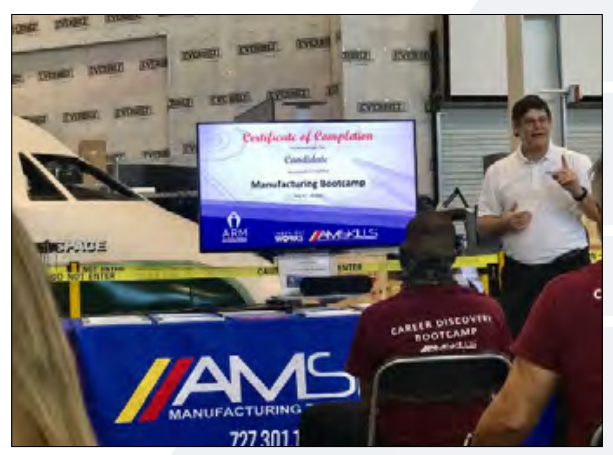

Individuals completing ARM's AmSkills initiative. Credit: ARM

\section{ARM Lowering the Barriers for a Career in Manufacturing}

The Amskills Apprenticeship Recruitment Initiative, an ARM-funded education and workforce development project, achieved early success. A Bootcamp was created as a fast-track program to recruit and assess candidates, many unemployed and from low-income communities, for manufacturers to hire into entry-level positions. The program teaches industry-identified skills and uses hands-on activities and projects to demonstrate ability. In addition to technical skills, participants are evaluated on soft skills, including time management, communication, and presentation abilities. On the final day of the Bootcamp, manufacturers are invited to conduct on-site interviews in a "speed dating" format to improve candidates' interviewing skills and introduce the candidates to the manufacturers for possible hiring. Of the 20 participants who completed the bootcamp, 11 were offered jobs, 
including a homeless veteran and others with criminal records, all looking for a second chance and a life-sustaining career.

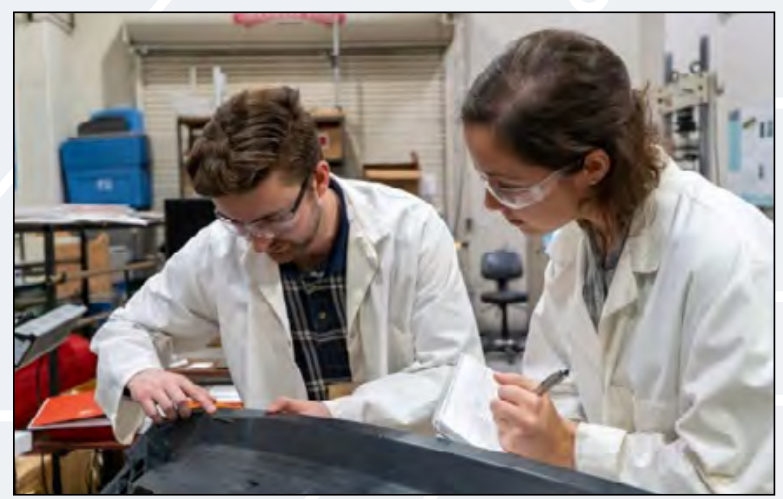

IACMI internship program. Credit: IACMI

\section{Energy-Sponsored Institutes}

\section{IACMI'S Internships in Advanced Composites}

IACMI created an internship program based on experiential learning, mentorship, professional development, and industry collaboration that has provided 119 internships with 40 partners at 25 different locations such as member companies, national labs, and universities. Students have received 50,000 participation hours working with mentors, peers, and partners to advance industry-led projects involving composites research and innovation.

\section{Live Online Remanufacturing Bootcamp with REMADE}

REMADE successfully adapted training to online platforms in response to COVID-19. In partnership with New York State and the Rochester Institute of Technology, REMADE offered a five-part online Remanufacturing Bootcamp. Totaling over seven hours of training from seven subject matter experts, the bootcampwas designed formanufacturersnew to remanufacturing, as well as skilled engineers and technicians seeking industry updates. The training covers an introductory overview of remanufacturing, clean technology, condition assessment, additive repair technology, and design for remanufacturing.

\section{Factory 4.0 Toolkit from CESMII, MIT, and PennState}

CESMII members Penn State University and MIT partnered to develop an instrumented, small-scale fiber extrusion kit that models realworld manufacturing scenarios along with smart manufacturing software applications and supporting educational modules, such as labs, projects, and sample data sets. This tool is designed for the classroom and includes use cases to make smart manufacturing education easily adoptable in a broad range of cross-discipline educational programs.

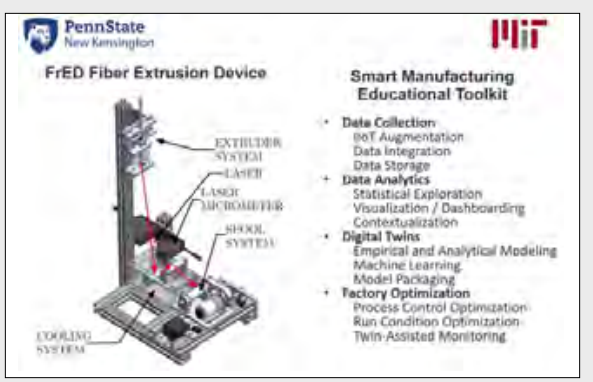

MIT's prior design for the equipment - a Fiber Extrusion Device known as FrED - was updated by Penn State to add power monitoring, an opensource software operating system, and an industrial control option, followed by software networks for data storage and connectivity to CESMII's Smart Manufacturing Innovation Platform ${ }^{\mathrm{TM}}$. Educational modules introduced smart manufacturing overview topics to business and engineering students and took the engineering students deeper into industrial internet-of-things (IloT), data analytics, digital twins, and process optimization. Tools were tested with ten engineering students and seven business students as part of an Industry 4.0 overview. The toolkit is available to educators in the CESMII network to use in their own curricula.

"The rapid pace of technology development has left educational systems scrambling to keep pace and adapt learning outcomes, inadequately preparing the manufacturing workforce at all levels. Projects like this will help change that."

-Joseph Cuiffi, Assistant Teaching Professor and Project Leader, Penn State University 


\section{MassBridge Collaboration with Six DoD Manufacturing Innovation Institutes}

In FY20, the DoD's Manufacturing Technology Program (DoD ManTech) awarded a \$3.2M grant to the Massachusetts Technology Collaborative to develop a manufacturing technician training program that will serve as a national model. Known as the "MassBridge" program, the initiative will develop and test a state-based training and career pathway model for manufacturing technicians that meets the talent needs of the DoD Manufacturing Innovation Institutes and their members.

The MassBridge program will boost training opportunities for technicians and better meet the workforce needs of employers. The program's key deliverable is the development of an integrated, statewide program that will provide a stackable set of training programs that will create connections from existing technician training programs to the skillsets that meet the demands of today's manufacturing sector. The goal will be to develop a model that can be replicated nationally. The program will work with existing vocational programs, high schools, community colleges, and supporting universities, to connect and engage students to encourage them toward careers in DoD institutes' technologies.

"This award is an important national acknowledgment of Massachusetts' successes in manufacturing and the competitive training programs that support our industry. It presents a major opportunity to supercharge our manufacturing sector by engaging new students and adult learners, and helping them develop skills to better succeed in these emerging industries. Our sincere thanks to the DoD and the ManTech leadership team for this award and for entrusting us with the opportunity to pilot this important project."

-Secretary Mike Kennealy, Massachusetts Housing and Economic Development

The award will build on existing strengths Massachusetts has in broad-based manufacturing technician training and its strong ties to the DoD institutes, which is working with several established institutes headquartered across the nation, including initial engagements with Cambridge-based AFFOA, AIM Photonics, NextFlex, ARM, America Makes and LIFT. The MassBridge program will be led by the Massachusetts Technology Collaborative, in partnership with the Massachusetts Executive Offices of Housing and Economic Development, Education and Labor and Workforce Development, MassHire, MIT AIM Academy, MIT Office of Open Learning, the Massachusetts Manufacturing Extension Partnership (MassMEP), and selected Massachusetts community colleges, vocational-technical high schools and state universities.

"Next generation products will require next generation workers, and this program will help us transition and upskill our workforce to meet the needs of the future industry."

-Sasha M. Stolyarov, Ph.D., Chief Executive Officer of AFFOA 


\section{BUILDING INNOVATION ECOSYSTEMS}

The pandemic revealed just how important it is to build and strengthen manufacturing supply chains to respond in times of crisis. When organizations of all types and sizes work together on manufacturing innovation, it reduces risk, improves business, increases U.S. competitiveness, and ensures that our nation's discoveries are turned into new products here in the U.S.

This whole-of-America approach is foundational to the creation and model of the Manufacturing USA institutes. Last year, the institutes had 2,013 member organizations representing large and small manufacturers $162 \%$ of members are manufacturing firms and nearly two-thirds represent small and medium-sized companies), community colleges, major research universities (representing $23 \%$ of members, and state and local economic development entities (15\% of members). These public-private partnerships include all the components of the U.S. industrial base.

To accelerate advanced manufacturing technologies, institutes and their members share facilities, expertise, state-of-the-art equipment, and funding to collaborate on applied R\&D and workforce projects deemed most valuable by stakeholders. The value that the institutes bring can be measured through the continued investment in projects by members and partners.

\section{\$163M federal program funds $\$ 262 M$ funds from industry, academia, other state and federal government awards}

\section{2,013 Member Organizations}

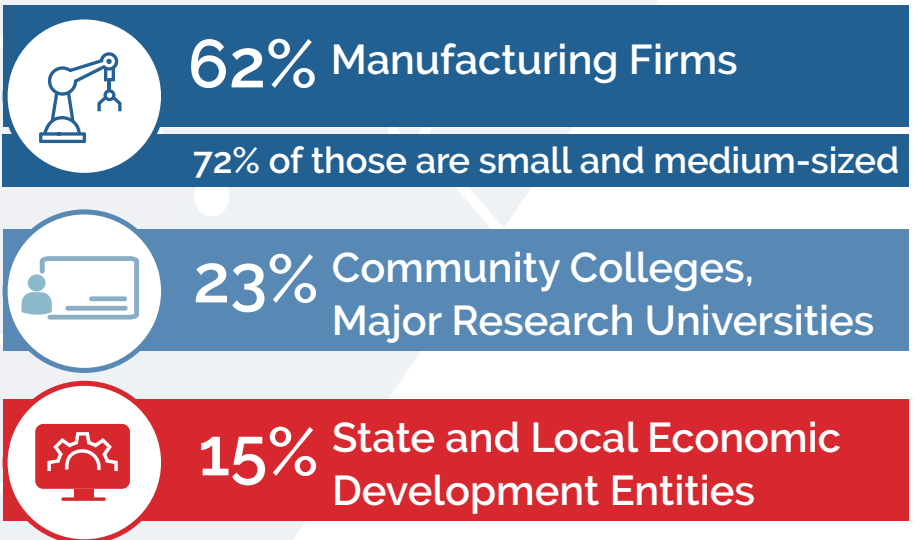

Credit: NIST

\section{Investments}

Institutes attracted \$262M from state, federal, and private investment funds not part of the $\$ 163 \mathrm{M}$ in base federal funding. This 1.6 to 1 investment match exceeds the program design goal and represents the catalyzing effect of matching investment.

In the pages that follow, a sample of each institute's projects and initiatives illustrates their work in building successful and productive innovation ecosystems that are delivering important results from collaboration.

From AIM Photonics' chip fabrication facility in Albany, NY to DoD research fellows embedded at the AFFOA-affiliated Defense Fabric Discovery Center (DFDC) at MIT Lincoln Laboratory and MxD's role in a national project to advance racial equity in manufacturing, the institutes continue to demonstrate the value of Manufacturing USA. 


\section{SUMMARY OF
INSTITUTE ACTIVITIES SUMMARY OF
INSTITUTE ACTIVITIES}

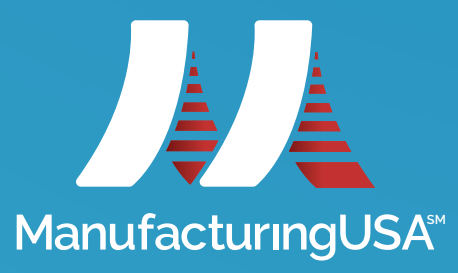

ManufacturingUSA
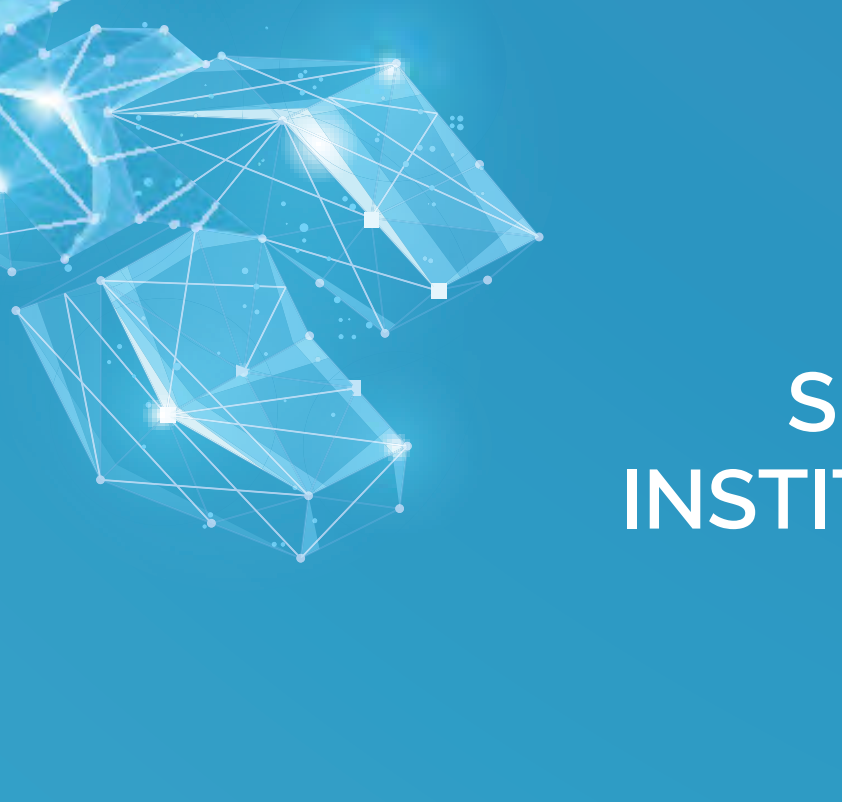
DEPARTMENT OF COMMERCE INSTITUTE HIGHLIGHTS

(i) 


\section{OVERVIEW}

NIIMBL advances the capability to manufacture biopharmaceutical medicines through technology innovation, workforce training, and standards development. Biopharmaceuticals are medicines made from biological sources, including therapeutic proteins, vaccines, and cell and gene therapies. These medicines improve and save lives by treating debilitating conditions such as cancer, diabetes, autoimmune disorders, and bacterial and viral infections untreatable with conventional pharmaceuticals. The institute's work enables the rapid and costeffective manufacturing of safe and efficacious biopharmaceutical products to improve health outcomes and save lives.

\section{TECHNOLOGY ADVANCEMENT}

"NIIMBL has helped Genentech

to provide more shots on goal for

innovative ideas and concepts

that we can bring into the way we

manufacture, release, and test our

products"

- Eric Fallon, Genentech
In FY 2019 and 2020, the institute engaged in 43 technical projects, including 35 newly launched. These projects address key challenges and opportunities facing the industry and include:

- Buffer Stock Blending System - NIIMBL collaborated with BioPhorum Operations Group to build a portable, flexible system for buffer stock preparation, estimated to reduce manufacturing floor footprint by $61 \%$, save \$20M per new facility built, and reduce buffer preparation time by approximately $30 \%{ }^{5}$ NIIMBL members Merck \& Co. (Kenilworth, NJ), MilliporeSigma (Burlington, MA), Sanofi (Bridgewater Township, NJ), GlaxoSmithKline (King of Prussia, PA), and Janssen (Raritan, NJ), as well as other leading companies from the biopharmaceutical industry are collaborating to de-risk the system so that these significant impacts can be realized. The system is currently available for testing at the NIIMBL headquarters at the University of Delaware or onsite at member locations.

- New Efficiencies in Product Quality Testing - NIIMBL member 908 Devices (Boston, MA) developed a table-top mass spectrometer to efficiently analyze cells during the biomanufacturing process. The equipment is 10-times smaller than traditional mass spectrometers and significantly easier to use. It doesnotrequire the extensive technicaltraining needed for traditional mass spectrometers, enabling companies to shift staffing resources toward more complex operations. Project participants include Bristol-Myers Squibb (Summit, NJ), MilliporeSigma (Burlington, MA), University of North Carolina Chapel Hill, and North Carolina State University (Raleigh, NC).

\footnotetext{
${ }^{4}$ Biophorum Operations Group. An Economic Evaluation of Buffer Preparation Philosophies for the Biopharmaceutical Industry. December 2019.

${ }^{5}$ Biophorum Operations Group. NIIMBL-Biophorum Buffer Stock Blending System: A More Advanced Concept for Buffer Manufacturing, December 2019.
} 
- Better Product Stability Through Lyophilization Modeling - Lyophilization, commonly known as freeze-drying, is a crucial part of the biomanufacturing process to ensure product stability. Physical Sciences, Inc. (Andover, MA) built software and hardware tools to help biomanufacturers better understand and model their lyophilization process. The project also led to the opening of the new Lyophilization Lab at the University of Massachusetts Lowell, a pilot-scale facility to support further research and testing of freeze-drying technology. Equipped with these tools, biomanufacturers can better understand their processes and limit potential disruptions that may lead to wasted products or supply shortages. Project participants include University of Massachusetts Lowell (Lowell, MA), Genentech (South San Francisco, CA), Merck \& Co., Inc. (Kenilworth, NJ), National Institute of Pharmaceutical Technology and Education - NIPTE/University of Connecticut (Storrs, CT), Purdue University (West Lafayette, IN), and Massachusetts Life Sciences Center (Waltham, MA).

\section{WORKFORCE DEVELOPMENT}

"Participants in the Door-to-Floor program have been able to advance their careers, with several receiving internships or employment at both innovative start-ups and leading biomanufacturers, such as BMS and Merck."

$$
\text { - Jenny Ligon, Texas A\&M University }
$$

NIIMBL builds a national capacity of skilled talent to meet the acquisition, training, and workforce development needs of the biopharmaceutical manufacturing ecosystem. Through industry and academic collaboration, NIIMBL has established a diverse portfolio of projects and programs aimed at building a world-leading biopharmaceutical workforce to meet rapidly growing industry needs.

Improving the Readiness of New Hires - Texas A\&M University (College Station, TX) created and launched its Door-to-Floor training program, which has awarded 47 students with advanced certificates in biopharmaceutical manufacturing. The program combines online with hands-on training and can be completed in half the time that it would take for a company to on-board a new employee with equivalent training. Other project participants included Akron Biotechnology LLC (Boca Raton, FL) and Vericel Corporation (Cambridge, MA).

\section{Supporting the Next-Generation Biopharma} Workforce - The NIIMBL eXperience introduces talented African American/Black, Latinx, and Native American students to the exciting career possibilities in the biopharmaceutical industry. Students learn how the biopharma industry impacts patients around the world by connecting directly with leaders at large biomanufacturers, small companies, academic institutions, and government agencies. In addition, biopharma companies connect with prospective candidates for future internships or entry-level positions. The program has been completed by 18 students with 17 organizations serving as in-person or virtual hosts. 


\section{Sharpening the Skills of New Biotech}

Employees - The University of Maryland (College Park, MD) partnered with Merck \& Co. (Kenilworth, $\mathrm{NJ}$ ) to develop and launch e-learning modules for new biotech employees or employees in cross-functional teams. The program features 24 modules, each up to nine minutes in length, so employees can complete sections with minimal disruption during work hours. After a successful pilot with 23 subject matter experts, Merck implemented the training into its onboarding program. The program is also available for other biomanufacturers to add to their new employee training programs.

\section{Providing Pathways for Community} College Students - The Jefferson Institute of Bioprocessing (Philadelphia, PA) teamed with two local community colleges and Merck \& Co. Inc. (Kenilworth, NJ) to create the NIIMBL Education Platform (NEP). The Platform offers community college students high-value skills and training for successful bioprocessing careers. Developed with extensive industry input, the five-week course addresses technical training gaps such as upstream and downstream operations, analytical methods, and quality control. Additional project partners included Bucks County Community College (Newtown, PA) and Montgomery County Community College (Blue Bell, PA).

\section{INNOVATION ECOSYSTEM}

"There is so much more benefit with

NIIMBL beyond having a project

selected. The connections we have

made and the value those relationships

have brought to our business is

invaluable."

- Lena Wu, Intabio

Collaboration is the foundation upon which NIIMBL is built. Through projects, events, workshops, working groups, and committees, NIIMBL brings together experts from across the biopharma ecosystem to solve manufacturing challenges and bring innovation to life. Nearly $90 \%$ of NIIMBL member organizations participate in institute activities and projects, embracing the opportunity to forge new connections and implement new technologies. For example, Intabio, a small company in Newark, CA, was able to expand the Early Access Program for its Blaze ${ }^{\text {TM }}$ Microchip technology from 3 to 20 companies as a result of joining NIIMBL. Boston-based 908 Devices credits the connections it made through NIIMBL with bringing its Rebe ${ }^{\circledR}$ at-line media analyzer to market faster. And Potomac Infinity Proteins (North Potomac, MD) may expand its business model from licensing technology to manufacturing after demonstrating through a NIIMBL project the scale-up production of cytokines, proteins used in cell culture to support growth. 


\section{COVID-19 PANDEMIC RESPONSE}

"Never in our lifetime have we experienced a global public health crisis of this magnitude. It presents a significant challenge but also an opportunity - one that I believe we are positioned to help overcome."

- Kelvin Lee, NIIMBL Institute Director

With a mission focused on biopharmaceutical manufacturing innovation, NIIMBL is uniquely positioned to assist with pandemic response by leveraging the expertise of global biomanufacturers and suppliers, small companies, and academic and federal scientists. In April 2020, NIIMBL announced a call for proposals for innovative project ideas to support pandemic prevention, response, and preparedness efforts related to COVID-19. As a result of this call, the institute awarded nine projects with funding from the Coronavirus Aid, Relief, and Economic Security (CARES) Act, including two projects highlighted below:

High-Throughput PCR Testing - In an effort to combat inadequate PCR testing and frozen supply chains, one project developed an alternate PCRbased assay to diagnose COVID-19 using the Roche $\operatorname{cobas}^{\circledR} 6800$ instrument. The new assay allowed Christiana Care, a large Delaware-based health system, to test for COVID-19 in-house rather than sending patient samples to third parties. The rapid testing capabilities enabled the health system to quickly identify and isolate infected individuals, preventing further spread of the disease. The team published the methods so other organizations could implement similar procedures. Other participants include: University of Delaware (Newark, DE), Roche Diagnostics (South Hackensack, NJ), and Incyte (Wilmington, DE).
Providing Virus Proteins to Improve Testing Capabilities - Three separate projects led by Wadsworth Center (Albany, NY), Johns Hopkins University (Baltimore, MD), and Texas A\&M University (College Station, TX), are focused on the production of the SARS-CoV spike protein and receptor-binding domain proteins required for various diagnostic and therapeutic uses including developing assays to measure COVID-19 antibodies and screening for plasma therapy candidates. This work directly impacts the federal response to COVID-19 on three fronts by enabling: 1. the identification of COVID-19 convalescent patients willing to serve as donors for antibody or plasma therapies; 2 . the screening of quarantined health care workers who wish to return to service; and 3. a benchmark in ongoing and forthcoming vaccine trials to assess vaccine efficacy. Project participants include: MassBiologics (Mattapan, MA), Army Research Lab (South Austin, TX), Rensselear Polytechnic Institute (Troy, NY), ProMechSys (Halethorpe, MD), Sartorius Stedim (Boston, MA), and collaboration with the National Institutes of Health and MilliporeSigma (Burlington, MA). 


\section{SUCCESS STORY}

\section{Alleviating PPE Shortage for Healthcare Workers}

During the early days of COVID-19, the lack of personal protective equipment hampered the nation's ability to fight the pandemic. However, through a NIIMBL-funded COVID-19 response project, the Nonwovens Institute at North Carolina State University was able to step up in a big way to act quickly and help ease those shortage concerns.

The project team developed and manufactured a novel filter medium that is suitable for the production of surgical masks and $\mathrm{N} 95$ respirators. The use of this new filter medium opens the door for higher throughput spunbound processes. The unique benefit of utilizing a spunbond structure is that it does not require electrostatic charging and can be re-used and re-sterilized. It is also strong enough to be cut and sewn for automated production of masks and respirators.

Equipped with this new technology, the Nonwovens Institute has developed partnerships with Blue Cross and Blue Shield of North Carolina (Blue Cross NC), Freudenberg Performance Materials, UNC Health, the NC Healthcare Association and NC Medical Society, Brooks Brothers, Hanes Brands, and Outdoor Research to quickly manufacture facemasks.

The team has provided 4.5 million square meters of the filter medium to its partners, which has resulted in the production of more than 100 million masks since March 2020 for frontline healthcare workers. In addition, the team has been able to supply North Carolina State University with approximately 60,000 masks per month since the start of the pandemic.

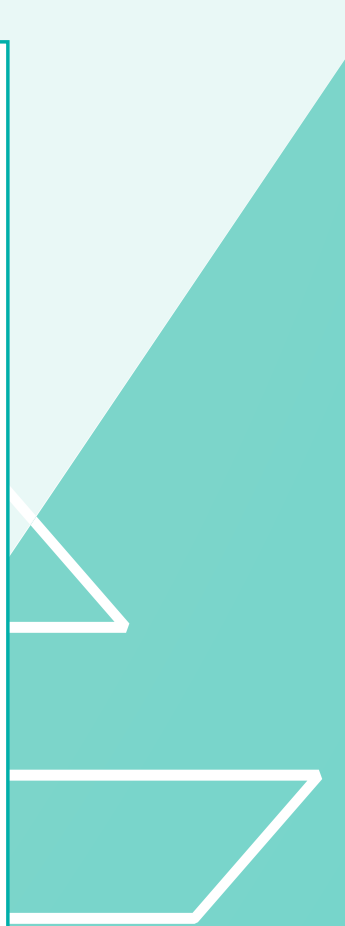

$$
60,000 \text { masks per month since the start of the pandemic. }
$$




\section{Leveraging the Power of the NIIMBL Community to Validate New Technologies for Business Growth}

Intabio's (Newark, CA) innovative technology, Blaze ${ }^{T M}$ Microchip System, measures the Critical Quality Attributes of biopharmaceutical products in real-time, significantly reducing time and costs. Intabio partnered with Merck and Co., Bristol-Myers Squibb, and MilliporeSigma on a NIIMBL project to test their technology on cells supplied by these large biopharmaceutical companies to validate efficiencies and improve market access.

The results: dramatic reductions in testing times and labor. Traditional testing timelines ranged from days to weeks per sample and required several hands-on steps. Only three to five samples could be tested at one time. Blaze eliminates manual steps and reduces testing times to only 15 minutes per sample, with the ability to test up to 25 samples over the course of a single day. In addition, the cost of testing decreased from $\$ 23,000$ per sample to approximately $\$ 65$ per sample. These successes are major steps in getting safe products to patients faster.

Not only was the project a technical success, it also serves as a prime example of the power of the NIIMBL community. Through connections and relationships built within the NIIMBL membership, Intabio was able to increase the number of companies in its Early Access Program from 3 to 20.

"We want to build something that really makes a difference.

One of the things that NIIMBL does is to identify the key issues in biomanufacturing and to me that was the equivalent value of having a large marketing group that I don't have. This helped us focus and direct our business and development with solid industry credibility."

- Lena Wu, Intabio CEO and President, Co-founder 


\section{SUCCESS STORY}

\section{Developing a Diverse Workforce in the Biopharmaceutical Industry}

The race to produce safe and effective COVID-19 vaccines emphasized the vital role the biopharmaceutical industry plays in protecting us from deadly diseases and attaining positive health outcomes. However, its growing pipeline and diversifying product types also increases the demand for skilled talent.

Students from Historically Black Colleges and Universities (HBCUs) and NIIMBL member institutions learned first-hand about the endless possibilities the industry offers during the $2020 \mathrm{NIIMBL}$ experience, held July through August. The program aimed to help African American/Black, Latinx, and Native American students learn about career opportunities in the biopharmaceutical industry through direct interactions with industry professionals. The mutually beneficial program also connects companies with promising young talent for internships and future workforce needs.

While the experience was originally intended for in-person interactions at biopharma manufacturing sites, it successfully shifted to a 4-week virtual experience in 2020 due to COVID-19. After a competitive application process, 13 students were selected to participate in the program. The students learned from Merck and Co. Inc., AstraZeneca, Genentech, Sartorius, Keck Graduate Institute, BioBAT, AABB, Vericel, Solano Community College, and United States Pharmacopeia, among others. The hosts provided an overview of the industry and offered career advancement advice during the interactive sessions. The program was developed in collaboration with the National Society of Black Engineers.

"I loved the wealth of opportunities that were available. I literally didn't know much about biopharmaceuticals, but knowing that this is such a vast industry, now it's like 'where has this been all along.'"

-Talia Gabrielle Scott, student, Lincoln University

The hosts also found tremendous value in the program.

"The eXperience program was a fantastic opportunity to have meaningful interactions with students, beyond what we may normally get to do during a traditional job fair. Not only do we get to talk about our industry, but we also learn from the insightful questions the students asked, what their interests are and where their concerns lie; both are vital feedback as we look to enhance our talent acquisition efforts."

- Rita Wong, Director, Head of Manufacturing 

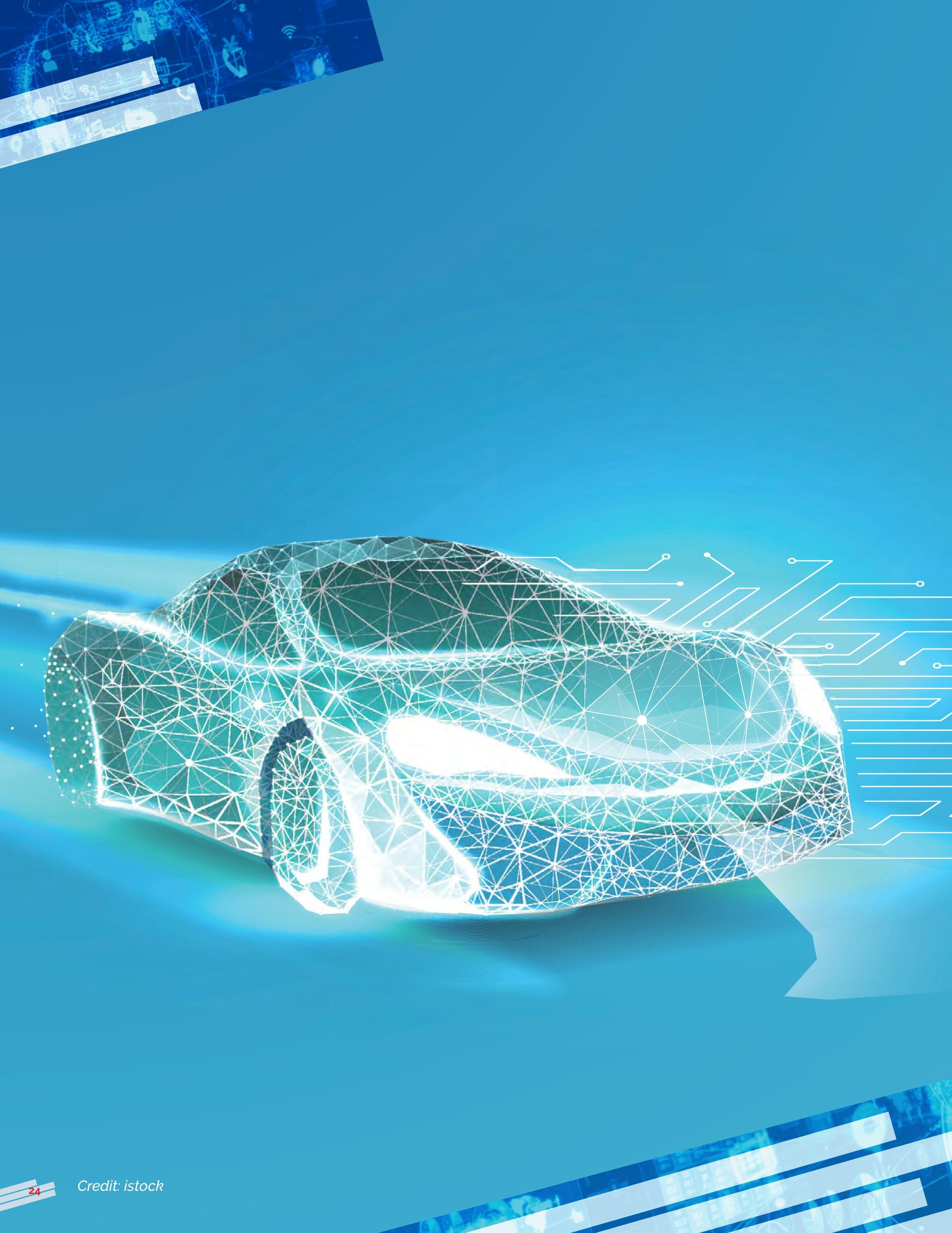
DEPARTMENT OF DEFENSE INSTITUTE HIGHLIGHTS 


\section{OVERVIEW}

America Makes is the nation's leading publicprivate partnership for additive manufacturing technology and education. America Makes members from industry, academia, government, workforce, and economic development organizations work together to accelerate the adoption of additive manufacturing and the nation's global manufacturing competitiveness focusing on three areas: developing additive manufacturing technology, developing an additive workforce, and maintaining a collaborative ecosystem.

\section{TECHNOLOGY ADVANCEMENT}

America Makes convenes technical expertise to build teams with capabilities beyond those of any single organization to address the specific needs of the Department of Defense. By fostering this collaborative mindset, America Makes accelerates the development and deployment of additive manufacturing solutions to enhance military readiness, strengthen alliances, and improve business performance and overall manufacturing affordability.

\section{First-Ever Joint Additive Manufacturing Model} Exchange - In January 2020, America Makes and the Defense Logistics Agency released the first-ever secure web-based system to collaboratively share 3D models in support of additive manufacturing across the Department of Defense. The Joint Additive Manufacturing Model Exchange (JAMMEX) links to various service-specific JAMMEX repositories containing 3D models, allowing users to search, view, and edit the 3D models and download the associated files. JAMMEX is accessible by Common Access Card authentication for all users, including the warfighter in the field.

DoD-Wide Cold Spray Roadmap - America Makes, in collaboration with the Department of Defense, led a series of workshops in March 2020 to develop a roadmap that identifies current state activities and common needs for cold spray technology, a method to make protective metal coatings. This roadmap prioritizes collaboration areas that enhance current activities and accelerate adoption of cold spray technologies. The roadmap was presented to the Joint Defense Manufacturing Council as preliminary findings to be implemented across the Department.

\section{Directed Energy Deposition Standard} Qualifications - An America Makes project produced two standard qualification procedures for directed energy deposition (DED) additively manufactured structures. These novel qualification builds offer a standardized methodology, including process and inspection frameworks, to quantitatively evaluate arc DED material and product quality. Process parameters and procedures demonstrated the feasibility of producing acceptable material devoid of fusion defects, porosity, or cracking. The geometries are relevant to a wide range of naval applications of arc DED, including pressure vessels, highperformance piping, valves, sonar equipment, sea water pump bodies, gears, weapons handling equipment, steam generation equipment, and desalination plants.

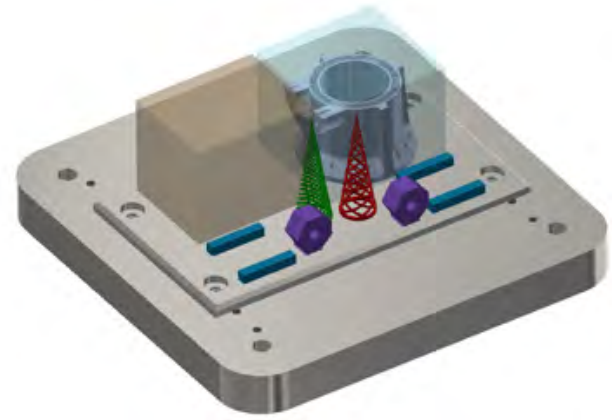

Three-dimensional rendering of representative build layout for experimental analysis of participant code submissions. Credit: America Makes

OASISChallenge-AmericaMakes, incollaboration with the Air Force Research Laboratory and General Electric Research recently announced the Open-Source Additive Scanning Implementation Strategy (OASIS) Challenge. The OASIS Challenge seeks the submission of open-source computer codes and algorithms to help advance laserbased powder bed additive manufacturing (AM). 


\section{WORKFORCE DEVELOPMENT}

"As the North Carolina MEP delves into additive manufacturing deeper in order to help our state's small and medium-sized manufacturers grow and explore new markets and technologies to produce goods, the work that America Makes is doing around workforce development will be invaluable to our state and local leaders as they adapt to meet the training and credentialing demands of the future workforce in AM."

-Evelyn Brown, Director, NC State Extension/Partnership

The America Makes portfolio contains numerous education and workforce development programs, from outreach in communities to K-12 engagement to post-secondary courses and warfighter training. It also includes many DoD and veteran training programs, assistance in building multiple apprentice frameworks, and validation of a variety of industry-recognized credentials. America Makes is dedicated to career pathways in additive manufacturing and community engagement through a variety of stakeholders. As a dynamic partner, America Makes executes projects, builds scale and scope, sets strategy, identifies and creates programs to meet new requirements, and establishes best practices through an advisory committee.
Ongoing Development of Additive Manufacturing Courses - With funding from the Office of Naval Research, America Makes offers 14 courses with nearly 15,000 students and workers participating. New courses are added each month and the institute is working to ensure this training is accessible to underserved populations and veterans.

Additive Manufacturing Technician Apprenticeship Program - America Makes partners AST2 and RCBI conducted a training program at the Naval Surface Warfare Center at Port Hueneme, CA. The training program centered around solving a current sustainment/ manufacturing challenge, a relay extender, for use during the training program. The extender is part of the Aegis fire suppression system used during maintenance activities, which is difficult to procure due to very limited availability. To address the shortage, sailors disassembled the existing range extender from ships being taken out of service, designed various components through 3D scanning and computer-aided design, and reproduced the components using additive manufacturing. In two days, a working prototype was developed and reviewed for use, and the final design was provided to Navy Regional Maintenance Centers (RMCs) for production using their facilities for maintenance activities at the RMCs and for fleet deployment.

\section{INNOVATION ECOSYSTEM}

"Through educational partnerships with organizations like America Makes, we introduce Girl Scouts of every age to STEM to help them see how they can improve the world. We recognize that Ohio is a leader in manufacturing. We want to make sure our girls are ready to engage and lead the next generation."

-Emily Fein, Chief Operating Officer, Girl Scouts of NE Ohio 
America Makes is a critical part of the manufacturing ecosystem in Youngstown, Ohio, which is connected to a larger national network to provide members access to additive manufacturing capabilities and expertise. America Makes expands that network through three satellite centers at the University of Texas El Paso, Texas A\&M Engineering Experiment Station at Texas A\&M University, and the National Institute for Aviation Research at Wichita State University. Each satellite center mirrors and enhances the efforts of America Makes to foster a collaborative infrastructure for the open exchange of additive manufacturing information and research, engaging with local companies and educational institutions to supply education and training in additive manufacturing technologies, and focusing on the transition of additive technology from the research lab to commercialization.

Furthering COVID Response Efforts - As a result of the Institute's successful collaboration with the Food and Drug Administration (FDA), the Veterans Administration (VA), and the National Institutes of Health (NIH) to mobilize the AM industry to address the PPE shortage early in the COVID crisis, America Makes received additional funding from NIST, the Office of the Secretary of Defense (OSD), and the FDA to build upon those successes. The NIST \$1.4 million grant supports education and workforce development initiatives and regional workshops to help develop a workforce that can respond in a time of crisis. The OSD portion focuses on making the America Makes repository of PPE designs an enduring framework for supply chain readiness across the advanced manufacturing sector, and the FDA portion will support mapping capabilities across the country to provide a forecast of where manufacturing can be deployed in a time of crisis.

\section{Support for Air Force Manufacturing Olympics}

- America Makes contracted with the Air Force Rapid Sustainment Office (RSO) and the University of Dayton Research Institutes on the Air Force RSO's 2020 Advanced Manufacturing Olympics. The America Makes team was assigned the tasks of 1) bringing together a broad community of experts from industry, academia, and government to explore new possibilities for how advanced manufacturing, with particular focus on additive manufacturing, can be deployed across the Department of Defense and the Air Force, 2) coordinate and promote the event, and 3) develop the event's technical challenges. America Makes launched their promotional campaign in support of the event in September 2020.

Additive Manufacturing Data Strategic Guide The ASTM International's Additive Manufacturing Center of Excellence worked with America Makes to debut a strategic guide that identifies gaps, challenges, solutions, and action plans for additive manufacturing data. The strategic guide comes as a result of a prior workshop on additive manufacturing data management and schema that was jointly organized by ASTM International and America Makes and brought together more than 100 experts from government, industry, and academia for a series of technical talks, panel discussions, and brainstorming sessions related to data in additive manufacturing.

"The Ohio Manufacturing Extension

Partnership (MEP) is excited to partner with America Makes. The projects feed nicely into our initiatives - Ohio MEP High School Internship and Defense Manufacturing Community designation application. We support America Makes' connection with the Ohio Manufacturers Association in workforce development and sector partnership activities. It feels great to have collaboration across the real partners who support Ohio's manufacturing ecosystem, building a new future for workers and the manufacturers!"

-Susan Foltz, Director, Manufacturing Assistance Programs, Office of Small Business and Entrepreneurship 

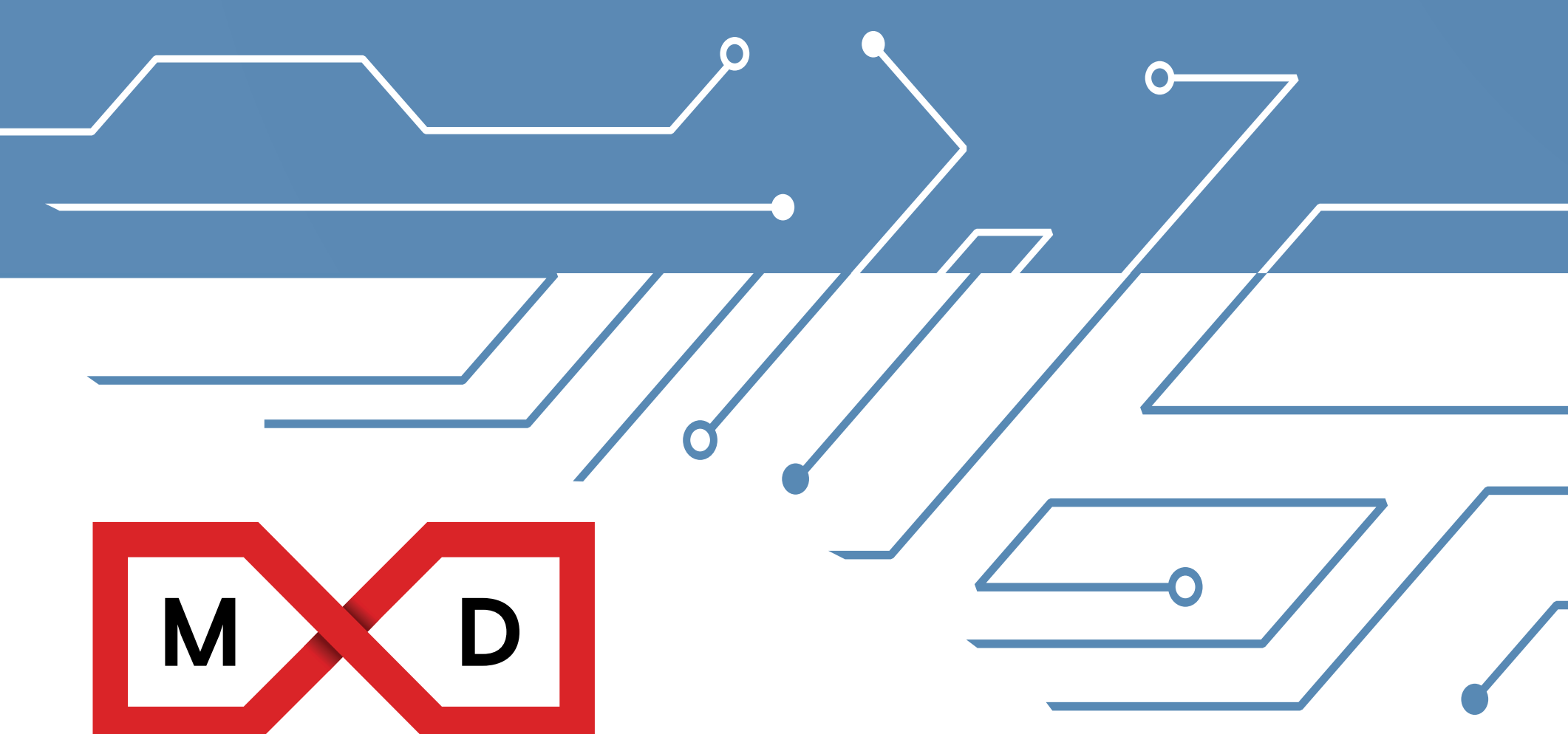

Manufacturing Times Digital

Established: February 2014

Headquarters: Chicago, IL

Mission: Provide the government and U.S. manufacturers with the digital tools needed to transform American manufacturing.

Members (as of September 30, 2020): 299

Total Committed Funding on Original and Follow-on

Agreements with DoD: \$84.5M Base Federal Funding; \$130.9M

Base Non-Federal Cost Share

Additional Committed Project Funding:

\$31.9M DoD-Sponsored Projects

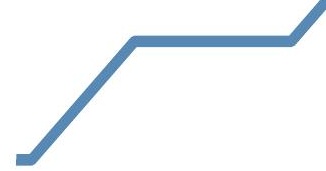

\section{mxdusa.org}




\section{OVERVIEW}

$M \times D$ is where innovative manufacturers forge their futures. In partnership with the Department of Defense, MxD provides manufacturers with digital tools and expertise to begin building every part better than the last. Institute members increase their productivity and win more business, powered by a workforce with the digital skills they need for a cybersecure industrial base. MxD also works with DoD manufacturers and contractors to assess and implement digital improvements throughout the industrial base.

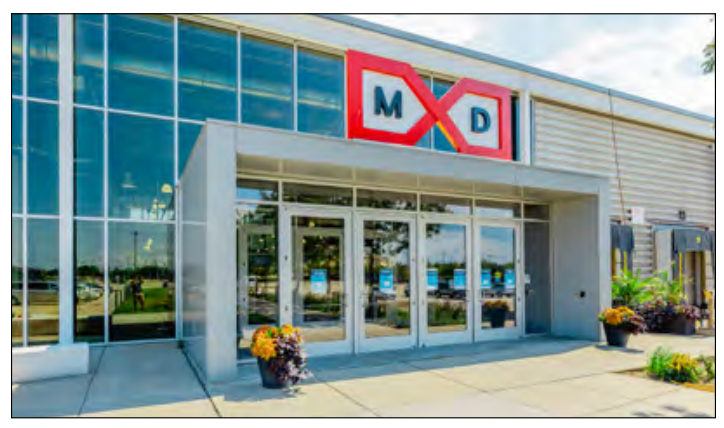

MxD's Headquarters. Credit: MxD

\section{TECHNOLOGY ADVANCEMENT}

"MxD is a big part of our team's heritage. We helped conceive and launch the project as part of a national team of experts from government, industry, and academia that came together to help advance digital manufacturing and design innovation. Now as Fast Radius expands our software platform and service offerings, we're excited to partner with $M x D$ to bring innovation into the manufacturing industry and to grow our company by bringing it back to our roots."

-Lou Rassey, CEO, Fast Radius
Ensuring the military has the most effective resources is a central driver of MxD's work. MxD partners with manufacturers to harness the power of the digital thread to drive forward advanced manufacturing technologies, while equipping the workforce (present and future) and the supply chain with the skills and cyber resiliency needed to ensure an innovative, secure, and prepared defense industrial base.

Digital Needs Assessments - Members of the MxD Government Engagement and Engineering Teams visited Rock Island Arsenal's Joint Manufacturing Technology Center (RIA-JMTC) to conduct an advanced manufacturing and cybersecurity Digital Needs Assessment. The team identified more than 30 problem areas standing in the way of JMTC's digital modernization efforts. MxD helped narrow this list to eight projects that would advance the adoption of digital technology on the production floor, while providing a tangible impact to the warfighter by improving RIA-JMTC's Production to Promise deliver rate from $70 \%$ to its goal of $100 \%$. The MxD team then submitted a proposal to implement the projects (which currently is in the contracting stage), while securing commitment of the Quad Cities Chamber of Commerce (an MxD member) and the Illinois Defense Network to provide support in connecting local small businesses directly to this projected $\$ 9.8 \mathrm{M}$ multiyear opportunity.

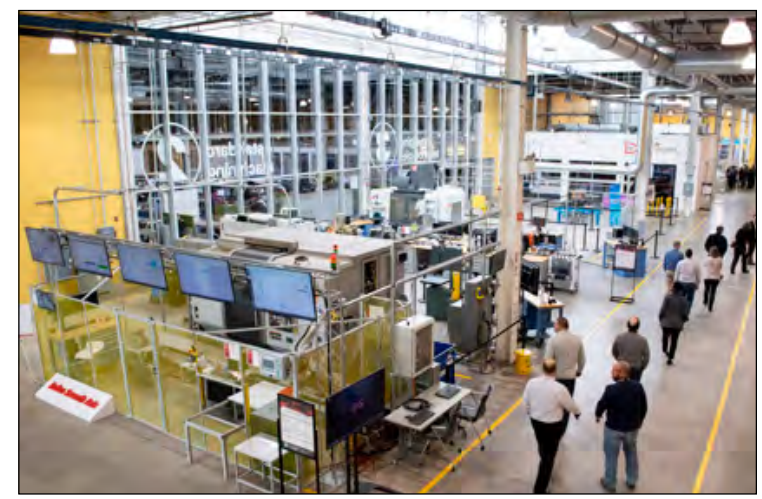

MxD's factory floor facility. Credit: MxD 
- 5G Added to Factory Floor - In collaboration with AT\&T Business, MxD added a dedicated $5 G$ and Multi-Access Edge Computing (MEC) testbed to the MxD Future Factory Floor. The testbed will enable prototyping and experimentation of $5 \mathrm{G}$ both for manufacturing companies and for the Department of Defense with the goal of accelerating the Office of the Secretary of Defense's modernization priorities.

\section{WORKFORCE DEVELOPMENT}

"The pace of change in manufacturing has accelerated - what we thought was next is now, and identifying and developing the cyber skills of the future is critical to the ongoing success of the industry in America.

That's why we are pleased to partner with MxD to bring together the cybersecurity expertise from our Experis brand with the deep insight of our Manpower Manufacturing business to create a common language to describe these emerging roles."

- Becky Frankiewicz, President ManpowerGroup North America

MxD's workforce development program, MxD Learn, fosters collaboration across industry, academia, government, and nonprofit leadership to ensure the current and future workforce is connected to the roles and competencies needed for digital and cybersecurity manufacturing applications.

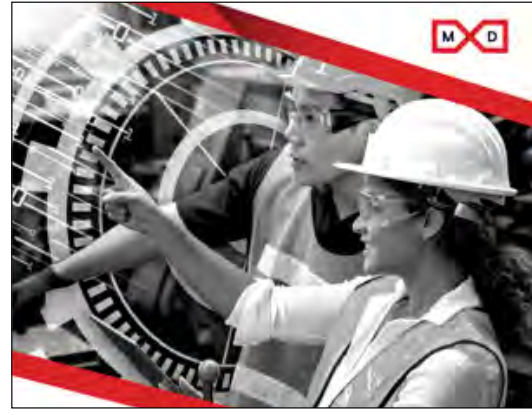

The cover of The Hiring Guide: Cybersecurity in Manufacturing released in 2020 by MxD. Credit: MxD

Cybersecurity Hiring Guide - MxD released The Hiring Guide: Cybersecurity in Manufacturing, a groundbreaking guide to help U.S. manufacturers build the workforce needed to protect the industry from growing cyber threats. The Hiring Guide identifies 247 cybersecurity-related job roles in manufacturing (both current and future), and details the skill sets, career paths, and education and training needed to prepare American workers for these jobs. The project, led by MxD and ManpowerGroup, engaged experts from more than 25 industry, academic, workforce development, and government organizations to define the state and future of manufacturing's cybersecurity workforce. The Hiring Guide examines and provides comprehensive descriptions of three job roles especially crucial to the future of cybersecurity: cybersecurity information technology/operational technology integration engineer, secure design product life cycle manager, and supply network cybersecurity compliance manager. More job descriptions will be added as MxD partners with more companies, foundations, and other funders on the effort. The Hiring Guide is available for free download at mxdusa.org/HiringGuide.

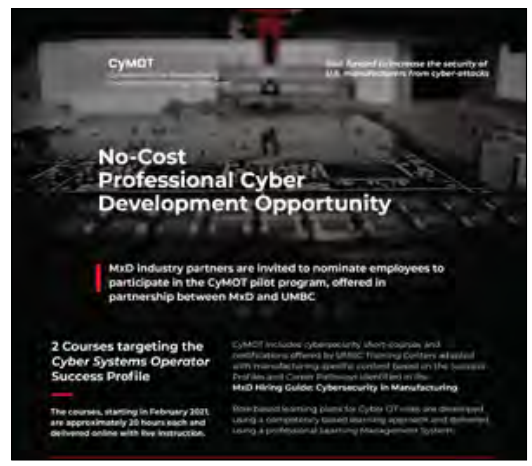

MXD and UMBC are partnering up to offer a CYMOT pilot program and are currently recruiting applicants. Credit: UMBC 
Launched Cybersecurity Training - The University of Maryland Baltimore County (UMBC) in partnership with $M \times D$ launched a program to provide cybersecurity training for current manufacturing workers. Nearly $\$ 650,000$ from the DoD Office of Economic Adjustment is funding the program which is the first to focus on increasing workers' cybersecurity skills. The multi-phased project is developing a curriculum for webbased courses on manufacturing cybersecurity fundamentals, eventually leading to more advanced training and specialized coursework that will be delivered with immersive training technologies such as virtual reality.

\section{INNOVATION ECOSYSTEM}

"The MxD team connected me with several additive manufacturing subject matter experts from within its membership to aid with innovative technology commercialization efforts through our DoD/DLA-funded Small Business Innovation Research project. Conversations with these experts helped us to capture excellent voiceof-the-customer inputs and perform early customer validation of our novel technology, which can benefit both the defense industrial base and civilian industrial manufacturers. Without MxD's help, making such high-quality connections with potential end users would have been challenging for a small business like ours."

-Ram Shetty, Founder/CEO, OPEX Systems

Through its robust network of industry, academic, and government partners, MxD supports U.S. manufacturing with workshops, federally funded project opportunities, workforce development tools, and a 22,000 square-foot future factory floor innovation center to advance the digital transformation of U.S. manufacturers to accelerate innovation so they produce "every part better than the last."

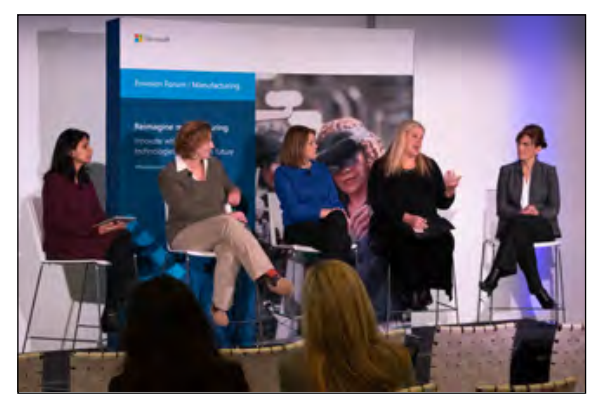

Chandra Brown of MXD and others participate in Women's Leadership Panel hosted at MXD's headquarters. Credit: $M x D$

Microsoft Envision Forum - MxD hosted the Microsoft Envision Forum on Manufacturing, bringing together 365 visitors to gain real-world insights from peers and accelerate their path to intelligent manufacturing across supply chain, factory, warehousing, and product innovation. The event shared case studies from manufacturers adopting new technologies across all areas of business with focus areas including reimagining manufacturing, delivering new services, empowering the workforce, and optimizing digital operations. After the event, Microsoft upgraded its partnership with $M \times D$ and started the buildout of a space on MxD's factory floor to demonstrate relevant technologies.

3D Printer Cybersecurity for DoD - 3D printers currently used by the armed services and other members of the industrial base generally do not meet NIST's Cybersecurity Risk Management Framework requirements. The framework is complex, and a lack of secure printers means they cannot be easily connected to DoD enterprise networks, preventing DoD from maximizing the potential of additive manufacturing and $3 \mathrm{D}$ printing. To resolve this, $M \times D$ partnered with the DoD Joint Additive Manufacturing Working Group (including members from Rock Island Arsenal and the United States Air Force), to establish a pathway that improves the cybersecurity of a commonly used 3D printer provided by MxD member Markforged. 

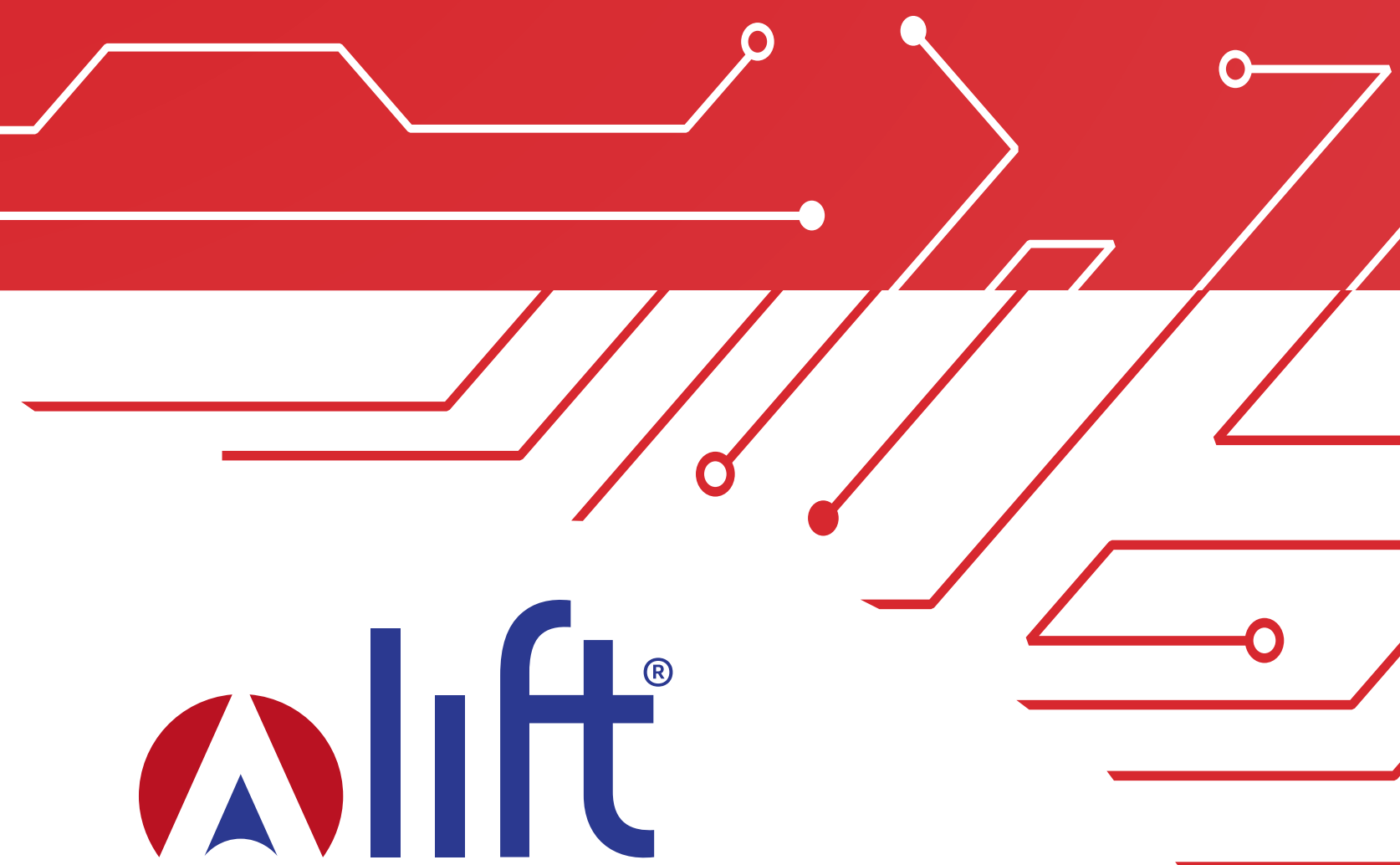

Operated by the American Lightweight Materials Manufacturing Innovation Institute (ALMMII)

Established: February 2014

Headquarters: Detroit, MI

Mission: Advancing American manufacturing into the future through technology and talent development and driving rapid implementation of smarter manufacturing by connecting the materials, processes, and systems together with the talent needs of the future.

Consortium Organizer: America Lightweight Materials Manufacturing Innovation Institute (ALMMII)

Members (as of September 30, 2020): 106 Member Organizations; 189 Academic Partners

Total Committed Funding on Original and Follow-on

Agreements with DoD: \$83M Base Federal Funding; \$84M

Base Non-Federal Cost Share

Additional Committed Project Funding:

\$28M DoD-Sponsored Projects

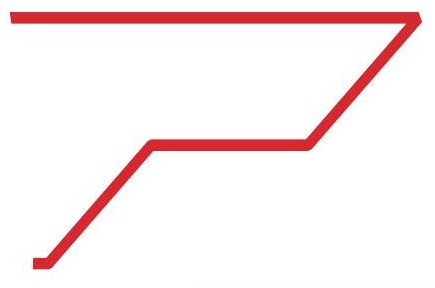

www.lift.technology 


\section{OVERVIEW}

LIFT solves the manufacturing equation by connecting materials, processes, systems, and talent needed to drive American manufacturing into the future.

LIFT - Leading Innovations For Tomorrow, the institute's technology program, develops and deploys new advanced materials manufacturing technologies and processes, including lightweighting, and multi-material processing in support of our national economy and national defense.

LIFT - Learning Innovations For Tomorrow, the institute's talent program, delivers a new advanced manufacturing curriculum in its immersive Learning Lab environment and to schools across the nation to address the skills gap in the U.S. workforce, providing workers with the skills, knowledge, and abilities required by new innovative technologies.

\section{TECHNOLOGY ADVANCEMENT}

"LIFT is having a direct and positive impact on soldiers and sailors. With LIFT innovations, Humvees are less prone to rollover and ships are being built lighter. LIFT is also filling a critical skills shortfall for the nation's manufacturing sector through Operation Next, an innovative training and credentialing program for service members transitioning from activeduty military to civilian life."

- Dr. Lisa Porter, Former Deputy Under Secretary of Defense for Research and Engineering
LIFT is the leading smarter manufacturing research institute in the country and has built an ecosystem of manufacturers and educators in support of the industrial manufacturing base, our national defense, and the U.S. economy. LIFT's "Fast Forge" technology program brings large industry, small companies, and academic partners together to deliver rapid solutions to manufacturing problems across industry.

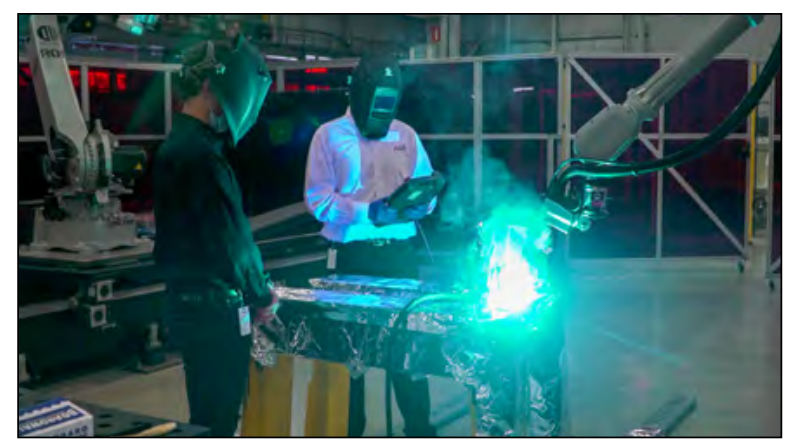

Wire Arc Additive Manufacturing is one of the innovative new processes undergoing research at LIFT. Credit: LIFT

- Wire Arc Additive Manufacturing - LIFT and UTC (now Raytheon) aerospace divisions developed and launched a project in magnesium components for lightweighting and dynamic properties, including interest in additive manufacturing for custom designs and shorter lead-times. Magnesium is among the most challenging of materials for additive manufacturing due to its high flammability. The teams applied Wire Arc Additive Manufacturing (WAAM) techniques, which leverage welder-robot integration to enable large platform metal additive manufacturing. Outcomes include a successful demonstration of WAAM on the LIFT robotic platform, and the team selected a new low-flammability magnesium alloy with successful production of wire feedstock for WAAM.

- Hybrid Vehicles - LIFT's hybrid vehicle project with Odyne Systems (Pewaukee, WI) has furthered technology development through market planning, prototype development, and manufacturing feasibility. A market study determined likely candidates for hybridization 
without modifications and a likely modification kit. A prototype is in development to solve challenges of packaging, programming, and kit development. LIFT also helped developed the feasibility for the Army to place initial bids for full-scale production.

- Developed Cold Spray Processes - LIFT provided Army Research Labs a process to distribute hand-held cold spray in limited quantities. Since surface preparation was discovered to be paramount to success of the project, surface scale was removed for optimum adherence. LIFT developed and provided a heat mitigating process. LIFT also found that ballistic testing proved the robotically applied cold spray had superior adhesion properties compared to the manual application. Further testing is required to develop superior techniques for the handheld cold spray process.

\section{WORKFORCE DEVELOPMENT}

"What I enjoyed the most teaching at

LIFT is that students were engaged and invested in their own learning.

They were involved with decision making, designing, and building, and I enjoyed hearing them brainstorm. I was impressed at how students would go above and beyond what was asked at times to 'perfect' their own vision for a project. I saw their competitive edge as they compared their work and showed a desire to excel."

-Angela Anatalio, UPREP high school instructor in the LIFT Learning Lab

LIFT has developed curricula and a one-of-akind immersive Learning Lab to educate and train the next generation of high-level advanced manufacturing technicians to help fill the existing skills gap in the U.S.

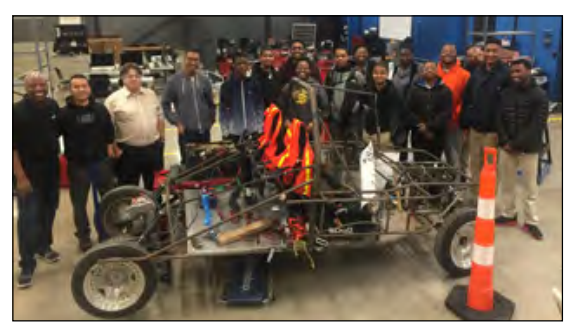

Heroes' Alliance engages Detroit area high school students in after-school engineering and manufacturing activities. Credit: Heroes' Alliance

Supporting Heroes' Alliance - LIFT supports Heroes' Alliance, a Detroit non-profit focused on empowering youth in urban communities through education and workforce development. LIFT has partnered with Heroes' Alliance to house their Cooperative Learning Center (CLC), an after-school science, technology, engineering, and math (STEM) program focused on vehicle technology. At CLC, students from six Wayne and Oakland County high schools design, build, test, and race electric and solar vehicles.

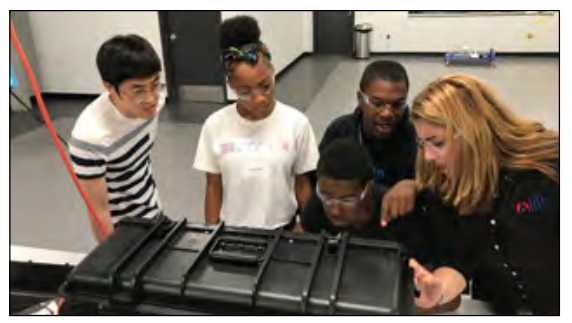

LIFT'S IGNITE Mastering Manufacturing curriculum provides hands-on and project-based experiences to prepare students for 21st Century manufacturing jobs. Credit: LIFT

Successful IGNITE Graduates - Students from University Prep Science \& Math (UPSM) High School in Detroit finished their first year of LIFT's "IGNITE: Mastering Manufacturing" curriculum. Developed by a national partnership led by LIFT, and supported by funding from the Department of Defense, IGNITE is a three-year foundational competency-based educational program for the multi-skilled technician needed in today's workplace. UPSM is the third high school to pilot the curriculum that pairs learning with project-based experiences built around real industry problems and emerging technologies to prepare students for a 21st-century production environment, as well as for additional post-secondary education to become engineering technicians, technologists, or engineers. 


\section{INNOVATION ECOSYSTEM}

"The Kearney Digital Model Factory

at the LIFT Manufacturing Innovation

Institute will provide a test-bed

for clients to experience the next

generation of digital technologies.

This will increase their understanding

of the link between technology

and business performance while

demonstrating how connecting

different facets of the factory floor can

enable a step change in performance."

-Harris Ng, Partner, Kearney

LIFT, with its 100,000 square-foot R\&D lab in Detroit, rapidly contracts, designs, develops, prototypes, and tests innovative technologies for DoD to speed technology transition to the warfighter while building the future workforce of America. The institute also benefits the manufacturing ecosystem by convening members from across industries to learn from each other and find solutions to pervasive problems; building an ecosystem of companies of all sizes to learn and work together to advance manufacturing; and growing initial investments by attracting funding from additional federal and commercial sources to expand programming, research, and services.

\section{Signed Department of Defense Agreement -} LIFT signed an agreement with the Army to lead new technology programs to support the U.S. warfighter. The Other Transactional Agreement (OTA) between LIFT and the U.S. Army Combat Capabilities Development Command Ground Vehicle Systems Center (Detroit Arsenal in Warren, Michigan) allows LIFT to deliver new technologies over the next five years. Under this OTA, LIFT will research materials maturation, product design, and manufacturing process improvements, and the development of models to evaluate the feasibility and usefulness of various lightweight materials and manufacturing processes. Research and development will lead to prototypes, directly relevant to enhancing the mission-effectiveness of military personnel and the materials, components, systems, and supporting platforms used by the armed forces.

Featured in Michigan Makers Magazine - LIFT worked with DBusiness and the Grand Rapids Business Journal on the inaugural issue of Michigan Makers magazine, focusing on the need for advanced manufacturing talent. LIFT executives met with the editor to discuss LIFT, its work with the DoD, and its talent development work. The institute's headquarters and key staff were featured in the inaugural issue.

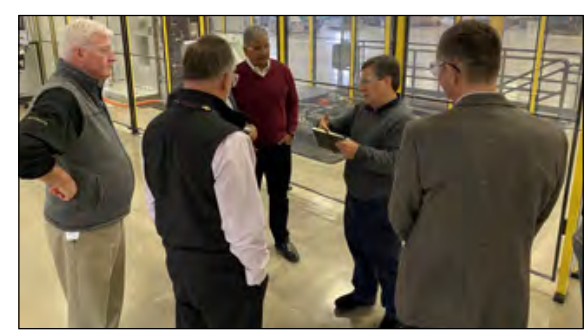

LIFT executives provide Siemens executives with a tour of the LIFT High Bay in Detroit. Siemens joined LIFT as a Platinum member in 2020. Credit: LIFT

Growing Membership - LIFT developed a new Platinum level of membership, expanding the institute's reach to key global companies positioned to help connect the manufacturing ecosystem with materials, processes, and systems. The three initial Platinum members of LIFT- Kearney, Siemens, and Hexagon--have committed to establishing a presence in the LIFT high-bay facility and working together to advance manufacturing innovation as a group.

\section{Advancing Combat Vehicle Structures -} Aluminum manufacturing and repair technologies are core to building and sustaining ground combat vehicle structures. LIFT worked with U.S. Army Combat Capabilities Development Command (CCDC) Ground Vehicle Systems Center (GVSC) to review and explore new provisions added to implement cost-cutting manufacturing and joining technologies, including involving LIFT's ecosystem and roadmapping processes that offer a significant opportunity to solve issues, drive change, and improve affordability. 


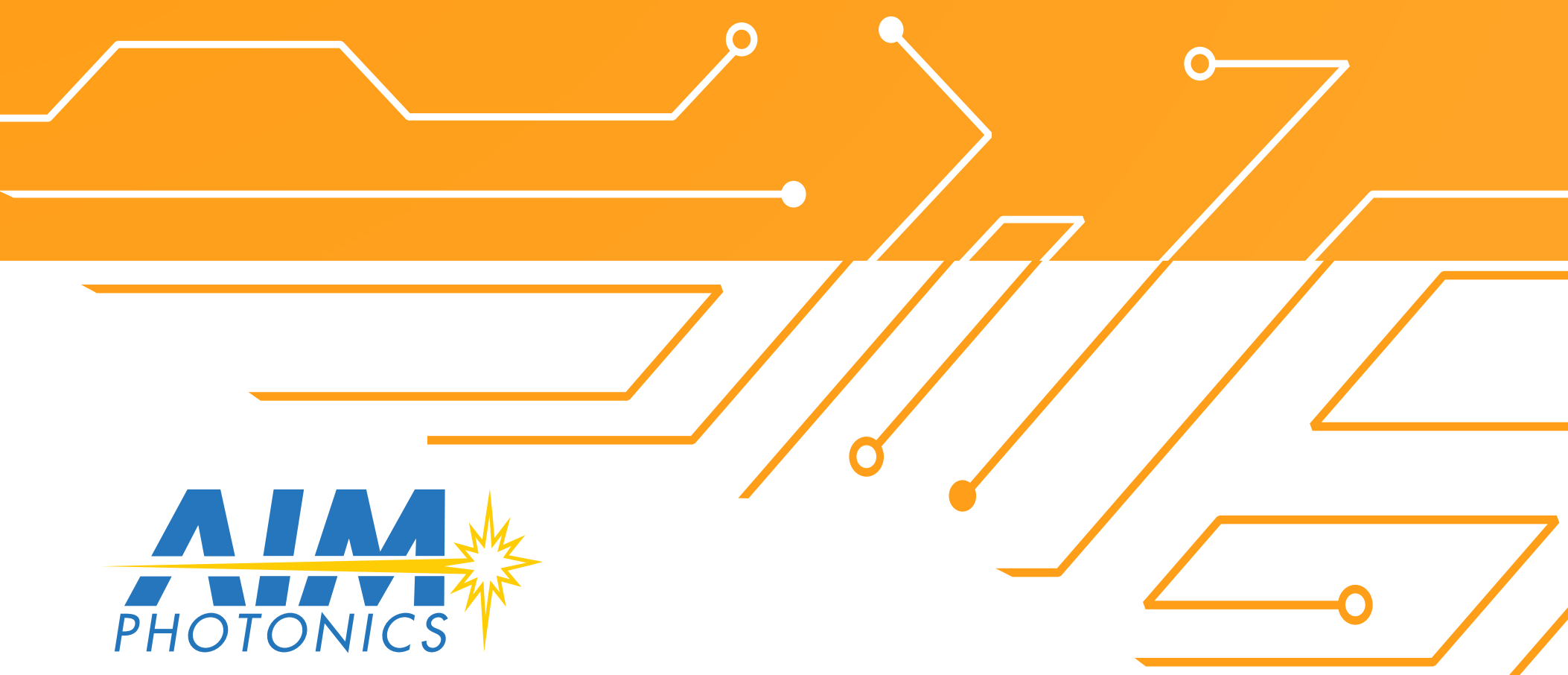

American Institute for Manufacturing Integrated Photonics

Established: July 2015

Headquarters: Albany, NY (photonic chip fabrication facility) and Rochester, NY (photonic chip test, assembly, and packaging facility)

Mission: Advance integrated photonic circuit manufacturing technology development while simultaneously providing access to state-of-theart fabrication, packaging, and testing capabilities for small-to-medium enterprises, academia, and the government; create an adaptive integrated photonic circuit workforce capable of meeting industry needs and further increase domestic competitiveness; and meet participating commercial, defense, and civilian agency needs in this burgeoning technology area.

Satellite Location: Santa Barbara, CA

Workforce Location: Massachusetts Institute of Technology (Cambridge, MA)

Consortium Organizer: Research Foundation for the State University of New York

Total Committed Funding on Original and Follow-on Agreements with DoD: \$110M Base Federal Funding; \$502.8MBase Non-Federal Cost Share Additional Committed Project Funding: \$14.4M DoD-Sponsored Projects 


\section{OVERVIEW}

Photonics, the use of light for applications traditionally addressed through electronics, enables significant new opportunities in a wide range of areas including telecommunications, laser-based radar, data communications, and sensing. Integrated photonics dramatically improves the performance and reliability of electronic integrated circuits while significantly reducing size, weight, and power consumption.

Developing a widely accepted set of processes and protocols for the design, manufacture, and integration of photonics systems will not only advance this technology, but also present the U.S. with great economic opportunity. The Yole Silicon Photonics 2020 Market and Technology Report predicted, "Silicon photonics continues to be a very active field of innovation across many industries, with a broad range of companies and R\&D labs involved worldwide. As a result, the silicon photonics market is expected to grow from \$480M in 2019 to $\$ 3.9 B$ in 2025." Integrated photonics is expected to advance established industries and enable new ones in the same way that semiconductors fostered the revolution in computing, telecommunications, and other fields over the past 40 years.

\section{TECHNOLOGY ADVANCEMENT}

"This is a terrific opportunity to move on things we've been developing for decades as fundamental science, making one or two at a time with fairly slow technology. Now we have an opportunity to prove we can do things very fast and use them to improve people's lives. AlM Photonics makes all that possible."

-Ben Miller, Professor of Biomedical Engineering, University of Rochester

AIM Photonics has created a complete Photonic Integrated Chip (PIC) manufacturing ecosystem, which provides the photonics community and DoD access to advanced technology, capabilities, and resources throughout the entire product development cycle. This reduces time to market and advances national security.

Demonstrated High-Capacity Photonic Interconnected Systems - The AIM Photonics High-Capacity Photonic Interconnected Systems project made noteworthy progress in the datacom/telecom field. Leveraging AIM Photonics' $300 \mathrm{~mm}$ silicon photonics technology offering, the project team designed, fabricated, and tested two novel wavelength division multiplexing (WDM) transceiver architectures scalable beyond 400G (400 gigabit). The team also demonstrated an external cavity quantum dot laser capable of producing up to four selfaligned transmitter channels. Viability as a WDM directly modulated laser transmitter is currently under further investigation - which, if successful, would be the worlds' first. 


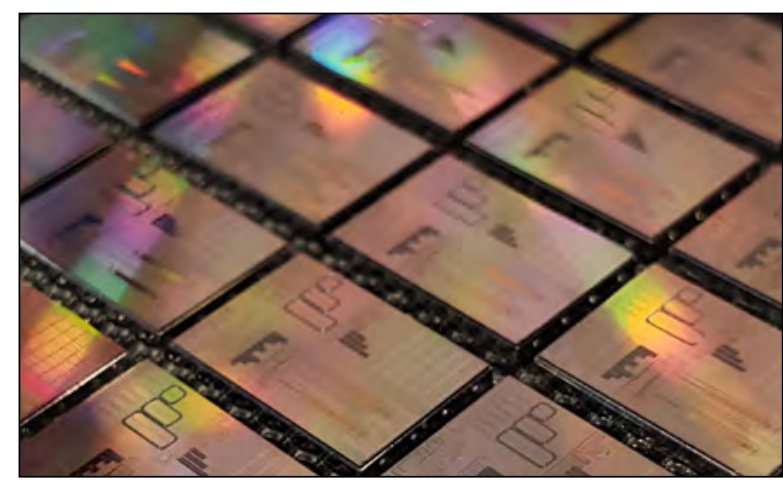

Photonic Integrated Chips from AIM Photonics $300 \mathrm{~mm}$ MWP programs ready to ship to TAP facility for final test and packaging. Credit: AIM Photonics

Successful Multi-Project Wafer Runs - In July 2020, AIM Photonics released another iteration of its $300 \mathrm{~mm}$ Si photonics multi-project wafer (MPW) technology to government, academia, and industry, including small-to-medium enterprises (SMEs). AIM Photonics' MPW provides access to the most advanced state-of-the-art $300 \mathrm{~mm}$ semiconductor processing research fab in the world. Of the 21 organizations receiving AIM Photonics' July 2020 technology offering, 15\% were government users, 15\% were large businesses, 40\% were SMEs, and 30\% were academic. Since its inception, AIM Photonics has provided MPW services to more than 140 organizations including 43 SMEs and 80 academic institutions.

\section{WORKFORCE DEVELOPMENT}

"One year ago, I attended the AIM Academy at the Massachusetts Institute of Technology (MIT). Through the academy, I was cross trained in electromagnetic (EM) theory, integrated photonic design, simulation, fabrication, testing, and characterization. Flash forward to today. I am now doing a co-op with AIM Photonics as a photonic design engineer at their fabrication site in Albany, NY...WOW! Hard work \& resilience always pays off."

- Erica Graham, Photonics Design Engineering co-op at AIM Photonics

AIM Photonics Academy spearheads education and workforce development initiatives in integrated photonics at every level of technical expertise.

Successful edX Course - In August 2020, AIM Photonics offered its "Fabless Design of Photonic Integrated Circuits within the AIM Foundry Ecosystem" course for a second time. Nearly 1,500 students enrolled in the six-week summer edX course in integrated photonic circuit design.

AlM Academy Bootcamp - AIM Academy, a collaboration between AIM Photonics and Massachusetts Institute of Technology (MIT), offered a weeklong integrated photonics boot camp in 2020 to students who used the opportunity to use lab equipment to test passive photonic chips. The boot camp prepared students for challenges they could face on the job. The course was developed by a faculty member at MIT and attended by a diverse group of engineers composed of industry veterans, graduate students, and college professors. 


\section{INNOVATION ECOSYSTEM}

"Working with partners like Ortho Clinical Diagnostics and Syntec Optics gives us the manufacturing and commercialization perspective needed to rapidly bring these technologies to market. The New York State photonics ecosystem, including AlM Photonics, is key to fostering these partnerships and making this project a success."

-Nate Cady, Professor, SUNY Polytechnic

Integrated photonics is approaching a high growth phase in key technologies, and AIM Photonics has established manufacturing methods supporting these key technologies to ensure the needs of the market are addressed. In addition, AIM Photonics has the most advanced $300 \mathrm{~mm}$ semiconductor processing research fab in the world.

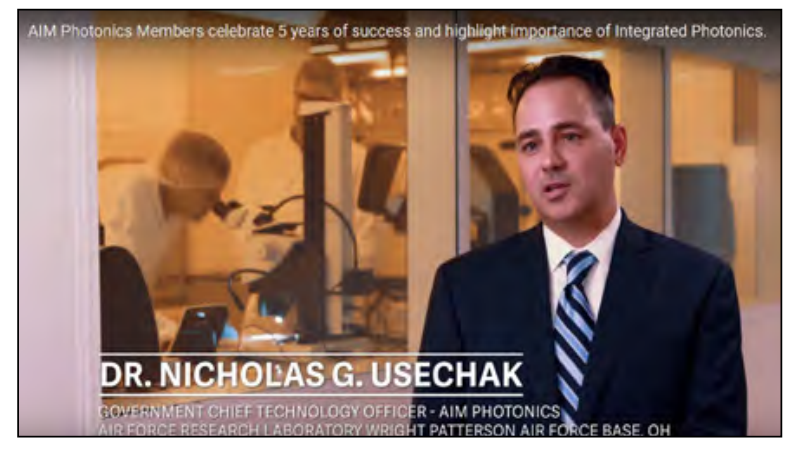

Dr. Nicholas G. Usechack participating in an AIM Photonics video. Credit: AIM Photonics

Featured on Television - AIM Photonics was featured on the Public Broadcasting System's (PBS's) television program "Information Matrix," hosted by award-winning actor Laurence Fishburne. The episode aired on more than 200 public television stations, providing greater public awareness of the integrated photonics industry, AIM Photonics' role in fostering that ecosystem, and DoD's interest in the technology and institute. 


\section{OVERVIEW}

NextFlex facilitates the development and manufacturability of flexible hybrid electronics (FHE) technology that integrates low-cost printed electronics with the processing power of thin semiconductors to create a new category of stretchable, bendable, conformable, and flexible electronic devices. FHE manufacturing relies on flexible and/or conformal substrates, additively processed circuit elements, small discrete components, thinned bare-die integrated circuits, and application-dependent packaging that retains these advantages. The low cost, thin size, and lighter weight of FHE devices delivers the long-promised "Internet of Everything." The NextFlex flexible circuit board is only one-third the weight and is produced in fewer than half the process steps of traditional rigid circuit boards, making it cheaper and faster to market through digital design and manufacturing.

NextFlex is advancing the manufacturability of FHE devices and systems and driving manufacturing readiness levels toward commercialization, with emphasis on device integration and packaging, printed flexible components and microfluidics, materials, modeling and design, and standards, testing, and reliability. The manufacturing processes used at NextFlex's Technology Hub use production-level tools that, in some cases, have been adapted to deal with unique requirements such as the handling and attachment of ultra-thin dies.

NextFlex focuses on five areas of FHEenabled application areas: human health and performance monitoring, structural health (bridges, buildings, aircraft wings, etc.) and asset monitoring, soft robotics, flexible power, and integrated antenna arrays. NextFlex convenes institute members to collaboratively identify and actively overcome manufacturing challenges in commercializing FHE-enabled systems and devices. NextFlex is the first and only facility of its kind for FHE in the world.
TECHNOLOGY ADVANCEMENT

"NextFlex serves as the technology

hub and the most important driving

force for FHE activities in the US, ranging from manufacturing technology and platform demonstration to FHE designmanufacture ecosystem. Without NextFlex and the project calls sponsored by NextFlex, the FHE manufacturing community in the U.S. would not be as strong as today. NextFlex is also an integrator that encourages multi-disciplinary collaborations and sponsors innovative projects to benefit the FHE manufacturing community."

-Dr. Jim Huang, Senior Research Scientist, HPE

NextFlex is developing design, development, prototyping, and pilot-scale manufacturing of $\mathrm{FHE}$ for a range of military and civilian applications at its Technology Hub facility and through member and partner organizations across the country. The combination of in-house development and projects distributed throughout the ecosystem disseminates knowledge and produces practical connections among participants. Funded project teams typically comprise several members working in collaboration, and each team reports its progress to other members so that they can learn from the effort. 


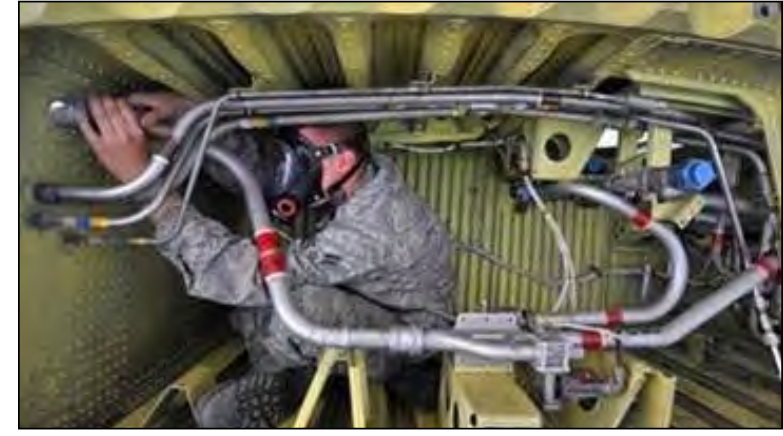

A worker inside an aircraft wing fuel tank is monitored remotely via a wearable atmospheric chemical sensor. Credit: Air Force Research Laboratory (AFRL).

\section{Developing Atmospheric Chemical Sensors}

- NextFlex, in conjunction with the Air Force Research Laboratory, is developing a wearable atmospheric chemical sensor to monitor the safety of personnel operating in hazardous environments such as inside fuel tanks of aircraft wings. The device has Bluetooth connectivity to alert the user and coworkers if vapor levels are harmful, and it fits easily and unobtrusively in the uniform of the wearer. This new technology could be deployed in a wide range of uses for safety monitoring as part of a networked set of on-body smart devices for soldiers, enabling a variety of nodes for environmental monitoring and/or vital signs monitoring under a common platform that is easy to apply and comfortable to wear. Automated testing protocols have been developed along with firmware for programming and testing, enabling rapid fabrication and testing at pilot production levels. This automated/robotic testing can now be used across a variety of FHE systems.

\section{Developing Defense Application Antennas}

- NextFlex and the Missile Defense Agency Manufacturing Technology Program have jointly funded a project to develop a conformal antenna for telemetry for a Missile Defense Agency application. Led by Boeing, this project is producing manufacturing processes and capabilities, designs, and prototype antennas at full missile diameter, along with preliminary data as a test of the full FHE and composite manufacturing fabrication process.
WORKFORCE DEVELOPMENT

"The public-private partnerships

facilitated by NextFlex and focused

on the strategic priorities informed

by its members are the foundation of

a critical infrastructure that fosters

high-impact collaboration."

- Terri Burgess Sandu,

Director of Talent and Business Innovation, Lorain County Community College

NextFlex facilitates and enables the creation of the talent needed by our industry partners over time.

AdaptedFlexFactor-FlexFactoris an outreachand recruitment program designed to engage the nextgeneration workforce with emerging technologies and advanced manufacturing careers. FlexFactor challenges small teams of students to identify a real-world problem, conceptualize an advanced hardware solution, and build a business model around it. At the end of the program, students pitch their ideas to a panel of professionals. The program is located at a community college and run in partnership with local industry to showcase the potential of advanced technologies and STEM careers. In response to the global COVID-19 pandemic, NextFlex worked with members Jabil and DuPont to create a suite of new resources in the FlexFactor program that provide immersive, experiential virtual engagement for participants. Through this important program, NextFlex is working with industry and academic partners to recruit students into the domestic STEM pipeline.

\section{Expanding FlexFactor to Reach More K-12} Students - Launched in 2016, FlexFactor has expanded in partnership with local K-12 school districts, community colleges, industry members, nonprofits, and local government entities. Beginning in 2018 in partnership with Boeing, the Office of Naval Research, and a wide network 
of community college partners, the program expanded to 14 new sites around the nation. Additionally, in partnership with Manufacturing USA and the Department of Defense, NextFlex is working with eight other manufacturing innovation institutes to create adapted versions of the program in their respective technology focus areas.

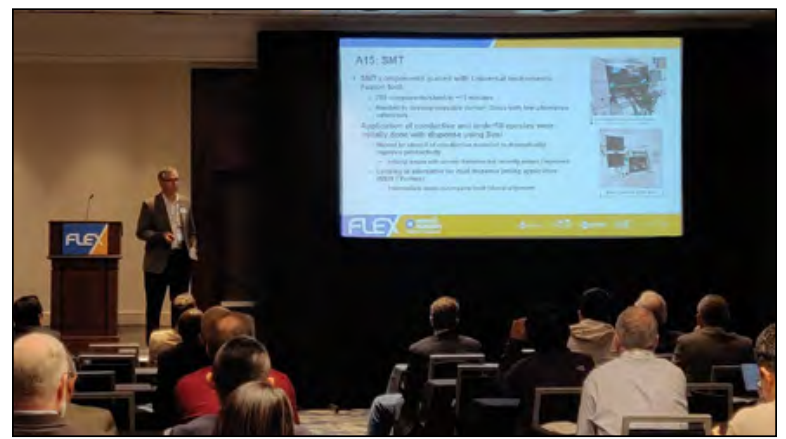

Dr. Art Wall, NextFlex Director of Fab Operations, presents at the annual FLEX Conference in February 2020. Credit: SEMI-FlexTech

\section{INNOVATION ECOSYSTEM}

"Innovation thrives when a strategic vision unleashes the creative spirits of leading topic matter experts from many aspects of a new application field such as FHE. The best ideas emerge in a realm that fosters both collaboration and competition but is respectful of each stakeholder's motivations and sensitivities. NextFlex has succeeded in developing a framework that delivers on all these aspects and is dedicated to providing critical funding and resources to nurture the emerging FHE ecosystem towards a sustainable future that serves both national and commercial interests."

-Dr. Chris Stoessel, Senior Manager for Process Development, Eastman Chemical
NextFlex convenes the U.S. FHE ecosystem to align technical advances with application-driven needs from industry and government, ensuring rapid transition into manufacturing and U.S. FHE industry global competitiveness. Working with state partners, NextFlex also facilitates formal and informal regional networks for the industry, including nodes in New York and Massachusetts, to convene practitioners and support supply chains and regional economic development. Both of these NextFlex Nodes are partially funded by the respective states.

Convening Community through Impactful Member Events - In 2020, NextFlex hosted its first Virtual Innovation Days, which enabled a broader and deeper participation from both members and DoD. The event featured more than 80 hours of presentations, 62 FHE demonstrators, and 400+ participants. Overwhelmingly positive feedback for the event has prompted NextFlex to explore holding more virtual events in the future.

\section{Sharing Information through Conferences} - NextFlex routinely participates in technical conferences to raise awareness of the state of the art in FHE. Its session "State of the Art Flexible Hybrid Electronics (FHE) Manufacturing" for the annual Flex Conference in February featured presentations from NextFlex, Jabil, Boeing, Sheldahl, University of Massachusetts Amherst, Flex, and the Army's Combat Capabilities Development Command Armaments Center. Designed to connect the full flexible hybrid electronic manufacturing process from design to testing and reliability, the session had record attendance. 


\section{OVERVIEW}

AFFOA's vision is a globally competitive, domestic supply chain in advanced fibers and fabrics. The institute delivers breakthrough capabilities and innovations for national security. AFFOA centralizes the revolutionary fiber and fabric technology capabilities of startups, manufacturers, industry, and academia and organizes them to produce and manufacture advanced textile systems for DoD and commercial markets.

AFFOA addresses the spectrum of manufacturing challenges associated with developing and scaling advanced fibers and textiles from design through pilot production, helping to transition innovative technologies and training the nextgeneration manufacturing workforce. The institute's Fabric Innovation Network of member companies enables the development and commercialization of textile products that can see, hear, sense, communicate, store energy, regulate temperature, monitor health, and change color while delivering the conventional qualities of fabrics to benefit the commercial consumer and warfighter.

\section{TECHNOLOGY ADVANCEMENT}

\section{"AFFOA's stance during these}

challenging times has been clear, decisive, and pragmatic. Their leadership has been a guiding beacon that has enabled our collective energies to be put towards realizing tremendous success in tremendously little time."

-Haden Quinlan, Program Manager, Massachusetts Institute of Technology

AFFOA and its diverse ecosystem of members are developing and transitioning advanced fiber and fabric technologies that enable a multitude of capabilities and apply to a variety of applications and industries.

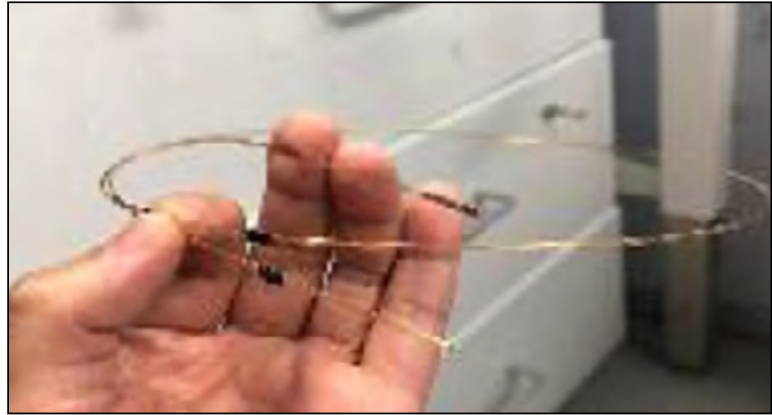

Any chip anywhere fiber containing two individually addressable inertial measurement units (IMUs), terminated with a flexible printed circuit connector. Credit: AFFOA

Demonstrated Novel "Any Chip Anywhere" - AFFOA successfully demonstrated a new approach in the fabrication of device fibers known as "any chip anywhere." This process permits the fabrication of fibers with virtually any type of device positioned at virtually any location or density within the fiber. Each chip can be individually addressed by a microcontroller, thereby converting fabrics into multiplexed sensing devices. To-date, the institute has created system demonstrators that can map heat across a fabric, track the motion of users, and detect the presence of various liquids like fuels. The entire system, including data telemetry, power, and computation, is embedded within the fabric structure. From a process standpoint, the team has achieved a Manufacturing Readiness Level 5 (i.e., capability to produce prototype components in a production relevent environment) and is currently producing the advanced fibers for both DoD and commercial sponsored programs.

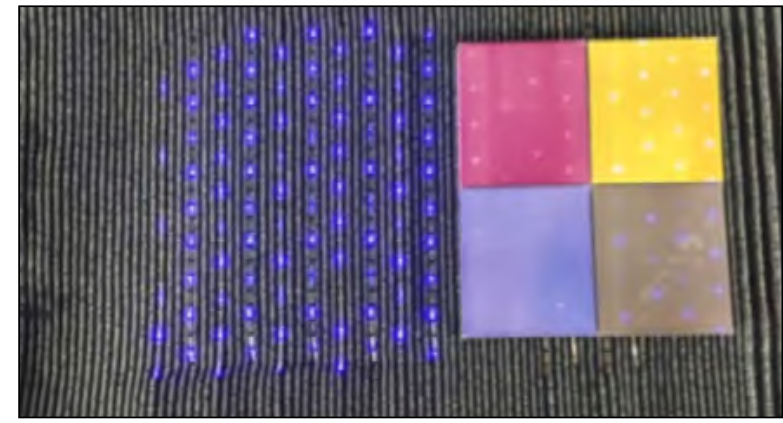

Proof of concept showing successful color switching on fabrics using AFFOA's blue LED fiber. Credit: AFFOA 
Developed Color Change Fiber - AFFOA partnered with the Massachusetts Institute of Technology to develop a photochromic color change fiber leveraging MIT's emerging technology coupled with AFFOA's textile engineering capabilities. This new technology promises to provide low-power color change opportunities through printed and additive textile methods for enhanced camouflage and signature management applications.

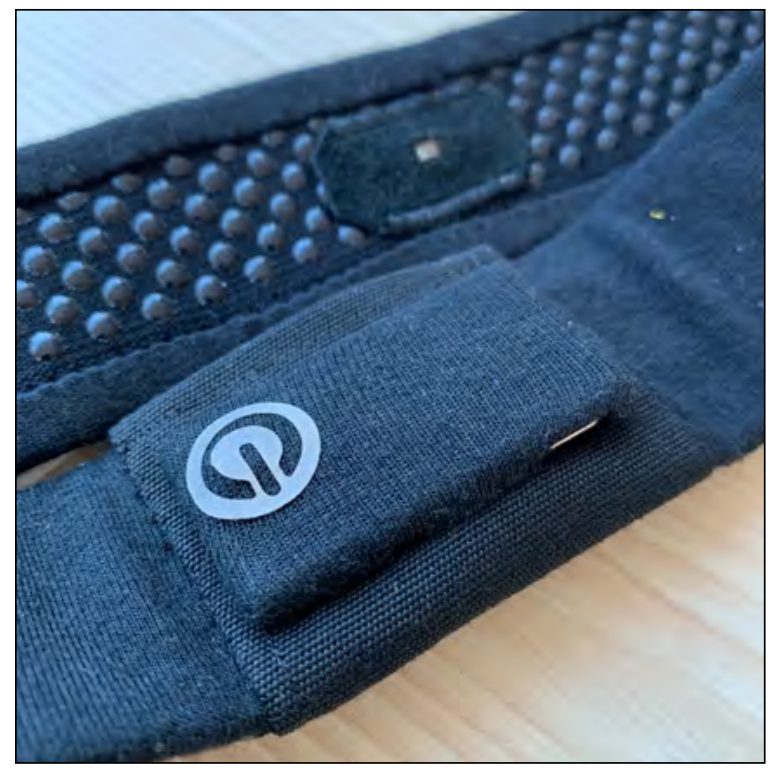

AFFOA's team has completed final prototypes of physiological monitoring headbands and submitted them for user feedback and testing. Credit: AFFOA

\section{Developed Physiological Monitoring} Headbands - AFFOA and its Defense Fabric Discovery Center developed 12 prototypes of fully integrated physiological status monitoring headbands for the U.S. Army Research Institute of Environmental Medicine. Each headband can monitor heart rate, oxygen saturation, and user motion. Compared with traditional wrist or chest monitoring devices, a headband offers the benefit of excellent blood profusion in the forehead and reduced motion artifact. The headband can also reduce user burden through comfortable integration with the helmet and wireless data transmission.

\section{WORKFORCE DEVELOPMENT}

"The partnership between AFFOA and Greater Lawrence Technical School has resulted in students gaining knowledge and skills in a new and exciting industry that offers life-changing career opportunities. As we continue this partnership, we know that many new educational and workforce pathways will develop into additional new careers for students to pursue."

-John Lavoie, Superintendent, Greater Lawrence Technical School

AFFOA is focused on creating educational and workforce development programming and partnerships to inspire, prepare, and grow the domestic textile industry's workforce to meet the current and future needs of the advanced fiber and fabric industry.

Assessed National Workforce Skills - AFFOA contracted with Educational Data Systems Incorporated to conduct a national needs assessment focusing both on workforce skills required to implement AFFOA's technology and on the current skills needed by textile employers and manufacturers to support the state of the industry. The goal of this assessment is to provide AFFOA with a national landscape of education and workforce resources, gaps, opportunities, strengths, and weaknesses specific to the textiles industry. The assessment will lead to a comprehensive strategy around education and workforce development for the textile, advanced fibers, and fabrics industry that will inform AFFOA's future portfolio of work. 


\section{Hosted High School Advanced Functional} Fabric Laboratory - Seniors from Greater Lawrence Technical Schools visited AFFOA to present their final layout of a dedicated Advanced Functional Fabrics (AFF) work/lab space at their school. Students worked diligently to ensure plans optimize workfow and protect equipment from malfunction, manage electrical work and maintenance of each piece of equipment, and provide space for students to work and innovate. This space will include all of the necessary equipment for a functioning AFF lab, including a Shima Seiki knitting machine, vacuum oven, CNC (computerized numerical control) mills, a hot press, and a student-created miniature fiber draw tower.

\section{INNOVATION ECOSYSTEM}

"It is really excellent to see AFFOA maturing on many facets, especially in the last year. We are pleased to be members and look forward to helping the ecosystem evolve in capabilities and collaboration, and to see U.S. textiles and products become the marvel of the world!"

-Mark Weitz, Vice President of Research and Development, Kennon Products

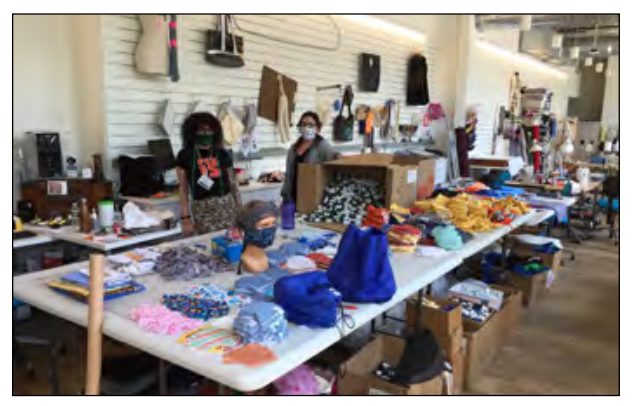

Director of the Fashion Makerspace, Diana Coluntino, and Director of Community Relations, Patricia Coffey, preparing and distributing face coverings to community partners. Credit: University of Massachusetts Lowell Fabric Discovery Center
In addition to the Fabric Innovation Network, AFFOA has three Fabric Discovery Center locations that are critical elements of its innovation ecosystem. Each has unique capabilities and focus areas relating to the advanced fiber and fabrics industry.

COVID-19 Support from Fashion Makerspace The Fashion Makerspace at AFFOA's University of Massachusetts Lowell Fabric Discovery Center has produced and distributed more than 5,000 face coverings to the community since March 2020 , totaling an in-kind value greater than $\$ 50,000$. Fashion Makerspace has a membership model for fashion designers, entrepreneurs, and innovators who believe that creative, sustainable apparel, textile design, and manufacturing practices will improve lives and better the world. Fashion Makerspace encourages apparel manufacturing and job growth in the commonwealth by contributing to the fashion and textile ecosystem through support for innovation, advanced manufacturing, and workforce development.

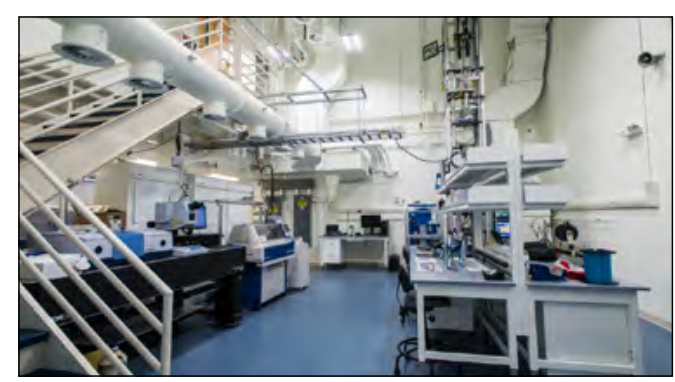

The Defense Fabric Discovery Center, a state-of-the-art prototyping facility, will enable researchers from Lincoln Laboratory to develop advanced fiber and fabric technology. Credit: MIT Lincoln Laboratory

Established Classified Capabilities - The Defense Fabric Discovery Center (DFDC) at MIT Lincoln Laboratory is a secure facility where classified research and development in advanced fibers and fabrics is applied to problems of national security. The center is equipped to design and produce smart fibers and fabrics including those with embedded microelectronics, enabling fabrics that change color, store energy, emit and detect light, monitor health, or facilitate communication. 

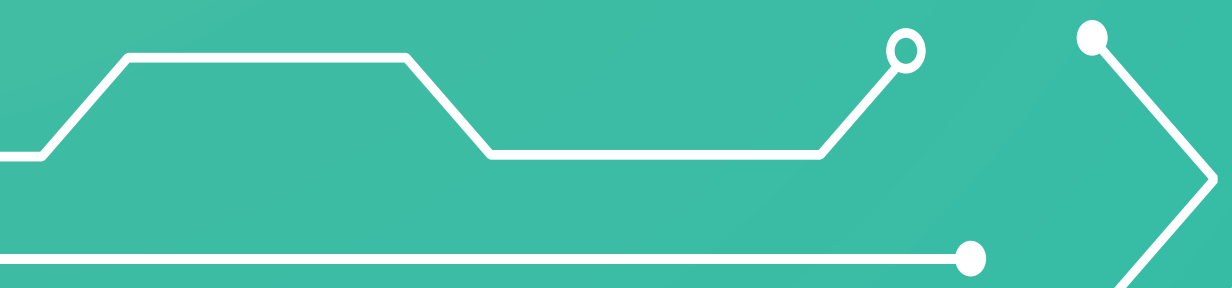

7
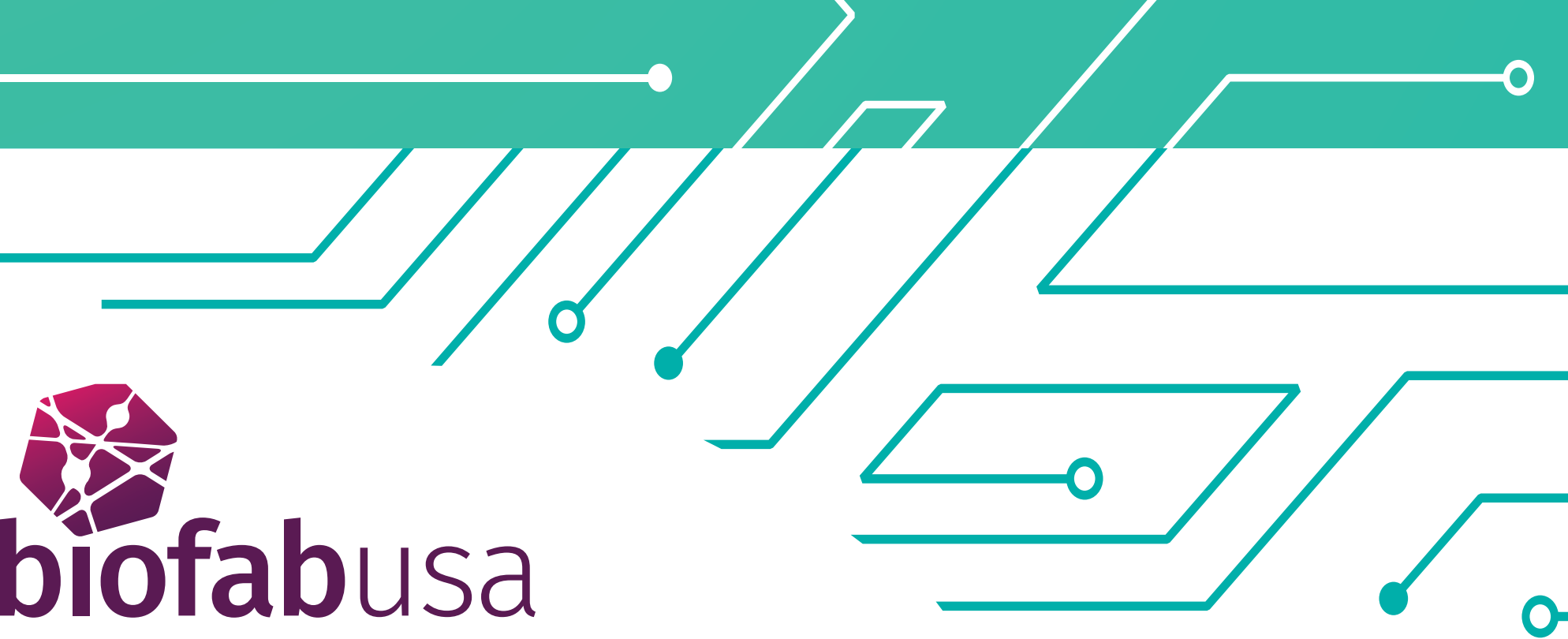

Advanced Regenerative Manufacturing Institutee

Established: December 2016

Headquarters: Manchester, $\mathrm{NH}$

Mission: Make practical the scalable, consistent, and costeffective manufacturing of engineered tissues and tissuerelated technologies to benefit existing industries and grow new ones.

Consortium Organizer: Advanced Regenerative

Manufacturing Institute (ARMI)

Members (as of September 30, 2020): 178

Total Committed Funding on Original and Follow-on

Agreements with DoD: \$80M Base Federal Funding;

\$214M Base Non-Federal Cost Share

Additional Committed Project Funding:

\$32.5M DoD-Sponsored Projects

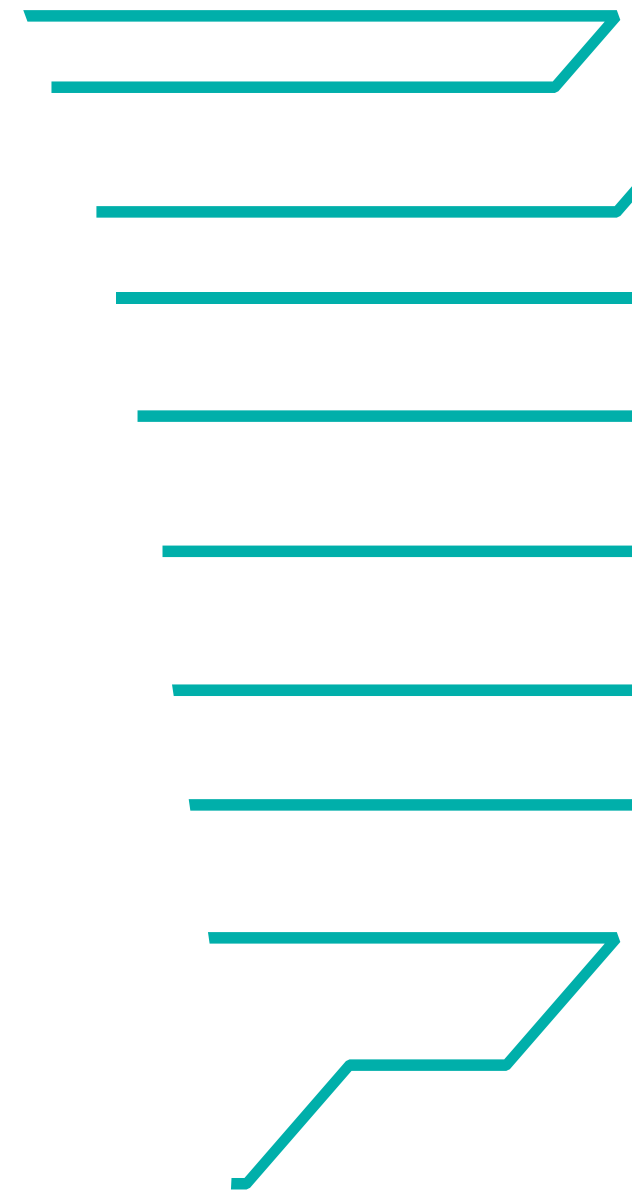

\section{biofabusa.org}




\section{OVERVIEW}

Significant breakthroughs in cell biology, biofabrication, and materials science in the last decade have laid the foundation for largescale manufacturing and commercialization of engineered tissues and tissue-related technologies. BioFabUSA has targeted the raw material, equipment, measurement, automation, logistics, and big data analytics challenges that hinder scalable, consistent, and cost-effective manufacturing. The development of tissueengineered medical products on an industrial scale enables the DoD to accelerate creation of numerous medical products for our wounded warfighters.

\section{TECHNOLOGY ADVANCEMENT}

"BioFabUSA has developed the first automated system that takes a set of cells, matures those cells in a closed, no-touch system, and via an automated production line manufactures a bone-ligament-bone graft. Think about the data available in that process, data necessary to understand environmental conditions to reliably achieve the same results. BioFabUSA is doing the foundational work to characterize cells and tissues, leveraging the power of data analytics that will lead to reproducible results, lower costs - and replacement organs for the hundreds of thousands of people currently on organ-donor waiting lists."
BioFabUSA is integrating innovative cell and tissue cultures with advances in biofabrication, automation, robotics, and analytical technologies to create research and development tools and FDA-compliant volume manufacturing processes that can accelerate medical products to improve human health and save lives.

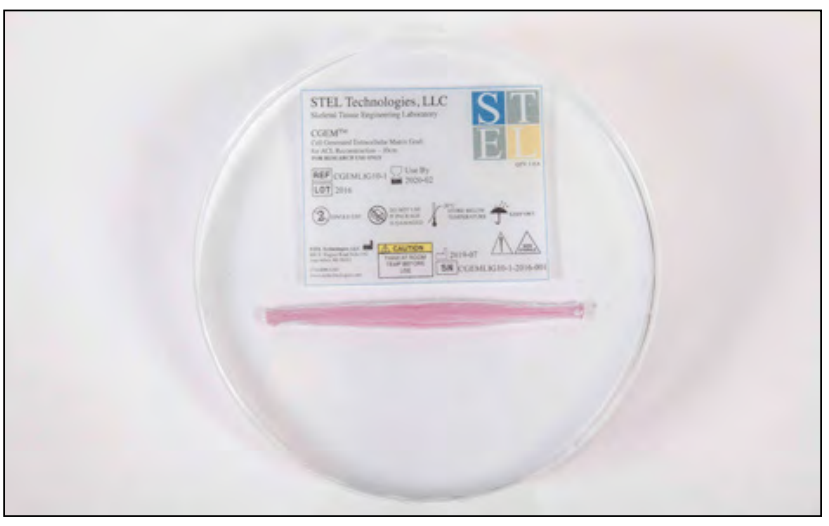

Automating the tissue manufacturing process. Credit: BioFabUSA

Automated Manufacturing of Bone, Ligament, and Muscle - BioFabUSA collaborated with STEL Technologies to automate a tissue manufacturing process as a first demonstration of BioFabUSA's Tissue Foundry. STEL's first product, CGEM ${ }^{\mathrm{TM}}$, is a tissue consisting of mineralized (bone) ends and a non-mineralized (ligament) middle region, generated by mesenchymal stem cells (MSCs). CGEM is intended to replace a damaged anterior cruciate ligament (ACL). BioFabUSA configured the Tissue Foundry to produce 10 CGEM grafts from a single vial of MSCs in a fully automated system. To demonstrate the adaptability of the Tissue Foundry, BioFabUSA is reconfiguring it to produce skeletal muscle units, a technology in development at the University of Virginia. Replacement of ACLs or skeletal muscle can maximize function for a warfighter's return to duty or civilian life following battlefield injury. 


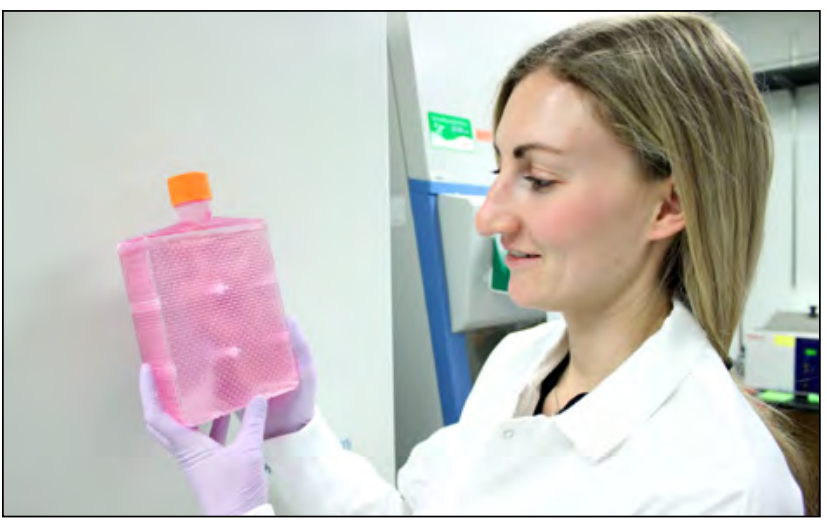

Beta cells for juvenile diabetes research. Credit: Juvenile Diabetes Research Foundation

Automated Manufacturing of Beta Cells to Address Juvenile Diabetes - BioFabUSA signed an agreement with the Juvenile Diabetes Research Foundation providing \$2 million of funding in support of the automated manufacturing of beta cells for researchers to ensure a consistent, reliable source for diabetes research. This beta cell manufacturing project is the first example of BioFabUSA manufacturing cell or tissue products for end-users, a capability that will be extended to others.

\section{WORKFORCE DEVELOPMENT}

"SEE Science Center is excited to be working with BioFabUSA in developing activities that highlight the intersection of healthcare, engineering, and manufacturing. Young students can use these concepts to solve problems all while being introduced to careers in biomanufacturing. It's important for students in this diverse community to see that these careers are attainable for them."

-Peter Gustafson, Deputy Director, SEE Science Center
BioFabUSA is preparing the workforce to meet the needs of this developing industry across the U.S.

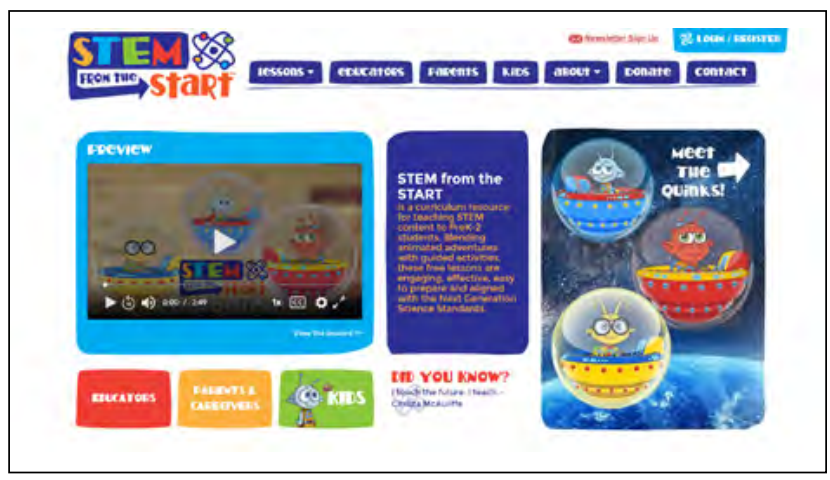

Screenshot of BioFabUSA's education program "STEM from the START" designed for K-12 students. Credit: STEM from the START

Launched K-12 Educational Videos - "STEM from the START" was launched in March 2020 as a result of a BioFabUSA-funded project with the Leitzel Center at the University of New Hampshire. The program's educational videos were produced in partnership with the New Hampshire Public Broadcasting Service and were made available nationwide on the web for virtual learning opportunities. By September 2020, thousands of different users in all 50 states across the country had accessed the videos, reaching an estimated 151,000 students. These first educational videos were targeted at elementary education students, and new videos for middle and high school students are in development. 


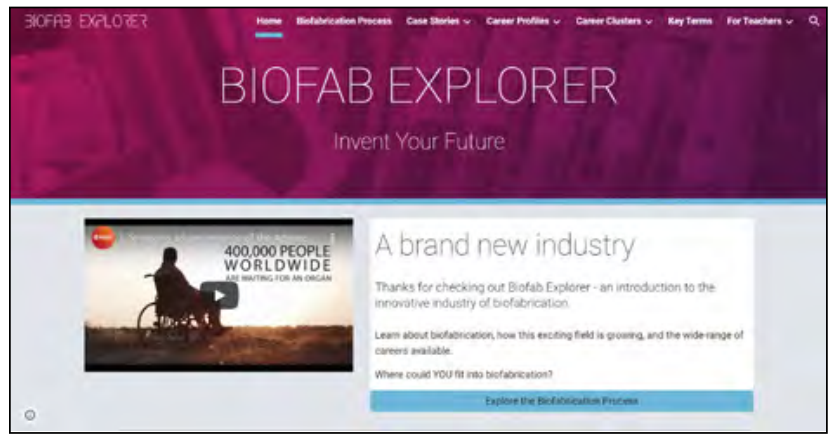

Screenshot of BioFabExplorer, a new career toolkit for those interested in biofabrication careers. Credit: CAST

Released Career Toolkit - The BioFabExplorer Career Toolkit was developed with support from members of the BioFabUSA ecosystem and provides students the opportunity to explore careers in the field of biofabrication. The "How to Use" video and the BioFabExplorer virtual career explorer will be available online for students, teachers, and career counselors.

\section{INNOVATION ECOSYSTEM}

"This is literally a life-changing approach and adds a new chapter to medicine. To apply technology across multiple disciplines to help people live longer, healthier lives - there's going to be nothing but more interest in that as the population ages and the technology becomes more capable."

-Blake Moret, CEO, Rockwell Automation

Prior to the establishment of BioFabUSA, the tissue engineering field was fragmented and lacked a mechanism with which to turn laboratory breakthroughs into manufactured products. BioFabUSA has filled a critical need by creating and convening this community.

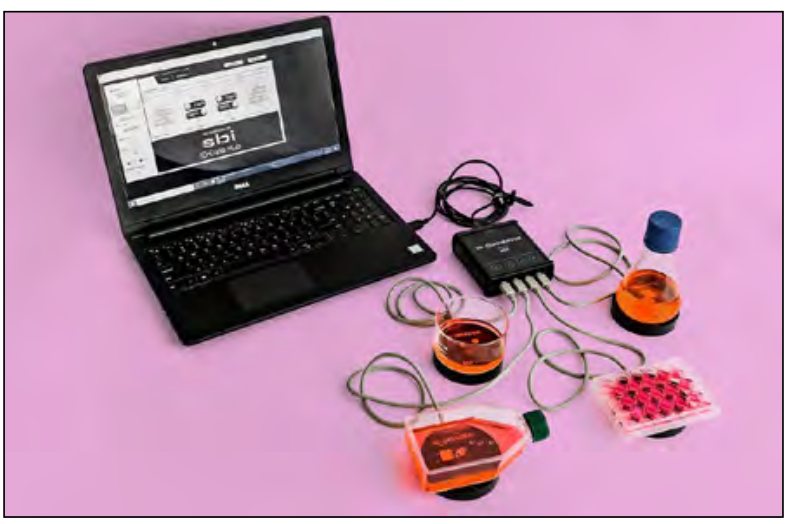

BioFabUSA's shared sensor development kits. Credit: Scientific Bioprocessing

Shared Sensor Development Kits - BioFabUSA member Scientific Bioprocessing (SBI) has provided members with free sensor development kits, a value of more than $\$ 20,000$ each, so that these members can develop their own noninvasive sensors for use in Tissue Engineered Medical Product manufacturing process development. These relationships help BioFabUSA fulfill the sensor needs identified in the BioFabUSA Technology Roadmap. President John A. Moore of SBI has committed $\$ 500,000$ of product to BioFabUSA members developing noninvasive sensors.

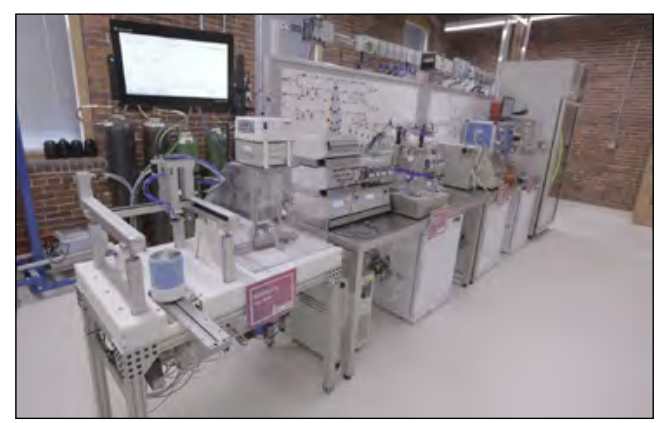

BioFabUSA's virtual foundry tour. Credit: BioFabUSA

Hosted Tissue Foundry Virtual Tour - Attendees at Phacillitate 2020 in Miami "walked through" BioFabUSA's Tissue Foundry in a virtual reality (VR) experience, seeing the Tissue Foundry in action and learning about the five modules of the BioFabUSA Tissue Foundry: Cell Culture and Expansion, Harvest \& Wash, Scaffold Fabrication, Tissue Assembly \& Maturation, and Packaging \& Preservation. The BioFabUSA Tissue Foundry VR experience allows the manufacturing vision of the Tissue Foundry to be shared nationwide. 


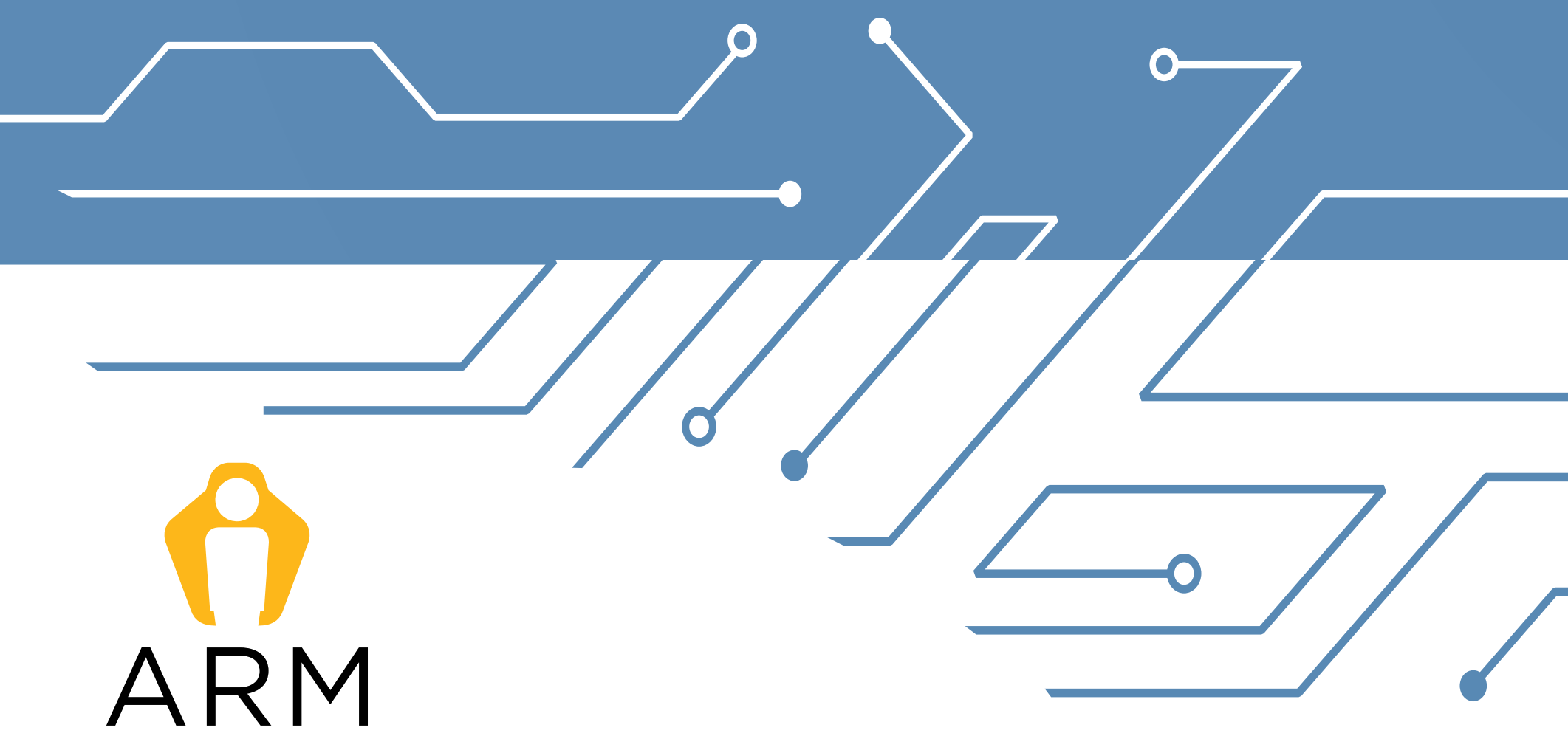

Advanced Robotics for Manufacturing Institute

Established: January 2017

Headquarters: Pittsburgh, PA

Mission: Accelerate the development and adoption of robotics technologies that are the foundation of every advanced manufacturing activity today and in the future. The institute leverages a unique, robust, and diverse ecosystem of partners across industry, academia, and government to make robotics, autonomy, and artificial intelligence more accessible to U.S. manufacturers large and small, train and empower the manufacturing workforce, strengthen the U.S. economy and global competitiveness, and elevate the nation's security and resilience.

Consortium Organizer: Carnegie Mellon University

Members (as of September 30, 2020): 280

Total Committed Funding on Original and Follow-on Agreements with DoD: \$80M Base Federal Funding; \$173M Base Non-Federal Cost Share

Additional Committed Project Funding:

\$8M DoD-Sponsored Projects

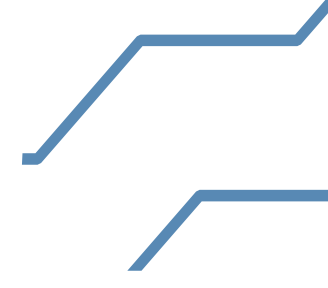




\section{OVERVIEW}

The ARM Institute is leading the way to a future where people and robots work together to respond to our nation's greatest challenges and to develop and produce the world's most desired products. Structured as a national consortium, ARM's members span industry, advanced technology, academia, and government organizations. ARM integrates diverse industry best practices and institutional knowledge about robotics technologies across many disciplines to realize the promise of a robust manufacturing innovation ecosystem. Key focus areas include human-robot interaction; interoperability; artificial intelligence; reconfigurable, agile, and flexible robotics systems; and easier adoption and risk reduction. ARM also works to prepare the U.S. workforce for Industry 4.0 careers working with robotics. In defining the robotics career pathways, ARM is working to expand the size, diversity, and skill set of the U.S. robotics workforce.

\section{TECHNOLOGY ADVANCEMENT}

"ARM has been extremely supportive throughout this process, and we could not have done it without them. The project funding has provided us an opportunity to build a program highly valuable to both military members and manufacturers, now and in the future."

-Bernie Lynch, CEO, Factory Unlocked
By leading projects related to human-robot interaction, $A R M$ is helping DoD meet its modernization goals related to autonomy. ARM's projects address issues related to persistence, speed, maneuverability, and reduced risk to human life.

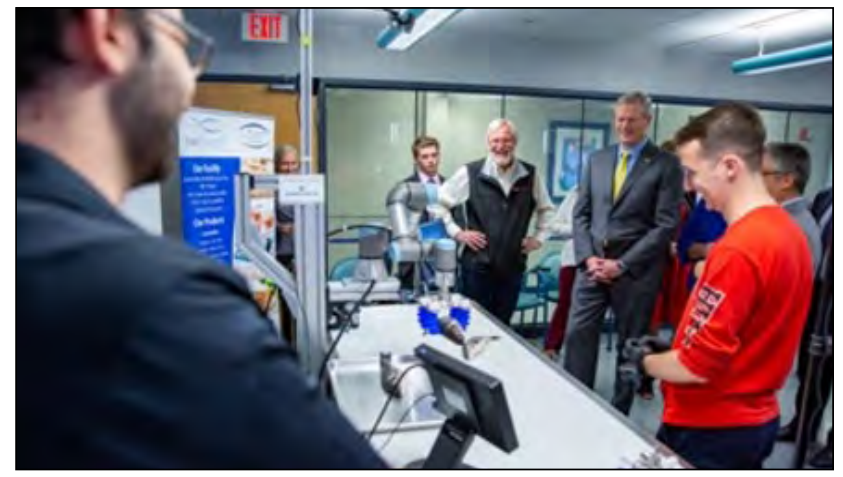

Demonstration of ARM's FISH Project aimed to bring processes back to the U.S. within the fishing industry through robotics. Credit: ARM

Advanced Robotics in Seafood Handing ARM's FISH (Fostering Innovation in Seafood Handling) project aimed to bring back processes within the fishing industry to the U.S. through the development of robotic technologies that work collaboratively with humans in a constrained factory environment. The project team developed perception and planning algorithms to identify and characterize different types of seafood, sort fresh seafood by weight, and identify seafood that fails inspection.

According to Dr. Taskin Padir from Northeastern University, the project's principal investigator, advancement of robotic technologies through the FISH Project could amount to \$20 billion annually in economic impact within the next five to ten years. The technical innovations may provide dual-use capabilities in such critical applications as explosive ordinance inspection, handling and logistics, and resupply for the Department of Defense. Most recently, Dr. Padir's team received a National Science Foundation grant to collect ephemeral data to study the adoption of new technology in the seafood industry while 
considering COVID-19's impact on worker and food safety concerns. The research team will assess the demand for and feasibility of adopting human-collaborative systems to process and package food more safely and efficiently at all stages of production. The results will also help to inform systems in agriculture and healthcare.

Patented New Passive Object Tracking - The ARM-funded Passive Object Tracking project aims to eliminate the need for unique identifiers and use advanced sensing and perception capabilities of robotics to track items throughout the manufacturing process and tie that information back into a company's Enterprise Resource Planning (ERP) software. The project team developed a novel system and method for component track and traceability via sensor fusion and digital twin technologies, resulting in several new patents. The final demonstration showcased the system's computer-aided design (CAD)-based perception algorithm in myriad ways, including accuracy of the robot's perception of its own location and the location of parts as well as the ability to avoid obstacles. The project's industrial partner, Indiana Technology and Manufacturing Companies (ITAMCO), estimates a payback period of only six months and a five-year return on investment of more than $\$ 300,000$ for one deployed robot. Siemens has continued the development and use of the technology modules with its own manufacturing process, and ITAMCO has planned the technology transition into their facility.

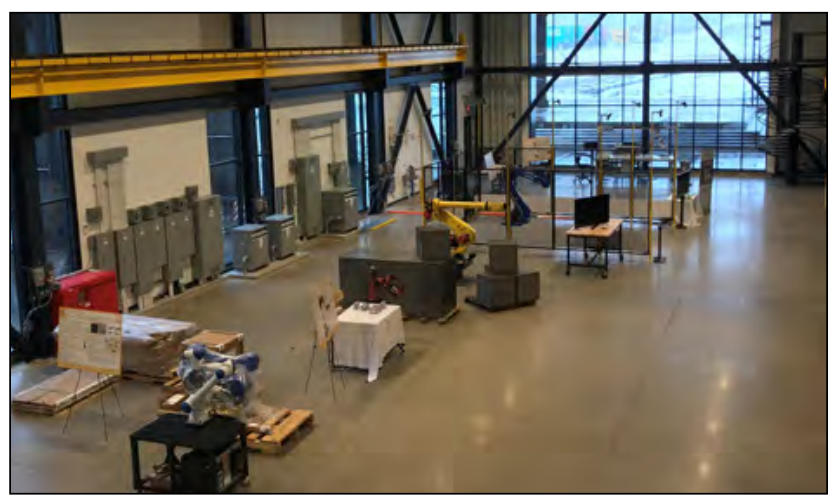

ARM's high bay at Mill 19 in Pittsburgh. Credit: ARM

Released Robotic Technical Handbook - ARM shared with its members the ARM Handbook of Robotic Manufacturing Tasks outlining the progress ARM members have made in advancing robotics technology across the ecosystem. The Handbook presents projects funded since inception in 2017 through the present, organized by logistics, manufacturing, and artificial intelligence tasks. Members can easily search the tasks and projects to avoid duplicating work or recreating existing technology. 


\section{WORKFORCE DEVELOPMENT}

"Duro UAS requires highly specialized talent to stay competitive. ARM's workforce development leadership and support have been essential to successfully navigating this challenge."

-Brian Wilson, CEO, Duro UAS

By expanding the size, diversity, and skill set of the U.S. manufacturing workforce, the ARM Institute catalyzes the U.S. manufacturing industry and its competitive position.

Launched Industry 4.0 Academy - Although military service members leave service with valuable skills, the transition to a civilian career can be difficult. ARM launched Industry 4.0 Academy to give service members valuable training-that builds upon skills they developed in service-that will prepare them for highvalue careers in robotics and manufacturing. The program also connect participants with hiring industry organizations partnered with the program. Project participants include: Dallas County Community College District (lead), Factory Unlocked, Prens, and Fivestar ${ }^{*}$ Development. The program also leverages a national consortium of partners and experts in Industry 4.0, including the DoD SkillBridge program.

\section{Published Education and Workforce} Development Guidebook - ARM's Education and Workforce Development Team has published an Education and Workforce Development Project Output Guidebook that outlines project outputs from the workforce-related project calls and demonstrates how they align with the various Industry 4.0 training programs available for manufacturing.

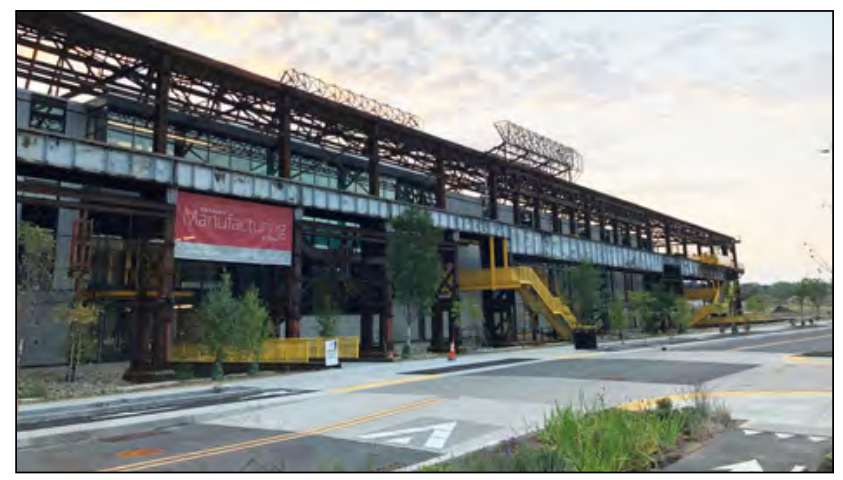

Sunset over ARM headquarters at Mill 19 in Pittsburgh. Credit: ARM

\section{INNOVATION ECOSYSTEM}

"I am very pleased to see the number and the diversity of members from many sectors, many industries, and many parts of the country."

-Petra Mitchell, CEO, Catalyst Connection MEP

By lowering the barriers to the adoption and expansion of robotics for manufacturing, ARM catalyzes the U.S. manufacturing industry and its competitive position.

\section{Developing a National Resource for Robotics} Career Pathways - ARM recently launched a new website, www.roboticscareer.org, the first national resource that will connect workers with vetted training opportunities in robotics formanufacturing. More than 10,000 robotics education programs across the United States will be identified on the website, including those endorsed as meeting the highest standards in the robotics industry in industry relevance, effective curriculum, efficient training, and program impact, sustainability, and transportability. 


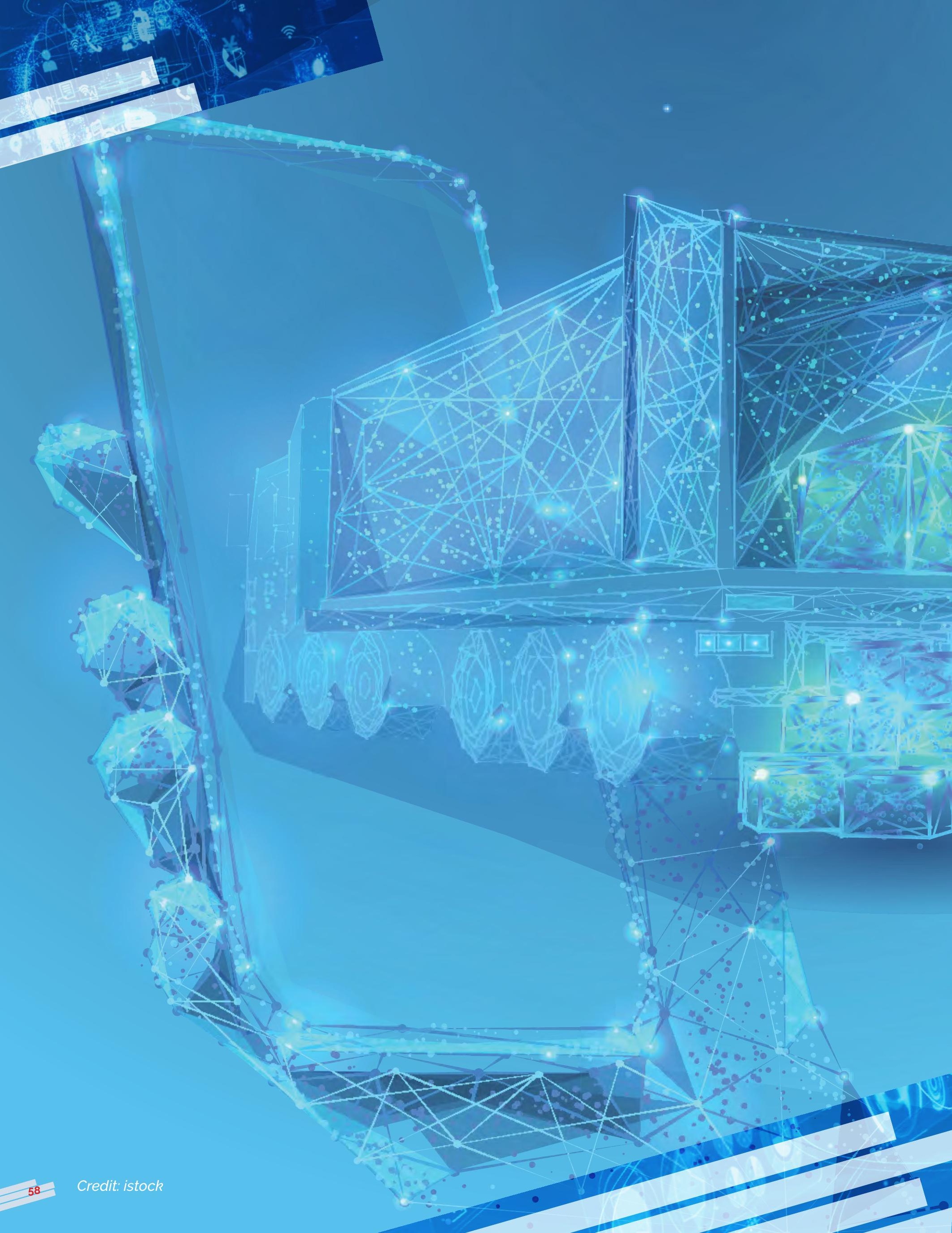




\section{DEPARTMENT OF ENERGY INSTITUTE HIGHLIGHTS}

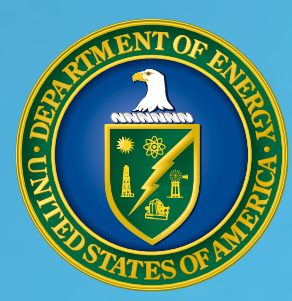




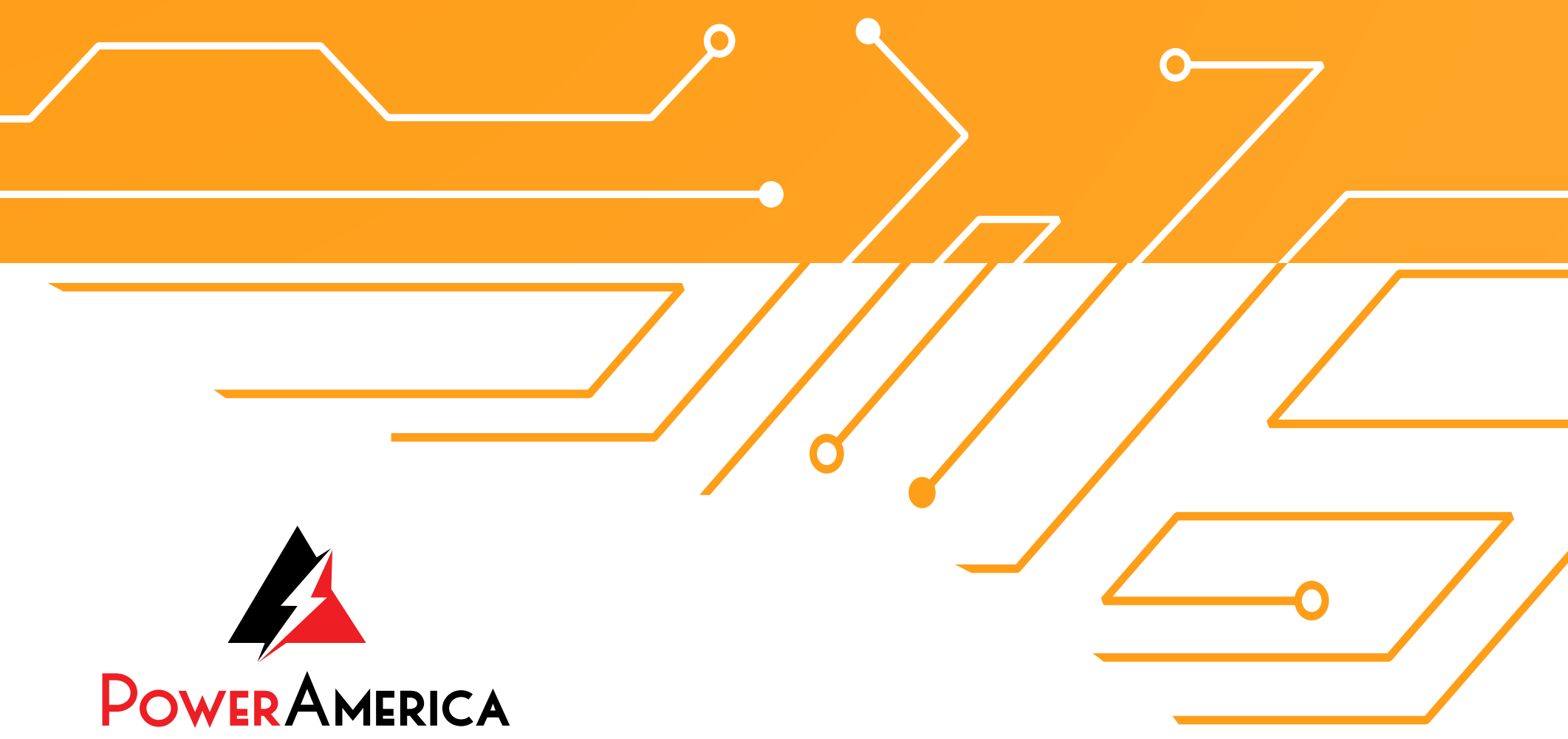

\section{The Next Generation Power Electronics Manufacturing Innovation Institute}

Established: January 2015

Headquarters: Raleigh, NC

Mission: : The PowerAmerica institute led by North Carolina State University (NCSU) seeks to save energy and create U.S. manufacturing jobs by accelerating the development and largescale adoption of wide bandgap semiconductor technology in power electronic systems.

Consortium Organizer: North Carolina State University

Members (as of September 30, 2020): 55

Funding (FY 2020): Federal, \$14.2 M; Non-Federal, \$10.2 $\mathrm{M}^{6}$

\section{poweramericainstitute.org}

${ }^{6}$ Federal dollars and cost share expended by the Institute during FY 2020 are reported here. It does not reflect federal funds appropriated in FY 2020 (if any) for a given DOE Institute. 


\section{OVERVIEW}

PowerAmerica was created to help ensure U.S. global leadership in the development and adoption of advanced power electronics made with silicon carbide ( $\mathrm{SiC}$ ) and gallium nitride ( $\mathrm{GaN}$ ) into a wide range of products and systems. These wide bandgap (WBG) semiconductors operate at much higher voltages, frequencies, and temperatures than conventional semiconductors and are smaller and more energy efficient than the high-power electronics widely available today.

The institute's objective is to reduce the cost and perceived risk inherent with this new technology. PowerAmerica brings together top researchers, industry, and government to foster an exchange of knowledge and processes and help develop a skilled workforce. This enables American industry to develop more innovative power electronics products and systems.

Wide bandgap semiconductors can greatly improve energy savings in industrial processes, data centers, and consumer devices; increase electric vehicle driving range; and help integrate renewable energy onto the electric grid - all while reducing the impact on the environment.

\section{TECHNOLOGY ADVANCEMENT}

In FY 2020, the institute engaged in 47 projects. The projects address key challenges and opportunities facing the industry and include:

\section{Standardizing Production at an Open Foundry -} Silicon carbide is a more efficient semiconductor material than standard silicon devices widely used in today's power electronics systems, but it is more expensive to produce. To address this through economies of scale, PowerAmerica and X-FAB (Lubbock, TX) have standardized processes for customers of their silicon carbide foundry to fabricate silicon carbide ( $\mathrm{SiC}$ ) devices, eliminating technical and logistical complexities that can occur with different design processes.
New Silicon Carbide Open Foundries SiCamore Semi (Bend, OR) recently acquired the former Microsemi $100 \mathrm{~mm} \mathrm{SiC} \mathrm{wafer} \mathrm{fab} \mathrm{and}$ is operating the facility as an open $\mathrm{SiC}$ power device foundry. PowerAmerica is supporting this new open foundry through a collaborative project with NCSU FREEDM Center and SiCamore Semi to produce $3.3 \mathrm{kV}$ SiC Planar-Gate Power MOSFETs (metal-oxide-semiconductor fieldeffect transistors) and JBSFETs, as well as $3.3 \mathrm{kV}$ $\mathrm{SiC}$ diodes. PowerAmerica is also supporting the establishment of another new $150 \mathrm{~mm} \mathrm{SiC}$ wafer fabrication line at the high-volume Microsemi Si fab in Colorado Springs

Launching a University Research Foundry NCSU is implementing SiC Block Process Steps in their University Research foundry that are compatible with the SiC Block Process Steps used in the X-FAB commercial foundry, enabling university research to be more easily applied to manufacturing processes at X-FAB.

Commercializing High-Voltage Devices -Highvoltage SiC power devices are not yet widely available from commercial vendors but have substantial promise for efficient fast electric vehicle chargers and inverters for rail, heavy-duty vehicles, photovoltaic systems, wind applications, and more. PowerAmerica supported CREE/ Wolfspeed (Durham, NC) to develop 10kV SiC MOSFETs that are compatible with their state-ofthe-art $150 \mathrm{~mm} \mathrm{SiC}$ wafers production foundry. Reliability qualification was also conducted to demonstrate technology readiness of the highvoltage SiC devices.

Supporting Industry Adoption of Advanced Power Modules - WBG devices necessitate modules capable of high voltage, high frequency, high temperature, and high current that are not currently available from the silicon ecosystem. PowerAmerica supported GE Aviation (Pompano Beach, FL) to develop a wide range of advanced power modules using die from several PowerAmerica members including gallium nitride and medium voltage SiC devices. PowerAmerica 
also supported Cree/Fayetteville to develop highspeed, high-power modules and in collaboration with the University of Alabama develop electrical interconnect models for the modules. The National Renewal Energy Laboratory provided thermal analysis and characterization for the module projects.

\section{Commercializing Lighter, More Efficient Devices in Medium-Voltage Drives - Researchers at} Toshiba International Corporation (Houston, TX) continued their development of the world's first commercial Sic-based one-megawatt, medium-voltage motor drive system, dramatically increasing power conversion efficiency to almost $99 \%$ and reducing weight by nearly half. In this project, Toshiba introduced operation capabilities to their medium-voltage motor drive leading to a more robust product. Toshiba plans to manufacture products incorporating this technology in the U.S. at its Houston manufacturing facility.

Developing Hybrid Electric Propulsion for Aerospace - Raytheon Technologies Research Center is accelerating WBG adoption in state-ofthe-art hybrid electric propulsion for aerospace applications. PowerAmerica supported development of a high-efficiency WBG-based multiport converter that interfaces simultaneously power flow between the following ports: 1. a 15 $\mathrm{kW}, 350 \mathrm{~V}$ variable frequency aircraft generator emulator, 2. a $7 \mathrm{~kW} 350 \mathrm{~V}$ auxiliary power unit emulator, and 3. a $15 \mathrm{~kW} 270 \mathrm{~V}$ lithium ion battery. The multiport converter has an efficiency of $98 \%$ at each conversion stage, a specific power $>2 \mathrm{~kW} /$ $\mathrm{kg}$, and a power density higher than $4 \mathrm{~kW} / \mathrm{L}$. This project is focused on broad usage of electric equipment in place of traditionally used jet engines and hydraulic systems. The developed technology is scalable and widely applicable to power converters used in industrial drives and heating and cooling systems.

\section{WORKFORCE DEVELOPMENT}

"A skilled workforce is key in creating the large WBG demand that will spur mass manufacturing with its costlowering benefits."

-Victor Veliadis, Executive Director and CTO PowerAmerica

A key component of PowerAmerica's mission is to create a skilled workforce interested in and capable of working in this critical technology area. In FY 2020, 106 students participated in training in 47 applied academia/industry collaborative projects, 488 professionals attended tutorials, and 88 attended short-courses organized by PowerAmerica. Over the lifetime of the institute, 410 students were trained in more than 110 university/ industry projects, more than 1,700 professionals participated in PowerAmerica organized tutorials, and 154 attended PowerAmerica wide bandgap power electronics short courses. These courses draw professionals with varying degrees of experience in wide bandgap semiconductor technologies from around the country to receive training in silicon carbide and gallium nitride technologies from experts in the field.

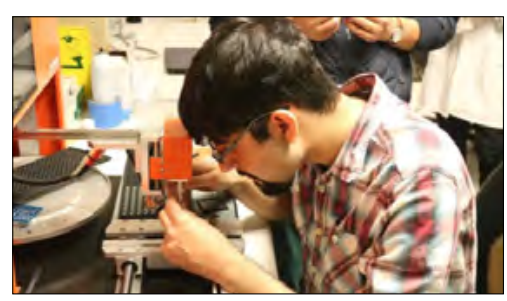

PowerAmerica short course student assembling WBG power semiconductor devices into a module. Credit: PowerAmerica

New Short Course for Wide Bandgap Power Devices - Researchers at NCSU's Nanofabrication Facility(NNF)andAnalyticallnstrumentationFacility (AIF) led two multi-day short courses covering the science and technology of wide bandgap power devices. The courses featured lectures, demonstrations of fabrication and microscopy equipment, and keynotes and panel discussions from world-class experts. Through these courses, NNF and AIF disseminated knowledge on "how 
best to design devices, modules, and systems that can exploit the superior physical characteristics of wide bandgap semiconductors."

Low-Cost Graduate Course with Virtual Fab and Hands-on Circuits Lab - Faculty at San Jose State University (San Jose, CA) created five course modules with content ranging from SiC virtual fabrication to SiC converter prototyping to prepare students and engineers to work in the SiC industry in Silicon Valley.

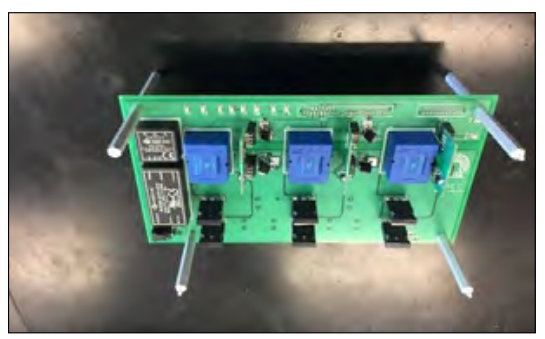

Plug \& Play training evaluation board for manufacturing-ready high-voltage, high-frequency WBG power electronics. Credit: San Jose State University

Short Course Module for Power Electronics Engineers and Students - NCSU faculty developed this short course module/tutorial that teaches the application of high-voltage SiC devices in MV power converters. All aspects of MV power converter design, characterization of devices for hard- and soft-switching rectifiers, isolated DC-DC converters, inverters, and AC-AC power conversion are covered. The course also includes demonstration of MV SiC-based power converters and HV SiC device characterization and test setups.

Testbed for Education and Electric Vehicle Industry Workforce Training - NCSU faculty also developed a modular $50 \mathrm{~kW} \mathrm{SiC} \mathrm{power} \mathrm{electronic}$ building block with high bandwidth and realtime control using reconfigurable software. It can operate as a WBG source and load emulator, and can assist with WBG power electronics testing. This project targets commercialization of the software-reconfigurable $50 \mathrm{~kW} \mathrm{SiC} \mathrm{motor}$ emulator platform that allows industries to train an industry workforce in testing electric vehicle drivetrain systems.

University and Industry Educational Partnership - Faculty at Texas Tech University and researchers at X-FAB developed two classes in SiC power devicesimulation, processing, and characterization to train undergraduates and graduate students in SiC power design and fabrication. The goal is to create a workforce knowledgeable in the manufacturing of these devices in large volume semiconductor foundries.

\section{INNOVATION ECOSYSTEM}

PowerAmerica is advancing the WBG power electronics ecosystem through collaborative innovation projects that span all aspects of the supply chain and represent important partnerships between academia, industry, and national labs. Institute members share best practices, connections, market opportunities, equipment, and invaluable knowledge, which extends the benefits across the industry and improves U.S. competitiveness in this important field. Key aspects of the PowerAmerica ecosystem include:

Foundry Access: PowerAmerica members X-FAB Texas (Lubbock, TX) and SiCamore Semi (Bend, OR) provide foundry access to other institute member companies that lack their own manufacturing facilities, such as GeneSiC (Sterling, VA), UnitedSiC (Monmouth Junction, NJ) and Sonrisa (Sante Fe, NM). University member North Carolina State University (Raleigh, NC) provides research fabrication capability.

Shared Devices: PowerAmerica member companies such as Wolfspeed-Durham (NC) and Microsemi (CO) supply devices to the module divisions of companies including GE Aviation Systems (Cincinnati, $\mathrm{OH}$ ) and WolfspeedFayetteville (NC), which then leads to system insertion demonstrations at member companies such as John Deere (Moline, IL), Toshiba (Houston, TX), ABB and numerous universities. PowerAmerica members that manufacture gallium nitride chips, such as Transphorm (Goleta, CA), provide devices to be used in applications by companies such as Lockheed Martin.

Knowledge Exchange: Member-initiated projects such as the third-party testing center of Texas Tech University and Group NIRE (both in Lubbock, TX) and NCSU are an important part of the PowerAmerica ecosystem, as they provide valuable feedback to device and module manufacturers while building confidence in the reliability of wide bandgap systems. 


\section{OVERVIEW}

IACMI - The Composites Institute is a $100^{+}$ member community of industry, academia, and government agencies leading innovation and workforce development initiatives to drive the adoption of advanced composites and grow U.S. manufacturing and support national security. Advanced composites provide strength and stiffness while being very lightweight, enabling advantages in transportation, energy, and infrastructure applications. Greater deployment of advanced composites can offer far-reaching benefits, such as safer, more energy-efficient vehicles.

IACMI is uniquely and systematically connecting innovation and workforce assets across multibillion-dollar industries positioned for significant future domestic and international growth. IACMI will make the U.S. a leader in the manufacture of these strategic materials and accelerate the growth of their markets.

\section{TECHNOLOGY ADVANCEMENT}

"IACMI provides us with leadership

and access to the entire supply

chain through projects with a

complete lifecycle perspective. The

broad network and vast resources

within the Institute bridge the gap

for collaboration across industry,

academia, and national labs."

-Rani Richardson, Dassault Systemes

During FY 2020, the institute engaged in 37 projects, of which eight were completed. These projects address key challenges and opportunities facing the industry and include:

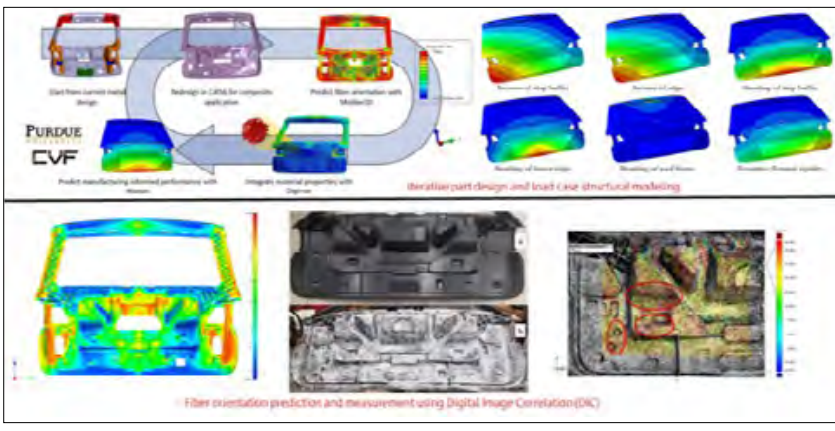

Integrated Modeling and Simulation for Design,

Engineering, and Manufacturing. Credit: IACMI

Integrated Digital Tools for Composite Design and Manufacturing - Purdue University (West Lafayette, IN) has developed and demonstrated the integration of modeling and simulation processes to simultaneously support component design for function and part consolidation and tool design for manufacturing. These digital tools were used to design and manufacture multi-component composite parts for full vehicle testing at IACMI Original Equipment Manufacturer partners. Both scale and full-size structural components with mechanical and surface finish are required to validate material and process for OEM production. The validations will enable increased use of carbon fiber reinforced polymer in auto body structures, leading to significant lightweighting and improved strength for fuel efficiency and crashworthiness. Multiple projects are using these tools, while also helping refine them for greater use. Collaborators include, among others: Dassault Systemes (Waltham, MA), Convergent Manufacturing (Seattle, WA), E-XStream/Hexagon (Ann Arbor, MI), ESI (Farmington Hills, MI), Analy Swift (West Jordan, UT), Moldex3D (Farmington Hills, MI), and Purdue University (West Lafayette, IN).

Novel Manufacturing Processes for Thermoplastic Wind Blades - The project team has successfully demonstrated and is continuing to advance complementary processes to enable novel thermoplastic materials for wind blades and received a 2020 R\&D 100 Special Recognition Award for Market Disruptor technology. In addition to scale wind blade testing and recycling, preliminary validations were completed for 
thermal welding for wind turbine blade joints atscale, facilitating deployment of this technology on larger, multi-megawatt blades. The use of thermoplastic resin systems in the production of wind blades better enables thermal welding blade components in the factory and will reduce cost and embodied energy while increasing blade recyclability. This also increases the opportunity to employ automation in production, and validations for robotic surface finishing are being planned. Project team members are: Arkema Inc. (Bristol, PA), Electric Glass Fiber America, LLC (Shelby, NC), SAERTEX USA LLC (Huntersville, NC), General Electric Company (Greenville, SC), TPI Composites, Inc. (Warren, RI), University of Tennessee, Knoxville (Knoxville, TN), National Renewable Energy Laboratory (Golden, CO), and Colorado School of Mines (Golden, CO).

\section{WORKFORCE DEVELOPMENT}

"Loving it in Rhode Island and TPI

Composites is pretty much spot on

for what I wanted to do right out of college."

-Darren Foster, IACMI intern

IACMI's workforce development initiatives train the advanced manufacturing workforce on technologies that are immediately relevant to industry and will continue to grow in importance. IACMI's workforce development initiatives span K-12 STEM outreach, internships, and technician training opportunities. IACMI recognizes that to support national security, manufacturing must occur in the U.S., and IACMI is training workers to meet industry needs.

\section{IACMI Advanced Composites Internship} Program - The IACMI integrated intern program is based on structured experiential learning, mentorship, industry collaboration, and professional development. To date, this program has orchestrated 119 appointments of interns with
40 partners at 25 unique host sites. Collectively, students have received almost 50,000 participation hours working with mentors, peers, and collaborating partners to advance industryled projects. Many students have participated in multi-site activities, broadening their experiences within a connected network of students hosted at member and partner locations across the U.S., providing an opportunity for composites research and innovation. Students engaged in hands-on learning at IACMI member companies, national laboratories, and universities, and presented their research at the IACMI Members Meetings.

\section{Students Collaborate on Award-Winning} Composite Structures for Pavilion - Carbon fiber braided arched composite beams manufactured for the International Friendship Bell were recognized with a 2019 CAMX Award for Composites Excellence (ACE) in the category of Most Creative Application. This project provided learning experiences spanning design to installation of novel multi-material lightweight beams that leverage the superior performance of carbon fiber. The Friendship Bell is part of the Peace Pavilion and symbolizes the spirit of the peace and friendship shared by the cities of Oak Ridge, Tennessee and Naka, Japan. Seventeen free-floating, 33-foot long, arched composite beams were manufactured from a combination of low- and high-density foam with a steel plate embedded in the center for assembly to the superstructure. The foam was over-braided with carbon fiber and, lastly, vacuum-infused. Partners include Oak Ridge National Laboratory, University of Tennessee, Knoxville, and Highland Compsites.

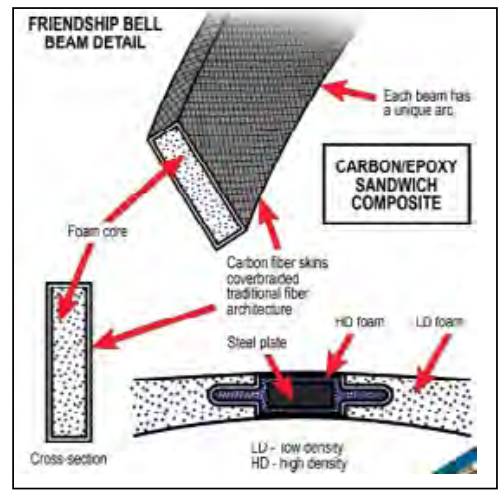

Braided Carbon Fiber Beam. Credit: IACMI 


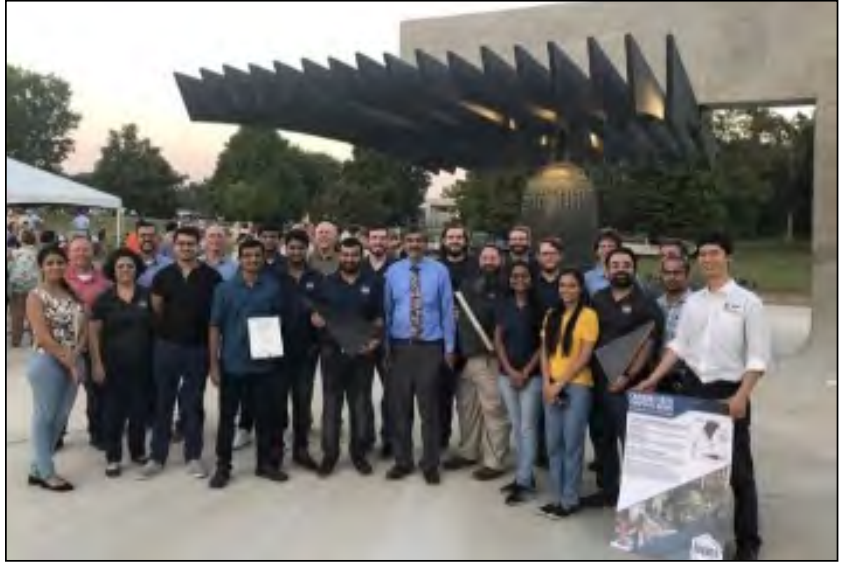

Friendship Bell Pavilion Student Team. Credit: IACMI

\section{INNOVATION ECOSYSTEM}

"Innovate UK has a long tradition of supporting companies to collaborate and innovate with international partners, and we are supporting some really exciting projects between the UK and the US. We are pleased to be working with IACMI, one of the institutes within Manufacturing USA."

-Simon Edmonds, Deputy Executive Chair, Innovate UK

IACMI continues to serve its membership and stakeholders through bi-annual meetings, dedicated sessions at technical meetings, active engagement with industry trade and supporting organizations, demonstrations and exhibits in key conferences, targeted outreach to share information, and opportunities for collaboration.

\section{International Collaborations Support U.S.} Manufacturing - IACMI is organizing and leading collaborations with strategic international partners, including the High Value Manufacturing Catapult Centers in the United Kingdom and Carbon United in Germany. IACMI has also convened leaders from national composites centers across the world to discuss common challenges such as standards, life cycle assessment, and recycling. Additionally, a project of UK Research and Innovation has created a partner program within their Innovate UK office and funds projects that have a complement within IACMI, with at least one common collaborator.

Volkswagen Group Innovation Hub - On January 17, 2020, Volkswagen Group of America (Herndon, VA) launched its first innovation hub in North America at the University of Tennessee Research Park at Cherokee Farm (Knoxville, TN). Announced in collaboration with Oak Ridge National Laboratory and the University of Tennessee, the facility focuses on developing materials and processes, including composite materials, in support of lighter vehicle components and their electrification strategy. This supports approximately \$3B of capital investment in new manufacturing facilities recently committed by VW and supply chain partners in Tennessee and northern Georgia.

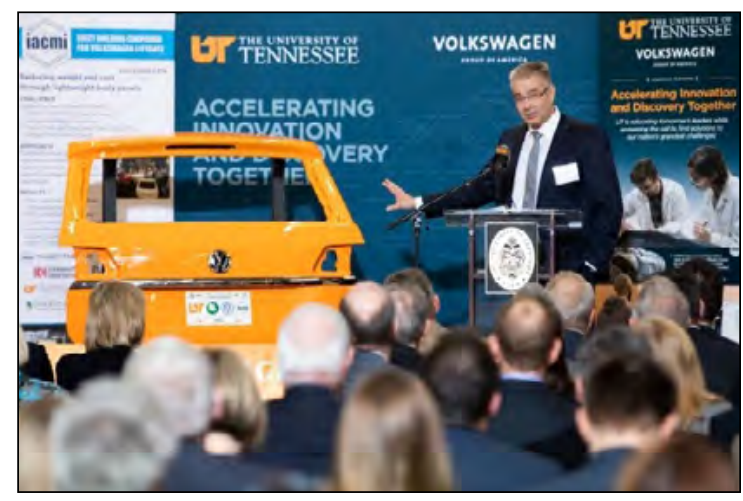

Dr. Nikolai Ardey, Executive Director, VW Group Innovation at ribbon-cutting for the VWUT Innovation Center. Credit: IACMI

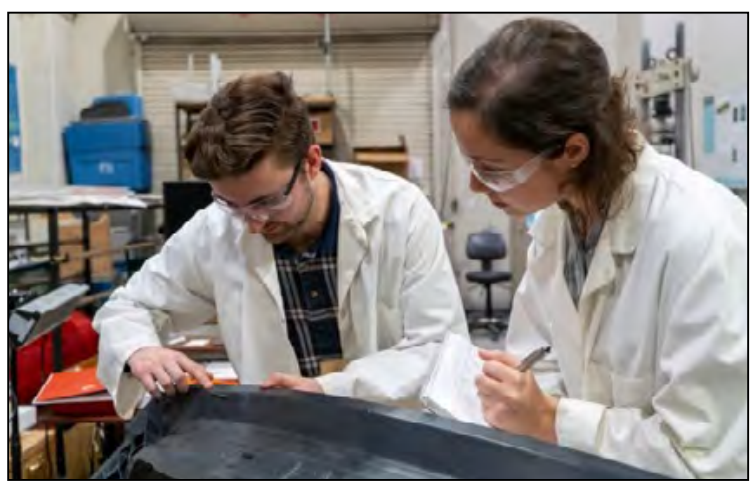

UT students Sean Lee and Tessa Patton working on VW composite liftgate. Credit: IACMI 


\section{OVERVIEW}

The Clean Energy Smart Manufacturing Innovation Institute (CESMII) is committed to transforming U.S. manufacturing through increased energy productivity and increasing global competitiveness via the application of Smart Manufacturing technologies. CESMII leverages an integrated portfolio of roadmap projects, application projects, services, and training enabled by the Smart Manufacturing Innovation Platform ${ }^{T M}$ and infrastructure. This assists the institute in meeting its objective of research and development of smart manufacturing technology for cost-effective, real-time management and control of energy in manufacturing across the process, facility, enterprise, and supply chain.

Through collaborative R\&D, CESMII is advancing key enabling technologies for smart manufacturing, including advanced sensors, data analytics tools, process controls, and data/information models - and building a unified innovation platform, marketplace, and ecosystem to scale smart manufacturing to all U.S. manufacturers. CESMII also has a technical education and workforce development program that leverages the national network of Smart Manufacturing Innovation Centers.

\section{TECHNOLOGY ADVANCEMENT}

"Openness and interoperability are critical to the success of the industrial Internet of Things, and we are committed to advancing the industry through the Open Manufacturing Platform. CESMII and their efforts to build a Smart Manufacturing Platform align well with our strategy, and we are excited to partner with them to simplify the customer journey in manufacturing."

-Sam George,
During FY 2020, the institute successfully continued the 10 Enabling R\&D projects launched in FY2019. A few highlights among them include:

Development of Edge Intelligence Platform for Sensor Integration - A team led by University of California Irvine (UCI) has developed E-Box, an edge computing hardware and software solution for low-cost integration of sensing systems. The E-Box is used to access and integrate data for camera-based human workflow monitoring that can be combined with machine learning algorithms to improve productivity and reduce energy consumption. The system has been tested in a nanosystems facility at $\mathrm{UCl}$, and is expected to be validated at Honeywell (Charlotte, NC) General Mills (Golden Valley, MN), and Aerospace Corporation (Palmdale, CA) facilities in 2021.

Energy Optimization of Metals for Aerospace and Orthopedics - University of Connecticut has developed systems-level optimization models for precision machining and hybrid manufacturing of metals in the aerospace and orthopedic industries. The models, along with sensor networks, predictive analytics, supervisory control, and scheduling algorithms will be demonstrated for improving energy efficiency at industrial manufacturing facilities. Other team members include Johnson \& Johnson, United Technologies Research Center, and Connecticut Center for Advanced Technology Inc.

Process Simulation \& Monitoring for Energy Optimization in Composite Brake Manufacturing - Virginia Tech and its partners are developing process simulation and in-process monitoring tools for thermally intensive processes. Along with dynamic models for energy consumption forecasting and key performance indicators, these solutions are targeted to be used for improvements in quality and energy consumption in composite brake manufacturing at Honeywell. Other team partners include Penn State, Commonwealth Center for Advanced Manufacturing, and University of Virginia. 
In FY 2020 the institute also selected awardees for eight new enabling R\&D projects, four education and workforce development projects, three platform capability projects, and five innovation projects launched in FY 2021. A few of the selected enabling R\&D projects include:

Paper Manufacturing Innovation - Auburn University and Rayonier Advanced Materials will develop a soft sensor and predictive control for anti-foaming agent usage, wash water flow, and pulp quality in paper manufacturing using statistics pattern analysis and machine learning.

\section{Pharmaceutical Manufacturing Process} Improvements - Rutgers, The State University of New Jersey, and Janssen Pharmaceuticals will develop advanced process models, sensors, and data integration architecture that will be demonstrated on wet granulation, drying, and milling in pharmaceutical manufacturing processes to improve the energy productivity and reduce energy intensity of pharmaceutical tablet manufacturing.

Simulation and Testing for Aerospace - UTRC, Purdue University, and the Connecticut Center for Advanced Technology Inc. will develop a simulation and testing framework to determine the feasibility of using ultrasound to mitigate defects in turbine parts in the Vacuum Arc Remelting process.

\section{WORKFORCE DEVELOPMENT}

"With this CESMII partnership, the North Carolina State Smart Manufacturing Innovation Center (SMIC) will be able to build and sustain a skilled and innovative Smart Manufacturing workforce with expertise in the requisite technology and best practices for interdisciplinary educational resources and programs.

The NC State SMIC continues to expand the world-class Smart Manufacturing demonstration facility through partnerships with industry and national laboratories for workforce education that keeps up with the pace of innovation and the needs of the industry. We are very excited about this new opportunity."

-Professor Yuan-Shin Lee, North Carolina State University

Education and Workforce Development is one of CESMII's four strategic pillars. The institute took steps forward to make Smart Manufacturing accessible through both formal education and less-formal knowledge sharing. Highlights include:

Education and Workforce Development Roadmap - Project teams are developing a Smart Manufacturing curriculum and hands-on tools to be shared in the education ecosystem. Two are in execution and four have been selected and will launch in FY 2021.

Forum on Smart Manufacturing and the Connected Workforce - CESMII convened partners to discuss and document current practices for integrating workers in the field into the data-control loop for the Smart Manufacturing 
factory. Participants included Gartner, General Mills, Honeywell, Johnson \& Johnson, P\&G, Linde, ArcelorMittal, Corning, Raytheon, Conagra, Clover, and PepsiCo.

\section{Smart Manufacturing Knowledge Sharing}

- CESMII expanded their library of recorded knowledge, sharing videos with professionals and experts of all industries and engaging with more than 3,000 viewers. The virtualized CESMII Annual Meeting, workshops, and educational webcasts conducted throughout the year educated over 500 people on the value, multiple dimensions, and fundamentals of Smart Manufacturing, including the impact on sustainability, energy productivity, and supply chain resiliency.

\section{INNOVATION ECOSYSTEM}

"We are a small tier 3 and 4 supplier of synthetic and natural rubber raw materials and our small team wears many hats. Our engagement with CESMII delivers value on many fronts, exposing us to the right technologies and techniques, and most importantly, letting us engage with a community of forward-looking manufacturers and technology providers that we would never have found otherwise. We needed digital transformation expertise for our business, and CESMII put us in touch with Flexware Innovation, an excellent system integrator. We never would have found them without CESMII."

- James Lawrence, Plant Manager, ECM Performance Materials Group
CESMII is "the Home of Smart Manufacturing" and brings together a diverse ecosystem of manufacturers, systems integrators, technology vendors, and academic institutions to tackle challenges no single entity can address on its own. CESMII's Small-to-Medium Manufacturers Affinity Group gives smaller organizations a voice to shape the future of the institute's roadmap and initiatives, just as industry-focused affinity groups do for specific vertical markets.

CESMII's network of university-based Smart Manufacturing Innovation Centers (SMICs) made significant strides in providing value to regional manufacturers, solution providers, and the entire manufacturing ecosystem. This includes the following accomplishments: 1) Integrating four on-campus production facilities at North Carolina State University with the Smart Manufacturing Innovation Platform for use in test beds and education; 2) Launching integration work for the SMIC at RensselaerPolytechnic Institute to connect the agile manufacturing learning environment and labs for use in test beds and education; and 3) Codeveloping a training course for manufacturing workers that introduces smart manufacturing concepts through lean manufacturing principles with the SMIC at El Camino Community College.

Another example of the value of this national innovationecosystem is in its response to COVID-19, as several CESMII members - industry-leading manufacturing and technology organizations responded immediately to prioritize and realize national supply chain responsiveness and resilience. Work began to enable a secure endto-end data backbone for real-time visibility and the mitigation tools to respond nationally to future disruption. 


\section{Reducing Energy Consumption in Cement Manufacturing through Smart Manufacturing Technologies}

This project's goal was to develop a predictive scale model of a rotary cement kiln to optimize parameters for reduced energy consumption. The lab model of a cement clinker production kiln was equipped with sensors and control system, combined with multi-physics (e.g., flow, heat transfer) predictive model was developed to optimize operating parameters for reduced energy consumption. The electronic controls for the kiln have been designed and constructed, as has the cooling system. The feeder system has been designed. The complete lab-sized kiln was constructed and instrumented; thermal and flow models have been developed and tested. The project also validated multi-physics predictive models that will lead to optimized operating conditions contributing up to $15 \%$ reduction in energy usage in production kilns. This project is addressing the following metrics related to the institute goals: 1 . develop and validate Smart Manufacturing technologies to improve energy productivity through improved efficiency by $25 \%$ (in 5 years) on a pathway to 50\% (in 10 years); and 2. validate smart manufacturing in first-of-kind applications for energy-intensive manufacturing processes and facilities as replicable models for widespread deployment.

The goal of the data analytics approach is to use quality control and process operation information provided by the Argos Roberta Cement Plant to develop machine learning tools that allow the use of these data to improve energy efficiency of the process.

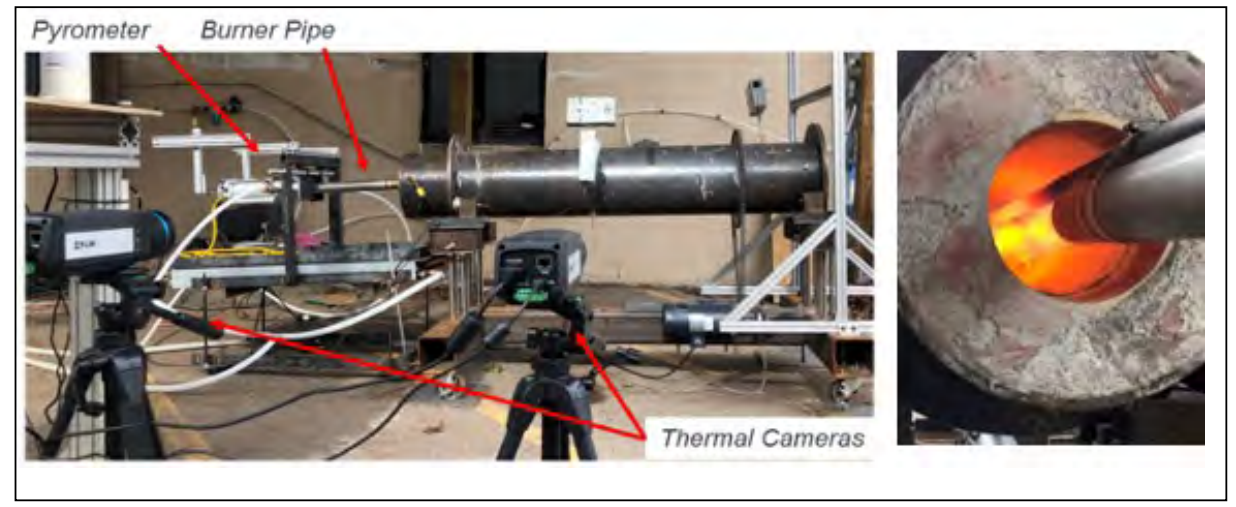

Scale Model of a Rotary Cement Kiln. Credit: University of Louisville 


\section{Real 'Factory 4.0 Toolkit' Brings Smart Manufacturing Education to the Classroom}

CESMII members Penn State University (PSU) and the Massachusetts Institute of Technology (MIT) partnered to develop an instrumented, small-scale fiber extrusion kit that models real-world practical manufacturing scenarios along with smart manufacturing software applications and supporting educational modules such as labs, projects, and sample data sets. This tool (shown below) is designed for classroom use, and makes smart manufacturing education immediately adoptable in a broad range of engineering, non-engineering, and cross-discipline educational programs.

In this project, MIT's prior design for the equipment - a fiber extrusion device known as FrED was updated by PSU to add power monitoring, an open-source software operating system, and an industrial control option, followed by software networks for data storage and connectivity to CESMII's Smart Manufacturing Innovation Platform ${ }^{\text {TM }}$.

Educational modules related to fiber extrusion device introduced smart manufacturing overview topics to business and engineering students and took the engineering students deeper into the industrial internet-of-things, data analytics, digital twins, and process optimization. The tools were tested with engineering and business students as part of an Industry 4.0 overview. The educational toolkit is available to educators in the CESMII network to leverage into their curricula.

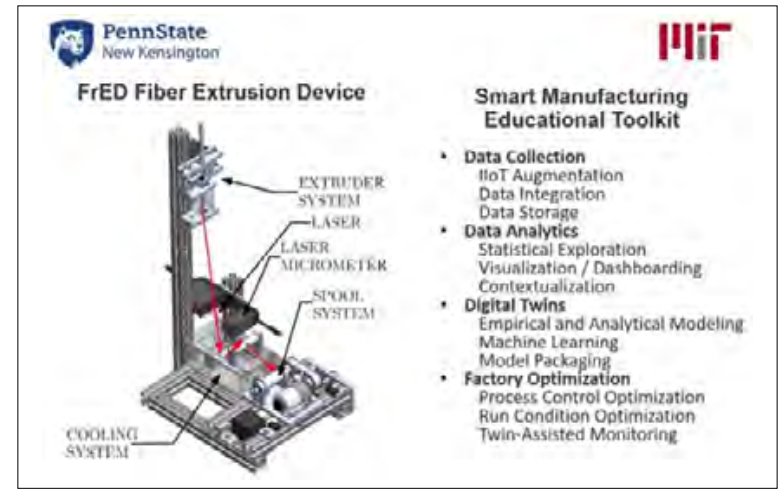

Fiber Extrusion Device. Credit: Penn State, MIT

\section{"The rapid pace of technology development has left educational systems} scrambling to keep pace and adapt learning outcomes, inadequately preparing the manufacturing workforce at all levels. Projects like this will help us change that."

-Joseph Cuiffi, Assistant Teaching Professor and Project Leader, Penn State 

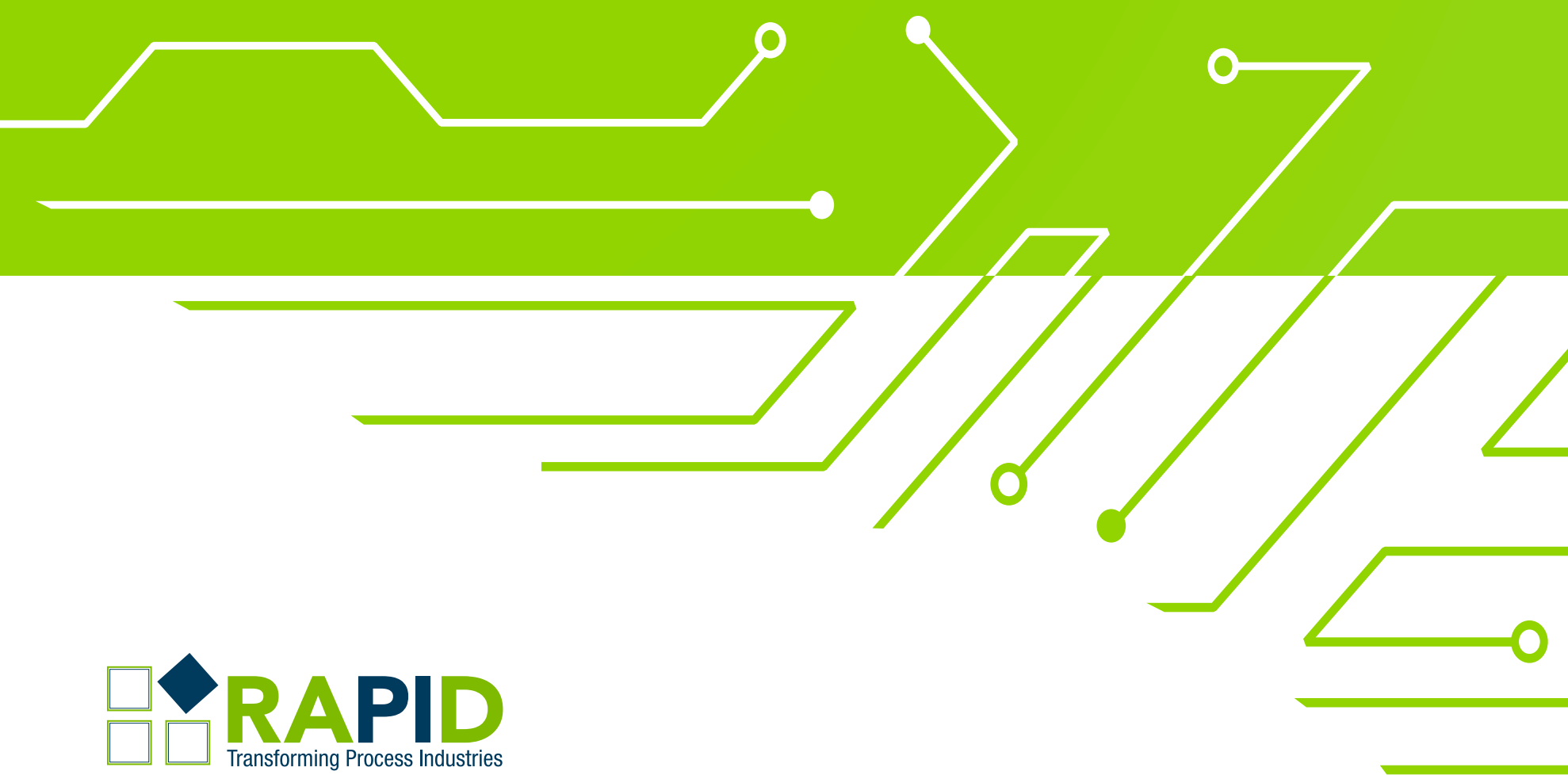

Rapid Advancement in Process Intensification Deployment Institute

Established: March 2017

Headquarters: New York, NY

Mission: Advance modular chemical process intensification technologies to reduce energy consumption, improve process efficiencies, and reduce investment and operating requirements.

Consortium Organizer: American Institute of Chemical Engineers (AIChE)

Members (as of September 30, 2020): 82

Funding: Federal, \$15.8 M; Non-Federal, \$19.6 $\mathrm{M}^{9}$

\section{aiche.org/rapid}

\footnotetext{
${ }^{9}$ Federal dollars and cost share expended by the Institute during FY 2020 are reported here. It does not reflect federal funds appropriated in FY 2020 (if any) for a given DOE Institute.
} 


\section{OVERVIEW}

For more than 100 years, chemical engineers have developed processes based on standard unit operations and scaled those processes to build large, centralized manufacturing facilities. These principles have served the process industries well, resulting in predictable methods for designing and building low-cost, high-volume operations. Over the last several decades, scientists and engineers have been advancing new technologies that are shifting this paradigm. Instead of achieving economies of scale by building larger facilities, modular processes are built on standardized, smaller-scale operations and are scaled in number. Process intensification (PI) enables new combined-unit operations that are more energy- and raw-material efficient and safer to operate.

While modular processing and PI stand on their own, when they are combined into modular chemical process intensification (MCPI) these technologies allow manufacturers to reduce risk by building and operating smaller footprint systems designed to produce just the amount of product needed to satisfy demand at any time, and then scale up to meet market needs. MCPI offers manufacturers the opportunity to build a more efficient, distributed supply chain that is both sustainable and resilient. RAPID was created to lead the nation's efforts to research and develop high-impact MCPI solutions for the benefit of members from industry, academia, national laboratories, and other nonprofits.

\section{TECHNOLOGY ADVANCEMENT}

\section{"Through our collaborative}

project with RAPID, we have

made key advancements toward

development and scale-up of our

surfactant bioproducts technology,

advancements that would have

otherwise been too challenging

and costly for a startup. The

resources, learning materials, and

network of RAPID have provided

innumerable opportunities for

our startup to engage with key

experts and companies in our

field, while networking events have

provided valuable opportunities

to meet colleagues in the process

intensification community."

-Christoph Krumm, Sironix Renewables

During FY 2020, the institute engaged in 33 projects. An additional five have been selected to launch early in FY 2021. The research and development projects were chosen to address challenges in RAPID's technology roadmap focus areas: 1) chemical and commodity processing; 2) national gas upgrading; 3) renewable bioproducts; 4) intensified process fundamentals; 5) modeling and simulation; and 6) module manufacturing.

Additionally, each of these projects support one or more of the institute's goals: $20 \%$ increase in energy efficiency; doubling of energy productivity; 10-fold reduction in capital cost and 20\% improvement in energy efficiency and emissions/ waste; $20 \%$ reduction in module manufacturing cost; and cost-effective deployment of MCPI at scale. RAPID also works with members to refine its technology roadmap, expanding areas of interest 
to include MCPI solutions for pulp and paper processing, carbon capture and utilization, postuse plastics reuse and valorization, and distributed manufacturing for the fixed nitrogen value chain. Projects of note include:

Intensified Continuous Manufacturing of Dispersants - University of Pittsburgh developed a continuous modular process to produce an existing specialty chemical at much lower operating and capital cost. The new process has a smaller footprint in the manufacturing plant than the existing batch process and produces higher-quality product with virtually no waste generation and 90\% less energy use. The project focused on production of specialty dispersants used in engine oil, with a particularly challenging chemistry requiring novel approaches. Pitt researchers performed measurements and modeling to understand the underlying reaction kinetics and mass transfer, which informed the design and fabrication of an intensified modular pilot skid. The pilot skid began production in FY 20 and completed the batch-to-continuous process conversion in under 24 months, with fabrication of a second-generation pilot skid underway. Other project partners include The Lubrizol Corporation (Wickliffe, OH).

\section{Energy-Efficient Separations of Chemical} Compounds - Compact Membrane Systems (Wilmington, DE) has developed a novel product and method for separation of olefins and paraffins. The team scaled up membrane fabrication for pilot testing and is preparing to deploy a membrane test skid to assess recovery of propylene from propane in a polymerization reactor purge stream, with the propylene recycled to the reactor. The team demonstrated a 34\% reduction in the cost of manufacturing the membrane modules, and techno-economic analysis predicts a 53\% improvement in energy efficiency compared to a distillation baseline. A field trial of the membrane skid at a Texas petrochemical plant is anticipated in FY 2021. Other project partners include Dow and University of Minnesota.
Efficient Conversion of Waste Biomass to Sugars and Other Bioproducts - lowa State University (Ames, IA) is scaling up a modular autothermal process for thermochemical conversion of woody and agricultural biomass to fermentable sugars and other value-added products at or below current market prices. The new process uses less process heat than existing processes, is expected to double energy productivity, and is well suited for distributed processing in modular units designed to fit in standard shipping containers. Other project partners include Stine Seed (Adel, IA).

\section{Microwave Chemistry for Enhancing Natural} Gas - West Virginia University (Morgantown, WV) is developing routes for conversion of natural gas to value-added products such as aromatic compounds using selective microwave reactor heating and catalysts. The new approach is more energy- and capital-efficient and could enable the conversion of U.S. natural gas resources to easily transportable liquid products. Initial technoeconomic assessments indicate the potential for over $60 \%$ improvement in energy efficiency and $50 \%$ reduction in capital costs compared to standard routes. Other project partners include the University of Pittsburgh, Shell (Houston, TX), and the National Energy Technology Laboratory (Morgantown, WV).

Modeling the Total Cost of Ownership for Scaling-Up with Modular - Oregon State University (Corvallis, OR) is developing tools to assess the total cost of ownership for scalingup processes using MCPI versus traditional approaches. The team is applying the modeling tools to existing RAPID case study projects where modular and PI technologies are deployed as alternatives to traditional volume-scaled processes. Results indicate that total cost of ownership can be decreased considerably and return on capital employed increased substantially. Other project partners include the Construction Industry Institute at the University of Texas (Austin, TX). 


\section{WORKFORCE DEVELOPMENT}

RAPID is working with members to create and deploy educational content that ensures a healthy pipeline of skilled engineers, operators, and technicians who are able to design, develop, and deploy modular chemical process intensification technologies. Highlights of RAPID's education and workforce development activities include:

Virtual Internship Program - In this ten-week virtual program, engineering student interns at RAPID member organizations join a virtual community and receive online safety, technical, and leadership training, as well as professional development and mentorship. The program provides smaller organizations access to interns nationwide and allows their student interns to become part of a broad virtual network across the U.S. This resulting shared learning community offers interns networking opportunities with other students and their host organizations and opportunities to discuss technical and professional topics. RAPID continues to offer rotations, engaging 15 to 20 new students each year.

Modular Chemical Process Intensification Boot Camp - RAPID developed and piloted a fourday course designed for practicing engineers interested in advancing modular chemical process intensification through the use of "number-up" plant designs. The curriculum covers all steps from concept to commission, including re-examining fundamental chemistry and physics, learning about design and advanced manufacturing of intensified process equipment, and understanding how modular chemical plants are built using intensified process equipment. RAPID partnered with Oregon State University's Advanced Technology and Manufacturing Institute for this course and is working with additional partners for three additional courses in development.
Emerging Membrane Processes for Water Purification - In partnership with the University of Arizona, RAPID developed and successfully piloted a four-day course at Arizona's West Center facilities. Participants worked in teams on experimental systems and modeled their results. The participants also learned about the operation of the Agua Nueva Water Reclamation Facility. Chemstations, a process modeling software tool provider and partner on the course, provided additional instruction.

Online Learning Content Continues to Drive Impact - In FY 2020, RAPID hosted seven webinars on topics ranging from computational catalysis and batch-to-continuous conversion to process electrification and designing processes for resilience. Between live offerings and archived recordings, RAPID webinars have reached over 6,000 registrations from undergraduate engineering students and industry professionals. Additionally, RAPID launched a second eLearning course on intensified reaction processes. More than 780 individuals completed a RAPID eLearning course in FY 2020, which along with the first two courses provide an initial curriculum for a Process Intensification Professional Certification program.

\section{INNOVATION ECOSYSTEM}

"We have proven how effective this patented technology is and are excited that it is now commercially available through Sour Gas LLC. Thanks to RAPID, we have delivered a viable system that is exceptionally well-suited to removing hazardous hydrogen sulfide directly at the wellhead." 
RAPID convenes its members quarterly to discuss progress and offer networking opportunities. At the AIChE Annual Meeting, RAPID hosted an annual poster session that provided networking and project information opportunities for members. During that meeting, as well as the virtual Spring Meeting, RAPID provided extensive programming to the broader process industry community. Throughout FY 2020, RAPID continued to offer a technology showcase series for members to highlight their research, product and service offerings, and challenges. The events continue to create opportunities for members to engage and develop new collaborations.

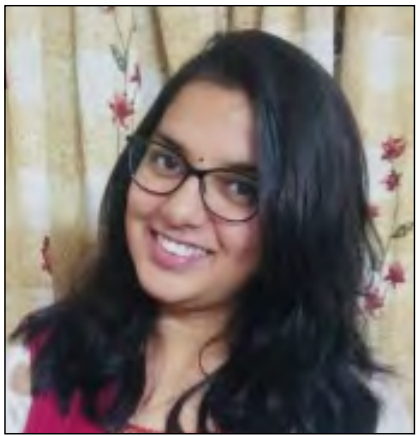

RAPID Intern Tanya Srivastava, Texas Tech University Credit: RAPID

\section{A RAPID Intern Spotlight}

The RAPID Intern Program provides an opportunity for students to work with members. This virtual program offers student interns $20^{+}$hours of $\mathrm{PI}$ leadership training and professional development opportunities including networking, career discovery, and public speaking/presenting. In 2020, 22 students from diverse member organizations participated in the RAPID Intern Program, and all said they would recommend the program to a friend.

Tanya Srivastava, a first-year graduate chemical engineering student at Texas Tech University participated in the Fall 2020 RAPID Intern Program during which she worked on a project entitled "Organic Solvent Nanofiltration" in her Reaction and Separations Lab. Tanya's project largely involved casting and evaluating membranes and reviewing the literature to generate protocols to synthesize organic solvent nanofiltration membranes.
"I wish to work as a Chemical Engineer in companies or research institutes and help make processes more environmentally benign. Paying attention to our carbon footprint is the need of the hour and as someone majoring in chemical engineering, I feel I can contribute to a large extent. I aspire to utilize my skills in an organization that shares the same goal as me.

With the RAPID Intern program, I got to know about Process Intensification and Modular Manufacturing and how my research aligns with it. I realized its application and demand in industry. The program also focused on our personal development with skills like networking, communication, and resume building."

\section{Delivering Cleaner Gas to Consumers: IntraMicron Team Hits 1,000 Hour Milestone at West Texas Wellhead}

Researchers from IntraMicron (Auburn, $A L$ ) and its subsidiary Sour Gas LLC have developed an energy-efficient and cost-effective alternative to traditional methods for purifying natural gas.

Natural gas used by consumers is far different than the natural gas flowing from the wellhead. The wellhead product can contain impurities, such as highly toxic hydrogen sulfide, that must be removed for natural gas to be safely distributed from the processing plant to the consumer. The company's SourCat ${ }^{\mathrm{TM}}$ technology selectively recovers elemental sulfur and can process natural gas feedstocks over a wide range of purities that cannot be economically purified by traditional desulfurization approaches.

The project team, which also includes Auburn University and Oregon State University, reached a major milestone in their commercialization trajectory by completing a 1,000-hour pilot demonstration at a west Texas wellhead.

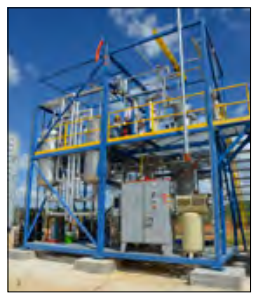

Intramicron, LLC and Sour Gas, LLC skid at a natural gas well site in TX. Credit: IntraMicron, LLC. 


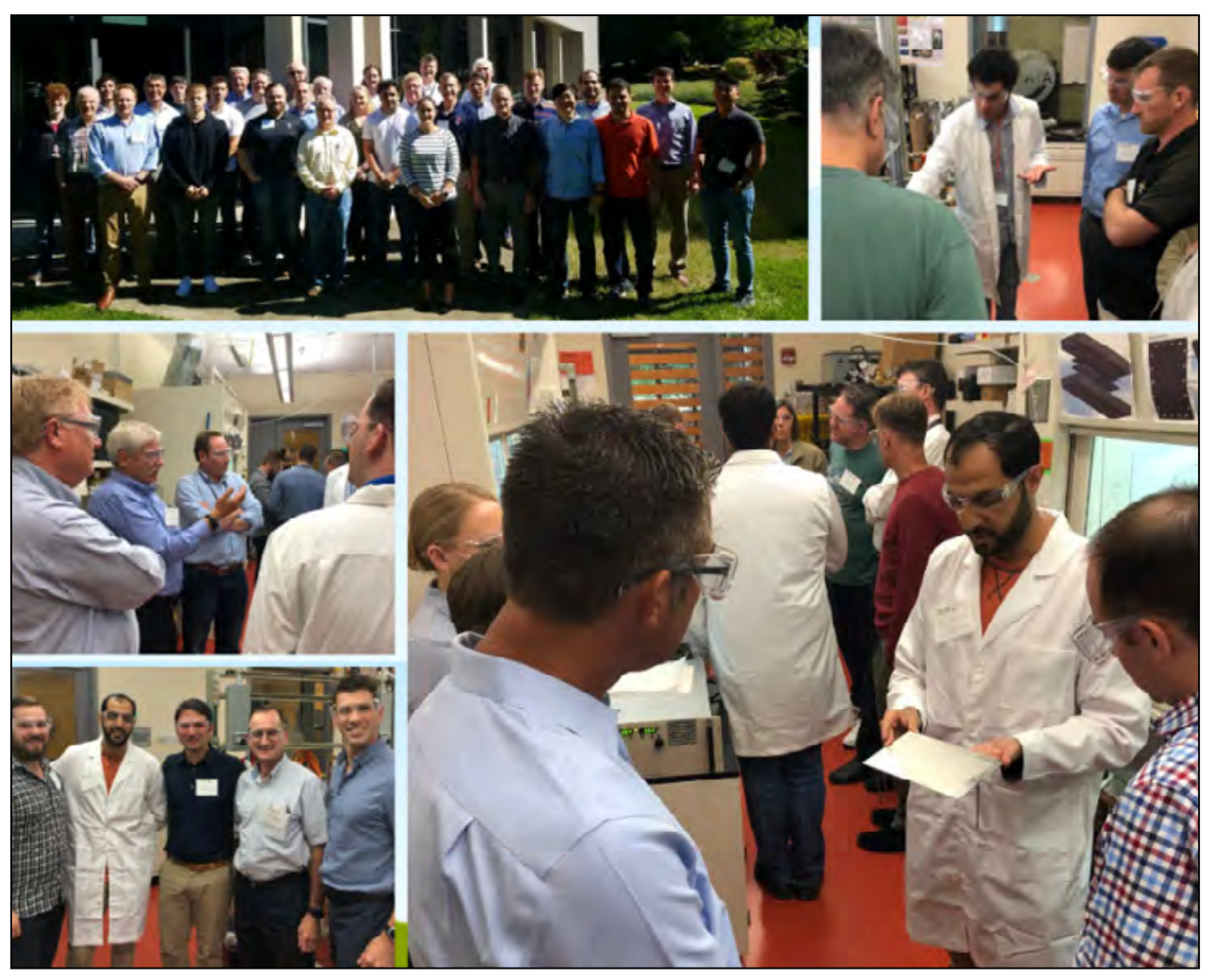

MCPI Boot Camp Participants. Credit: RAPID

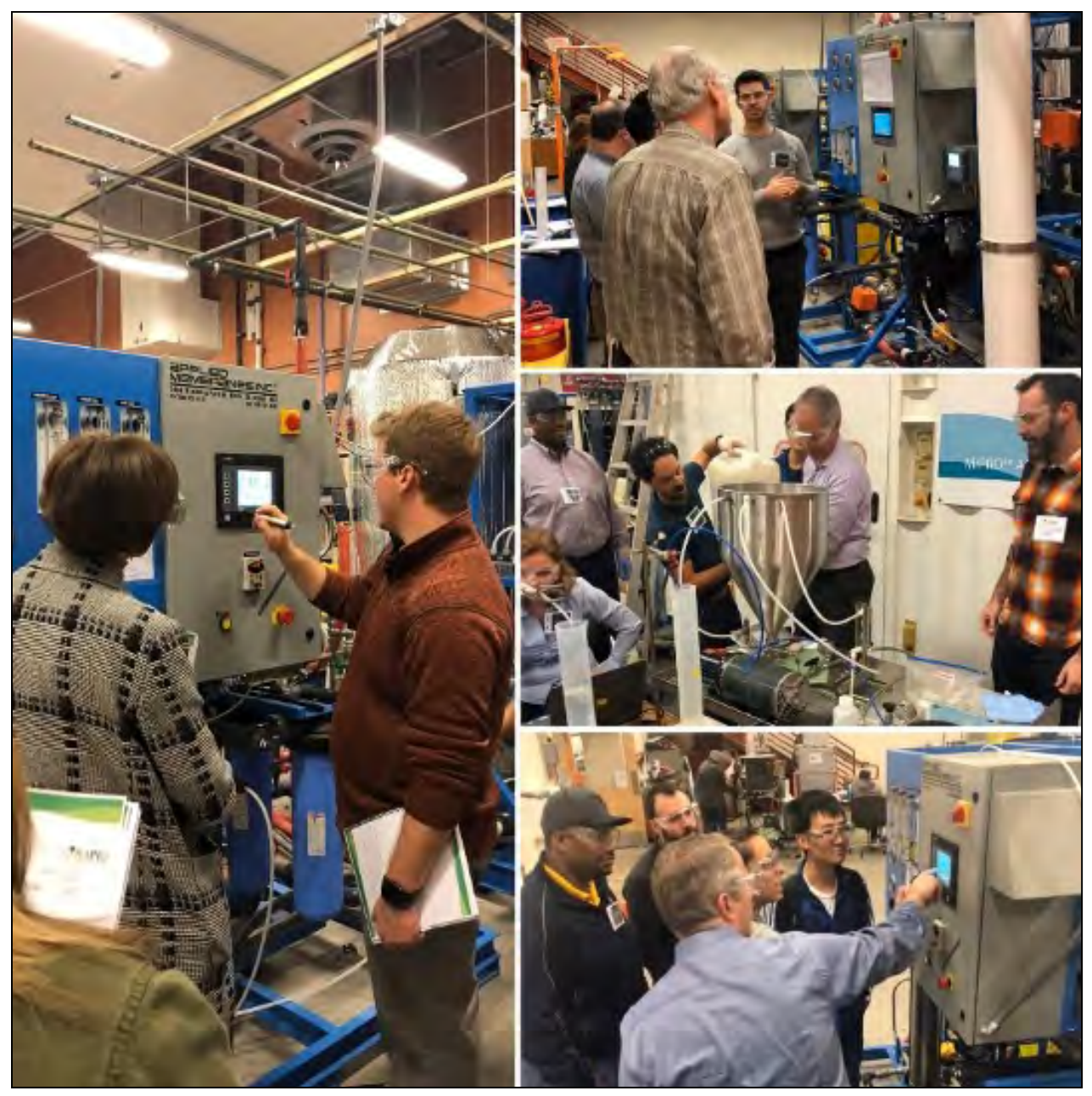

Emerging Membrane Processes Course Participants. Credit: RAPID 


\section{OVERVIEW}

A recent study by the United Nations Environmental Program predicted that global material consumption will more than double by $2060 .{ }^{11}$ Consistent with its mission to dramatically reduce the embodied energy and carbon emissions associated with industrial-scale materials production and processing, the REMADE Institute is developing technology solutions to reduce materials waste; innovate so that products are designed to be safely reused, remanufactured, or recycled; and circulate everything to keep it in the economy and out of the waste stream. Doing so will enable development of a manufacturing base that could generate new revenue, create jobs, conserve energy, and reduce greenhouse gas emissions.

REMADE is organized around five focus areas, or nodes, designed to address cross-cutting challenges through applied research and enable increased recovery, reuse, remanufacturing, and recycling (collectively referred to as $R e-X$ ) of metals, fibers, polymers, and electronic waste (e-waste).

\section{TECHNOLOGY ADVANCEMENT}

"As industry seeks to become a more responsible steward of the world's ecosystem, there is an urgent need for the development of advanced technology that supports a circular economy. By funding innovative technical research projects, REMADE is helping industry turn its sustainability commitments into delivered results."

-Dr. Subodh Das, CEO, Phinix LLC and REMADE

Governance Board member

By helping U.S. manufacturers tackle barriers that limit recovery, reuse, remanufacturing, and recycling of metals, fibers, polymers (plastics), and e-waste across the product lifecycle, REMADE is helping accelerate the transition to a circular economy in industries as diverse as automotive, consumer products, electronics, and heavy-duty equipment.

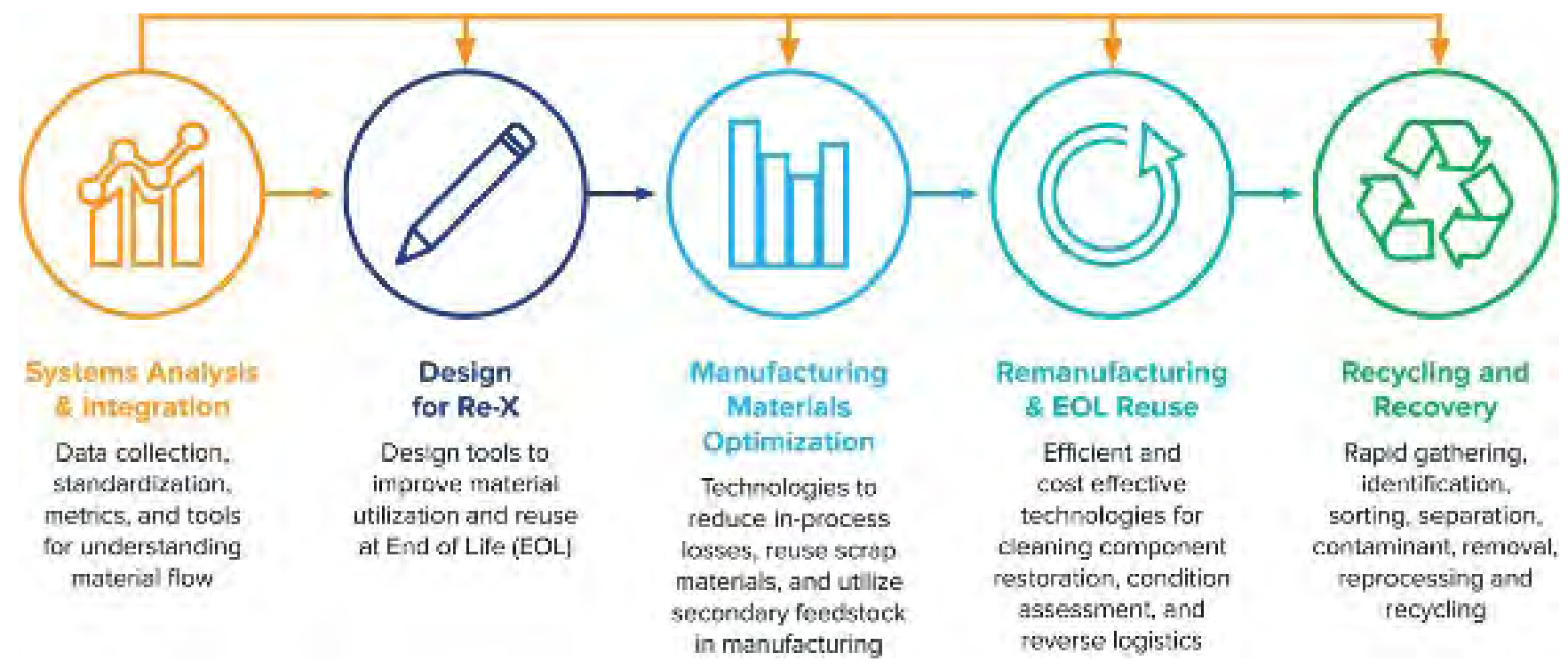

REMADE Nodes with Descriptions. Credit: (C2020 Sustainable Manufacturing Innovation Alliance Corp.

${ }^{11}$ OECD (2019), Global Material Resources Outlook to 2060: Economic Drivers and Environmental Consequences, OECD Publishing, Paris, https://doi.org/10.1787/9789264307452-en. 
With the support and commitment of its members, REMADE serves as a consortium of almost 100 partners from industry, academia, national labs, trade associations, and non-governmental organizations. Through the creation of an innovation ecosystem that promotes effective collaboration of its members, the institute leads the development of technology solutions that will foster a circular economy in the U.S. REMADE's research portfolio continues to expand and now represents 39 technology projects. Project highlights include:

\section{Development of New Cost-Effective Methods} for Removing Trace Contaminants in Recycled Metals - Making an aluminum can from recycled aluminum saves more than $90 \%$ of the energy required to make a new can. ${ }^{12}$ However, efforts to increase the use of recycled aluminum are hindered by two key factors: the inability to adequately sort aluminum alloys that are collected for recycling and strict limits on contaminants, such as iron and zinc, allowed in aluminum alloys used in the automotive and aerospace industries. As a result, the United States exported ${ }^{13}$ or landfilled, ${ }^{14} 4.8$ million metric tons of aluminum in 2018. The Ohio State University, Alcoa USA and CompuTherm LLC have teamed up to develop a technology framework to cost-effectively neutralize contaminants and enable increased recycling of aluminum.

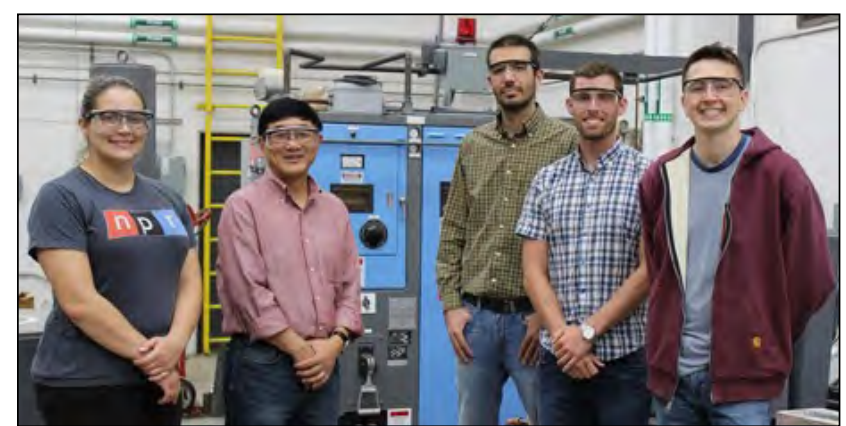

Professor Alan Luo and research team members. Credit: Ohio State University
"At John Deere, we're committed

to a better tomorrow. Through the use of JDLink telematics data, reliability analysis, and predictive technology we have the opportunity to collaborate with our customers and dealers as well as partners at lowa State and REMADE to significantly improve design for $R e-X$. This reduces downtime for our customers and minimizes the impact on the environment."

-Navaid Ahmed, Manager, Engineering \& Quality, John Deere Reman REMADE Strategic Advisory Council member

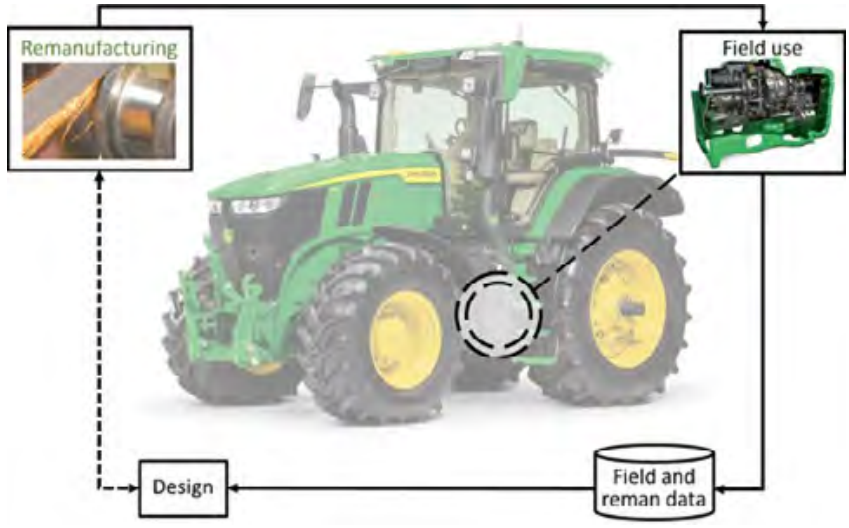

Agricultural tractor with a remanufactured High-Value Component, reducing cost and environmental impact. Credit: John Deere Reman

Data-Driven Design for $\mathrm{Re}-\mathrm{X}$ in Industrial and Agricultural Equipment - Design for $\mathrm{Re}-\mathrm{X}$ ensures that products can be reused, remanufactured, recovered, or recycled. Several factors have hindered efforts to address Re-X earlier in the design process. First, Re-X process models that quantitatively capture recycling and

\footnotetext{
12 The Environmental Footprint of Semi-Finished Aluminum Products in North America, a Lifecycle Assessment Report, The Aluminum Association, December 2013.

${ }^{13}$ Aluminum Mineral Commodity Summary, U.S. Geological Survey, January 2020.

${ }^{14}$ Advancing Sustainable Materials Management: 2018 Tables and Figures, Environmental Protection Agency, November 2018
} 
remanufacturing process knowledge do not exist. This makes it difficult to analyze how effectively a design balances performance and end-of-life Re-X using current design tools. Second, existing qualitative tools have not been integrated into the daily workfow of design engineers. Iowa State University and John Deere have partnered to develop a data-driven software tool to evaluate design options and make recommendations during the design of high-value metal components in industrial and agricultural equipment. When implemented, this tool is expected to reduce embodied energy by $7 \%$ and carbon emissions by $10 \%$.

Novel Ways to Evaluate Reusability of Metal Parts - Remanufacturing begins with the complete disassembly of the product. Next, the individual parts are cleaned and inspected to determine whether they can be reused. Although current inspection methods for metal parts can detect existing flaws, they cannot measure accumulated mechanical damage prior to crack initiation, which is essential to estimating the remaining useful life of the part. The University of Illinois at Urbana-Champaign and Penn State University are developing a new non-destructive evaluation method for metals based on multisensory fusions and machine learning that will allow them to make these measurements. This novel approach has the potential to increase the number of parts that can be reused and avoid the amount of energy and material that would be required to make a new part.

"This project will provide an effective, reliable tool for the remanufacturing industries to inspect fatigue damage in incoming recycled metal components and gauge their remaining useful life."

-Chenhui Shao,
Identifying Strategies to Maximize Benefit of Fiber Recovery through Systems Quantification - There are currently no integrated, marketwide tools to understand the impact of changes in recovery within fiber materials systems. The economic benefit of using recycled fibers over virgin feedstocks is often unclear. The Massachusetts Institute of Technology in collaboration with the American Forest \& Paper Association (AF\&PA) is developing a model to provide economic and environmental estimates of fiber recovery technologies and scenarios. This work will enable identification of the most significant opportunities across fiber systems by providing better estimation of the impact of fiber recovery.

\section{WORKFORCE DEVELOPMENT}

"REMADE's "Fundamentals of

Mechanical Recycling of Plastics"

certificate was well-organized, interesting, and informative. I look

forward to REMADE's release of additional certificates in recycling."

-Kelsea Schumacher, Ph.D., Circular Economy, NIST

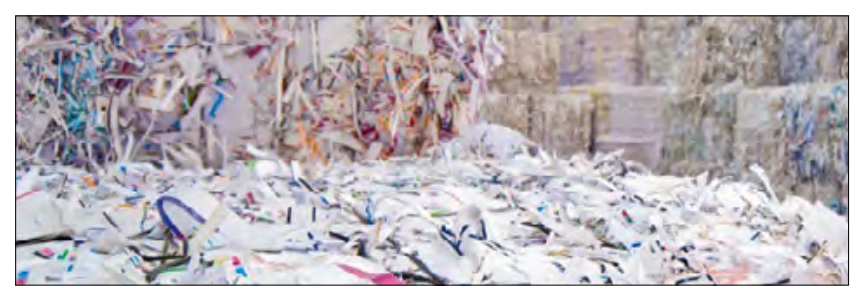

Credit: Sustainable Manufacturing Innovation Alliance Corp

REMADE Institute is driving development of cutting-edge training opportunities for the U.S. workforce targeting current and emerging engineers and technicians. The institute's certificate pathway training is organized into three competency levels: Awareness, Practitioner, and 
Expert. REMADE also offers outreach training to engage and encourage a new generation of U.S. workers to pursue careers in advanced manufacturing. REMADE's unique position at the crossroads of academia, industry, and government enables the institute to draw from the Nation's top subject matter experts to create training opportunities.
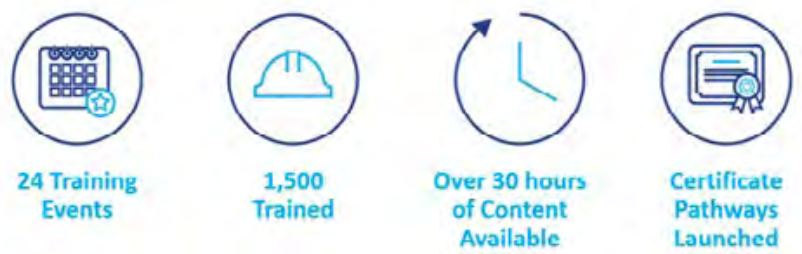

Credit: REMADE

Over the past year 1,500 people have participated in 24 training events. REMADE offers more than 30 hours of unique online training content including certificate pathways, short courses, and recorded webinars. Originally presented at the 2019 Plastics Recycling Conference, the Crash Course in Plastics Recycling was held three times in 2020 to over 600 participants and is now available on-demand. With the dramatic shift to online format due to COVID-19, REMADE expanded its webinar series for project teams to share the accomplishments of their REMADE-funded projects to both members and the general public. Many of the webinars include presentations by the students working on these projects. Over 50 students in engineering and science-related fields are working on REMADE projects, including undergraduates, graduate students, and co-op students. REMADE highlights student contributions in monthly communications through the Institute's "Rising Stars" newsletter.

This year, the institute developed and launched two Awareness-level certificate pathways in response to industry need:
Fundamentals of Remanufacturing - This five-part short-course series is designed for manufacturers new to the remanufacturing industry, skilled engineers and technicians, and incumbent remanufacturers looking for a deeper, technical dive. These short courses offer insights to advance capabilities in remanufacturing, as well as a comprehensive look into the technological advancements delivering widespread benefits to businesses that depend on remanufacturing.

Fundamentals of Mechanical Recycling of Plastics - This four-part certificate pathway series provides an overview on the technology and best practices of mechanical recycling of plastics. Participants will also understand the role of mechanical recycling as it relates to the circular economy and areas of opportunity for technology advancements.

REMADE would like to acknowledge our 2020 REMADE workforce development contributors.
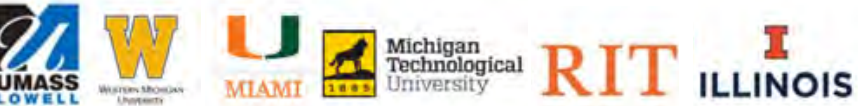

\section{INNOVATION ECOSYSTEM}

"Recognizing that significant, systemwide change is needed to overhaul traditional models of linear consumption, REMADE is bringing together a diverse set of stakeholders through its funded projects. Only through this sort of collaborative action can we yield not just the technology innovation but also the supply chain alignment needed to forge a new circular economy."

-Keefe Harrison, CEO, The Recycling Partnership and REMADE Governance Board member 


\section{Over 250 Participate in Live Online Remanufacturing Bootcamp}

\section{REMADE SUCCESSFULLY ADAPTED TRAINING TO ONLINE IN RESPONSE TO COVID-19}

In partnership with New York State and the Rochester Institute of Technology, REMADE offered a five-part online Remanufacturing Bootcamp. Totaling over seven hours of training from subject matter experts, the bootcamp was designed for manufacturers new to the remanufacturing industry and skilled engineers and technicians seeking industry updates. While training was originally intended for in-person delivery, the Institute quickly adapted to an online format due to the emergence of COVID-19 and the resulting country-wide shutdowns. The training covers an introductory overview of remanufacturing, cleaning technology, condition assessment, additive repair technology, and design for remanufacturing.

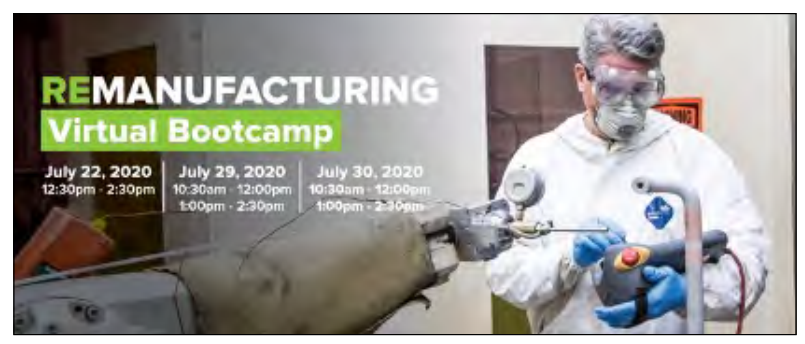

Sustainable Manufacturing Innovation Alliance Corp. Credit: Alex Tong, Rochester Institute of Technology

\section{Transitioning to a Circular Economy for PET and Olefin Polymers}

A team of researchers from Michigan Technological University and Idaho National Laboratory, and their industrial trade association partner, the American Chemistry Council, have developed and validated a modeling framework for systems analysis of polyethylene terephthalate (PET) and olefin polymers in a circular economy. The project was guided by an advisory board of experts from the plastics recycling value chain including Resource Recycling Systems, The Recycling Partnership, Titus MRF Services, Ravago, Association of Plastics Recyclers, 4RSustainability, BASF Corporation, Dow Chemical Company, and Unilever.

The model evaluated how the manufacturing and recycling processes in a plastics circular economy can be configured to minimize energy consumption and greenhouse gas emissions, and provide the greatest benefits economically. The model predicted that it is possible to reduce greenhouse gas emissions by $24 \%$ compared to the current linear economy for PET bottles. ${ }^{15}$ The transition to a circular economy for PET and olefin polymers would also help close an annual gap of more than 1 billion pounds between the current U.S. supply and projected 2025 demand for recycled PET for use in bottles. ${ }^{16}$

\footnotetext{
${ }^{15}$ Chaudhari, U., Lin, Y., Thompson, V., Handler, R, Pearce, J., Caneba, G., Muhuri, P., Watkins, D., Shonnard, D., 2020, Systems Analysis Approach to PET and Olefin Plastics Supply Chains in the Circular Economy: A Review of Datasets and Models, ACS Sustainable Chemistry \& Engineering, submitted Dec. 2020.

${ }^{16}$ The Bridge to Circularity, The Recycling Partnership, 2019.
} 


\section{OVERVIEW}

Funded by the U.S. Department of Energy and led by The University of Texas at San Antonio, CyManll was launched in FY 2020 and comprises 59 proposed members: three Department of Energy National Laboratories (Idaho National Laboratory, Oak Ridge National Laboratory, and Sandia National Laboratories), four manufacturing innovation institutes, 24 universities, 18 industry leaders, and 10 nonprofits. This national network of members will drive impact across the nation and solve biggest cybersecurity challenges facing the U.S manufacturing industry.

"CyManll will address fundamental cybersecurity challenges facing U.S. manufactures. We have already begun a robust and analysis of the cybersecurity technology gaps in our manufacturing."

- Dr. Howard Grimes, Chief Executive Officer, The University of Texas at San Antonio

The primary goal of CyManll is to implement a nationalvision formanufacturing cybersecurity that unleashes American innovation and takes on the challenges ahead in order to drive a cybersecure and energy-efficient U.S. manufacturing model.
"CyManll is the marrying of energy

efficiency and cybersecurity. Our

biggest challenge for this institute is to identify what is going to have the best impact on the industry; what are the innovations that they really need from us looking forward."

- Dr. Greg Shannon, Chief Science Officer, Carnegie Mellon University

\section{TECHNOLOGY ADVANCEMENT}

CyManll uses a clean slate approach to design a future-state based on state-of-the-art physical system design. Via their $\varepsilon$-PURE (epsilon-PURE) secure manufacturing architecture, CyManll also introduces a novel $\varepsilon$-ROI for companies to implement a secure measurement and verification standard across the nation's automated manufacturing operations and their supply chains. CyManll's work is critical if the United States is to be the global leader in manufacturing. Combining physical, cyber, and energy layers in legacy and new systems of manufacturing, this intelligent transformation requires starting with an EnergyEfficient $(\varepsilon)$ Pervasive, Unobtrusive, Resilient, and Economical ( $\varepsilon$-PURE) secure manufacturing architecture.

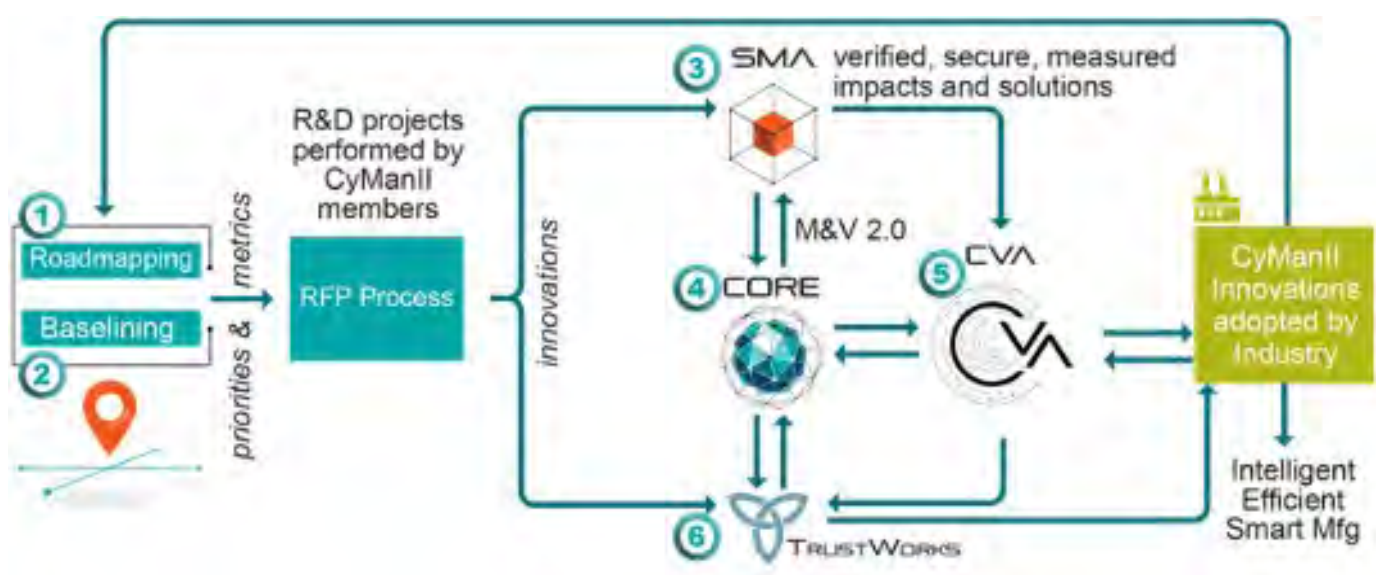

Credit: CyManll 
The intelligent transformation of manufacturing enables dramatic increases in overall equipment energy efficiency, which reduces cost and maximizes innovation. However, the intelligent transformation (combining physical, cyber, and energy layers in legacy and new systems) of manufacturing exponentially grows the cyber-attack surfaces that are challenging and expensive to secure. CyManll aims to tackle both the intelligent manufacturing transformation as well as the vulnerabilities such transformation may create.

\section{INNOVATION ECOSYSTEM AND WORKFORCE PLANS}

\section{"America's manufacturing industry}

is strong, admired, and poised for

transformation. We've assembled a

great team for this grand challenge

with an innovative approach to ensure

U.S. manufacturing is the most secure

and energy- efficient in the world."

-Wayne Austad, Chief Research and

Development Officer, Idaho National Laboratory

CyManll has 59 proposed members, including recognized leaders in smart manufacturing in connected environments and cybersecurity from academia, national laboratories, and industry. Collectively, they hold advanced capabilities in testing and evaluation of critical technologies and are the nation's leaders in threat identification, cyber exploitation, and attack detection in manufacturing environments. CyManll is currently recruiting proposed members to become official members of our network.

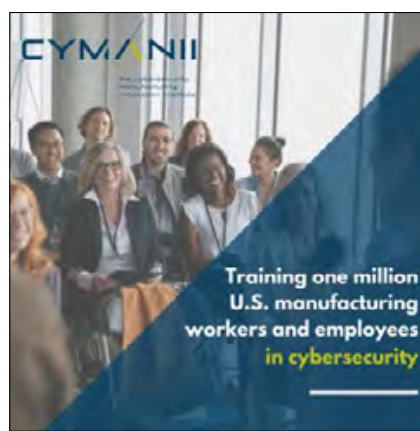

Credit: CyManll

CyManll is committed to facing the challenges within the cybersecurity and manufacturing industries both from a scientific and workforce perspective. Part of CyManll's workforce outreach is Trustworks-aaS (as a Service), a suite of services aimed at supporting industry transformation toward cybersecurity and energy efficiency. Led by a dedicated team of manufacturing workforce technical members, Trustworks is a fee-based service entity within CyManll that gives stakeholders support and education in three categories:

Science: Trustworks-aaS will support stakeholders and members for companyspecific research and development; validating secure practices; developing new solutions; and implementing vulnerability assessments.

Security: Trustworks-aaS will secure technical support for security assessment and implementation.

Education: Trustworks-aaS will provide access to educational content and technical training and provide workshops and in-person training for stakeholders and members.

Via a separate portal connected to CyManll's mainframe, Trustworks-aaS services will be made available to members and non-members alike. Members will enjoy customization and prioritization. Annual revenue raised from fees will be used to continue the support of our institutional research and development projects beyond DOE's initial financial support.

\section{Within the next five years, CyManll plans to train and educate one million workers and employees to make a direct impact on the country's future cybersecurity workforce.}




\section{APPENDIX A: FEDERAL AGENCIES PARTICIPATING IN MANUFACTURING USA}

\section{Department of Commerce}

The U.S. Department of Commerce (DOC) mission is to create the conditions for economic growth and opportunity for the nation. The Department hosts the Advanced Manufacturing National Program Office (AMNPO), an interagency team with participation from federal agencies involved in advanced manufacturing. The AMNPO oversees planning, management, and coordination of Manufacturing USA

The DOC conducts open-topic competitions for institutes, in which industry is invited to propose institutes dedicated to any advanced manufacturing area where new manufacturing technology development is not adequately addressed. The National Institute for Innovation in Manufacturing Biopharmaceuticals (NIIMBL). is the first institute with a focus area proposed by industry and the first funded by the DOC

The Department more broadly increases regional and national capacity for innovative manufacturing through partnerships with state and local governments, academic institutions, and the private sector. Through its convening power, regional economic-development programs, and statistical and economic analysis, it empowers industry-driven solutions to the shortage of indemand skills. Finally, the DOC supports research and development leading to transformative changes in technology and promotes intellectualproperty policy that supports and protects innovation. By all these means, the DOC helps accelerate technology development and strengthen the nation's position in the global competition for new products, new markets, and new jobs.

\section{National Institute of Standards and Technology}

The DOC's National Institute of Standards and Technology (NIST) is the only research laboratory in the U.S. Government specifically focused on enhancing industrial competitiveness; its robust research portfolio is concentrated on the technical challenges associated with advanced manufacturing. In addition, the Manufacturing Extension Partnership National Network is a critical resource for engaging small and mediumsized manufacturers to develop new products, expand into global markets, and adopt new technologies, such as those being developed at the Manufacturing USA institutes. NIST also serves as headquarters for the AMNPO.

\section{Department of Defense}

The U.S. Department of Defense's mission is to provide the combat-credible military forces needed to deter war and protect the security of our nation. To mature and transition DoD science and technology advances into production, the Department must have access to a robust and responsive U.S. industrial base armed with advanced manufacturing technologies that deliver critical products and systems affordably and rapidly. Manufacturing innovative technologies, which enable critical capabilities, ensure that there is never a fair fight between U.S. Service members and potential adversaries.

To help develop the technology and ecosystems needed to support the Department's mission, the DoD established nine manufacturing institutes through its Defense-wide Manufacturing Science and Technology (DMS\&T) program element within the DoD Manufacturing Technology (ManTech) program. Unlike the other manufacturing institutes, the DoD-sponsored manufacturing innovation institutes have the additional mission to develop innovative technologies that will ultimately aid the warfighter.

The DoD manufacturing innovation institutes address commercial and defense manufacturing needs within specific, defense-relevant technology areas and receive active participation and support from the military departments and defense agencies. The institutes' flexible business models and strong focus on enabling highly collaborative research and development catalyze important new organizational relationships across 
government, industry, and academia. Under the leadership of the Under Secretary of Defense for Research and Engineering, the Department continues to foster long-term engagement with the DoD manufacturing innovation institutes to support the DoD's modernization technology areas. Already, the institutes have shown progress in support of cybersecurity for manufacturing, micro-electronics, biotechnology, hypersonics, and automation, among other priorities.

As a key resource for the Department, the DoD intends to continue enriching their public-private partnerships in order to further enable the development of defense-critical technologies into affordable, domestic defense products. Continued strategic and tactical engagement helps to maintain and enhance manufacturing innovation ecosystems that enable shared access to state-of-the-art equipment and facilities for small, medium, and large manufacturers alike, as well as academia. Through fostering Department engagement, these public-private partnerships help ensure domestic and defense manufacturing needs can be met while protecting intellectual property and providing overmatching technology to the warfighter first. The DoD manufacturing institutes further the Department's vision for a National Technology Innovation Base and help ensure that key advanced technologies that are invented in the U.S. are manufactured in the U.S.

In October 2020 the Department of Defense announced the $\$ 87$ million, seven-year award to its ninth manufacturing innovation institute Biolndustrial Manufacturing and Design Ecosystem (BioMADE), a nonprofit created by the Engineering Biology Research Consortium (EBRC). BioMADE, headquartered at the University of Minnesota in St. Paul, will collaborate with public and private entities to advance sustainable and reliable bioindustrial manufacturing technologies. In support of this collaboration, the $\$ 87 \mathrm{M}$ in DoD funding will be combined with over $\$ 187 \mathrm{M}$ in nonfederal cost-share from 31 companies, 57 colleges and universities, 6 nonprofits, and 2 venture capital groups across 31 states.

\section{Department of Education}

The mission of the U.S. Department of Education (ED) is to promote student achievement and preparation for global competitiveness by fostering educational excellence and ensuring equal access. The Department administers the $\$ 1.29$ billion Carl D. Perkins Career and Technical Education Act, the purpose of which is to develop more fully the academic, career, technical, and employability skills of secondary- and postsecondary-education students who elect to enroll in career- and technical-education programs.

The Department has been active in helping develop Manufacturing USA from its formation. In the past year, ED has been working with the Department of Defense and the National Science Foundation to lead and sponsor a series of technical assistance programs. The assistance effort is helping participating institutes to position themselves as key intermediaries between secondary and postsecondary institutions, companies of all sizes, relevant local and state governments, and other key players in the workforce education system. Such efforts are to foster next-generation career and technical education pathways for students, helping them to attain careers in advanced manufacturing. In addition to the agencies listed, the effort was supported by the Department of Commerce.

\section{Department of Energy}

The mission of the Department of Energy (DOE) is to ensure America's security and prosperity by addressing its energy, environmental, and nuclear challenges through transformative science and technology solutions.

The Advanced Manufacturing Office (AMO) within the DOE's Office of Energy Efficiency and Renewable Energy (EERE) is the only technology development office within the DOE that is dedicated to improving the energy and material efficiency, productivity, and competitiveness of manufacturers across the industrial sector. Manufacturing accounts for $25 \%$ of total U.S. energy consumption at an annual cost typically ranging between $\$ 125$ and $\$ 150$ billion. Reducing energy costs can have a significant impact on manufacturing competitiveness, specifically 
improving energy affordability for manufacturers. In addition, manufacturing plays an essential role as a driver of overall economic growth, and manufactured products have a significant impact on energy use in every sector. A robust and competitive domestic manufacturing base is critical to national security because it ensures domestic supplies of key products and assures secure and reliable energy resources for U.S. citizens. To maintain manufacturing competitiveness for future generations, the United States will need to remain a leader in the development of next-generation manufacturing technologies.

AMO brings together manufacturers, not-for-profit entities, research organizations, and institutions of higher education to identify challenges; catalyze innovations; and develop cutting-edge material, process, and information technologies needed for an efficient and competitive domestic manufacturing sector. By targeting efficient manufacturing technologies, AMO seeks to drive energy productivity improvements in the U.S. manufacturing sector, efficiently utilize abundant and available domestic energy resources, and support the manufacture of energy products with benefits extending across the economy.

DOE uses a range of partnership mechanisms, including Manufacturing USA institutes and Energy Innovation Hubs to catalyze the development of advanced manufacturing technologies. As of the end of FY 2020, DOE had six operating Manufacturing USA institutes. Each DOE Advanced Manufacturing USA Institute is designed to accelerate U.S. advanced manufacturing by catalyzing the development of new technologies, national infrastructure, educational competencies, production processes, and products via shared contributions from the public and private sectors and institutions of higher education. These partnerships create an innovation ecosystem that accelerates technology development and facilitates the transition of innovative advanced manufacturing technologies to industry. Developing these national capabilities enables future global leadership in advanced manufacturing.

\section{Department of Health and Human}

\section{Services}

The mission of the U.S. Department of Health and Human Services (HHS) is to enhance and protect the health and well-being of all Americans. The Department achieves this mission by providing for effective health and human services and fostering advances in medicine, public health, and social services. The HHS considers robust manufacturing to be critical to public health security and resilience in the U.S.

The Food and Drug Administration (FDA), an operating division within the HHS, is responsible for protecting public health by ensuring the safety, efficacy, and security of human and veterinary drugs, biological products, medical devices, our nation's food supply, cosmetics, and products that emit radiation. The FDA continues to support development of new tools, standards, and approaches to evaluate the advanced manufacturing of FDA-regulated products. During the 2020 COVID-19 pandemic response, FDA collaborated with Manufacturing USA institutes, especially America Makes, to facilitate use of advanced manufacturing, where possible, for pandemic response and improvements to future responses. The FDA also has several Working Groups that monitor the technology landscape and work closely with Manufacturing USA Institutes. Promising technologies 5 to 10 years in the future are explored by the FDA Emerging Sciences and Technology Working Group. Technologies that are ready for implementation and adoption are considered by the FDA Advanced Manufacturing Technologies Working Group. Furthermore, the FDA awards projects through the FDA's Broad Agency Announcement to support emerging and enabling technologies for advanced manufacturing. Several of the FDA product Centers also have programs to facilitate and foster use of advanced technologies in medical products.

The HHS Biomedical Advanced Research and Development Authority (BARDA) engages regularly with manufacturing organizations through its DRIVe Broad Agency Announcement for funding proposals as well as through outreach efforts. BARDA has allocated $\$ 6.5$ billion in CARES 
Act funding to various critical manufacturing and development projects for pandemic response, including advanced manufacturing activities that will improve supply chain resilience and manufacturing efficiency.

\section{Department of Labor}

The U.S. Department of Labor's Employment and Training Administration (ETA) is the principal workforce development agency in the federal government. The ETA supports sustainable economic growth through leadership and a national investment portfolio that develops workforce skills necessary to support the jobs of today and is positioned to support the jobs of tomorrow, to the benefit of American job seekers and job creators. This portfolio includes significant investments in employment and workforce development solutions.

The ETA administers a number of programs that make up the public workforce system, which contributes to strong, growing regional economies by responding to the workforce needs of job seekers and job creators, including those in advanced manufacturing, to ensure positive employment outcomes for job seekers. Partnerships at the federal, state, and regional levels connect employers, educational institutions, the public workforce system, and economic development partners. These partnerships ensure that job creators have the talent they need to grow and thrive and provide job seekers the opportunity to develop in-demand skills through work-based learning and apprenticeships and to earn industryrecognized credentials.

The ETA supports and is part of the Manufacturing USA Interagency Working Team and the Manufacturing USA Education and Workforce Subcommittee. The agency continues to engage in partnerships, share tools and resources, and identify strategies that can be leveraged to support the Manufacturing USA institutes.

\section{National Aeronautics and Space Administration}

The NationalAeronautics and SpaceAdministration (NASA) is responsible for U.S. space exploration, space technology, Earth and space science, and aeronautics research. The National Aeronautics and Space Act states that, "The aeronautical and space activities of the United States shall be conducted so as to contribute materially to... The preservation of the United States preeminent position in aeronautics and space through research and technology development related to associated manufacturing processes...." ${ }^{18}$ The White House National Space Council's July 2020 policy paper, A New Era for Deep Space Exploration and Development further states that, "Additional efforts should broaden the scope of traditional aerospace industries to include new applications for space technologies and expand space capabilities by infusing technologies from nontraditional but promising fields, such as robotics, artificial intelligence, quantum applications, and additive manufacturing, which have much to offer the space community."19

The Space Technology Mission Directorate (STMD) rapidly develops, demonstrates, and infuses revolutionary, high-payoff technologies required for NASA's future missions in science and exploration while proving the capabilities and lowering the cost for other government agencies and commercial space activities. These collective efforts give NASA the ability to do first-of-a-kind missions and longer-term advancements in research and technology - those beyond what industry will take on and those focused on national advancement in aeronautics and space that also align with NASA's role in Manufacturing USA.

Advanced manufacturing research and development within STMD is focused in several areas, including materials for extreme environments, additive manufacturing, polymer matrix composites, metals processing/joining, robotics, computational physics-based modeling, nondestructive evaluation, and other highly

\footnotetext{
${ }^{18}$ National Aeronautics and Space Act, Pub. L. No. 111-314, 124 Stat. 3328 (Dec. 18, 2010), Title 51-National and Commercial Space Programs, codified at 51 USC \$20102. https://uscode.house.gov/view.xhtml?req=granuleid:USC-prelim-title51-section20102\&num=0 \&edition=prelim

${ }^{19}$ A New Era for Deep Space Exploration and Development, Executive Office of the President, National Space Council (July 23, 2020). https://www.whitehouse.gov/wp-content/uploads/2020/07/A-New-Era-for-Space-Exploration-and-Development-07-23-2020.pdf
} 
specialized areas. Research and development is conducted through a combination of in-house activities at NASA centers, competitively funded research with universities and industry, and collaborations with other government agencies, universities, and industry. NASA is leading the development manufacturing in space and infusing into industry to develop a strong space manufacturing economy. The rapid infusion of advanced manufacturing technologies into mission applications is a major emphasis of NASA's technology-investment strategy.

\section{National Science Foundation}

The National Science Foundation (NSF) supports fundamental advanced manufacturing research, education, and workforce training in its Directorates for Engineering, Biological Sciences, Computer and Information Science and Engineering, Education and Human Resources, Mathematical and Physical Sciences and Social, Behavioral and Economic Sciences and its Offices of Integrative Activities and International Science and Engineering, most notably through its Advanced Manufacturing Program, and through the Future Manufacturing solicitation, first published in 2020. It also promotes advanced manufacturing innovation through a variety of translational research programs, including the Small Business Innovation Research (SBIR), Small Business Technology Transfer (STTR), and Grant Opportunities for Academic Liaison with Industry (GOALI) programs, and by partnering with industry, states, and other agencies.

The NSF's advanced manufacturing investment supports fundamental research leading to transformative advances in process modeling, advanced sensing and control, smart manufacturing using sustainable materials, chemical-reactor design and control, and enabling technology to support a wide range of manufacturing industries, with emphases on efficiency, economy, and minimal environmental impact. Advanced manufacturing is also supported through the Engineering Research Centers (ERC), Industry/University Cooperative Research Centers (I/UCRC), and Advanced Technological Education (ATE) programs. With an emphasis on two-year colleges, the ATE program focuses on the education of technicians for the high-technology fields that drive our nation's economy.

All NSF programs welcome submission of proposals to collaborate with Manufacturing USA institutes on cutting-edge research and educational projects. Awardees whose projects are funded by NSF are also encouraged to request supplemental funding to perform research and/or educational projects in collaboration with institutes. It is expected that incorporation of the resources, expertise, and experience of the institutes and their member companies will increase the competitiveness of such proposals in merit review.

\section{U.S. Department of Agriculture}

The U.S. Department of Agriculture's (USDA) mission is to provideleadershiponfood, agriculture, natural resources, rural development, nutrition, and related issues based on public policy, the best available science, and effective management. USDA provides economic opportunity through innovation, helps rural America to thrive; promotes agriculture production that better nourishes Americans while also helping feed others throughout the world; and preserves our Nation's natural resources through conservation, restored forests, improved watersheds, and healthy private working lands. Each day, the work of USDA scientists and researchers touches the lives of all Americans - from the farm field to the kitchen table and from the air we breathe to the energy that powers our country. USDA intramural and extramural science helps to protect, secure, and improve our food, agriculture and natural resource systems.

Advanced manufacturing R\&D areas of interest include biomanufacturing and other advanced technologies for manufacturing of bio-based products. Products made from feedstocks such as forest-sourced and agricultural fibers are biological and renewable, both traits of materials of the future. Biobased products such as biofuels, industrial chemical intermediates, and performance polymers, present a significant 
opportunity for the United States. Advanced manufacturing technology has the potential for the sustainable harvest and use of renewable biomass while continuing to support food, feed, forest, and fiber markets and create thousands of jobs, many in rural areas. Automation and remote sensing are additional cross-cutting, scientific areas of interest impacting agriculture and rural communities. USDA supports both technology R\&D and infrastructure development. For example, the ReConnect Program furnishes broadband capacity loans and grants for rural areas to implement digital technologies, automate processes, increase productivity, and expand into the global market. Remote work capabilities allow these areas to transcend traditional geographic boundaries to attract the best and brightest minds to their operation.

USDA's Office of the Chief Scientist supports scientific prioritization and coordination across the entire Department including engaging in partnerships, sharing tools and resources, and identifying strategies that can be leveraged to support the Manufacturing USA institutes. 


\section{APPENDIX B: ADVANCED MANUFACTURING NATIONAL PROGRAM OFFICE INTERAGENCY WORKING TEAM PARTICIPANTS}

\author{
Advanced Manufacturing \\ National Program Office \\ Michael F. Molnar (Sponsor) \\ Frank W. Gayle \\ Robert Rudnitsky \\ Said Jahanmir \\ Kelley Rogers \\ Zara Brunner \\ Jessica Strickler \\ Hasan Khan \\ Lisa Fronczek
}

Department of Commerce

Mojdeh Bahar

Mary Ann Pacelli

Ben Vickery
Department of Defense

Tracy Frost (Sponsor)

Mark Jackson

MicKenzie Roberts-Lahti

Mark Gordon

Abhai Kumar

Michael Britt-Crane

John Christensen

David Heckman

Department of Education

Gregory Henschel (Sponsor)

Robin Utz

\section{Department of Energy}

Nebiat Solomon

Sudarsan Rachuri

Michael McKittrick

Chad Schell
Department of Health and Human Services James Coburn, FDA (Sponsor) Jeff Baker, FDA

Department of Labor

Robin Fernkas (Sponsor)

Mark Toal

National Aeronautics and Space Administration John Vickers (Sponsor)

Frank Ledbetter Justin Jackson

National Science

Foundation

Bruce Kramer (Sponsor)

Andrew Wells

U.S. Department of

Agriculture

World Nieh (Sponsor)

Daniel Cassidy

Suzanne Thornsbury 
Disclaimer: Any mention of companies or commercial products within this document is for information only and does not imply recommendation or endorsement by the National Institute of Standards and Technology (NIST) or other federal agencies participating in Manufacturing USA.

Permissions: Unless otherwise noted, tables, figures and images in this report were provided by the participants in the Advanced Manufacturing National Program Office Interagency Working Team. Institutes provided permission for any third-party materials in their sections. 


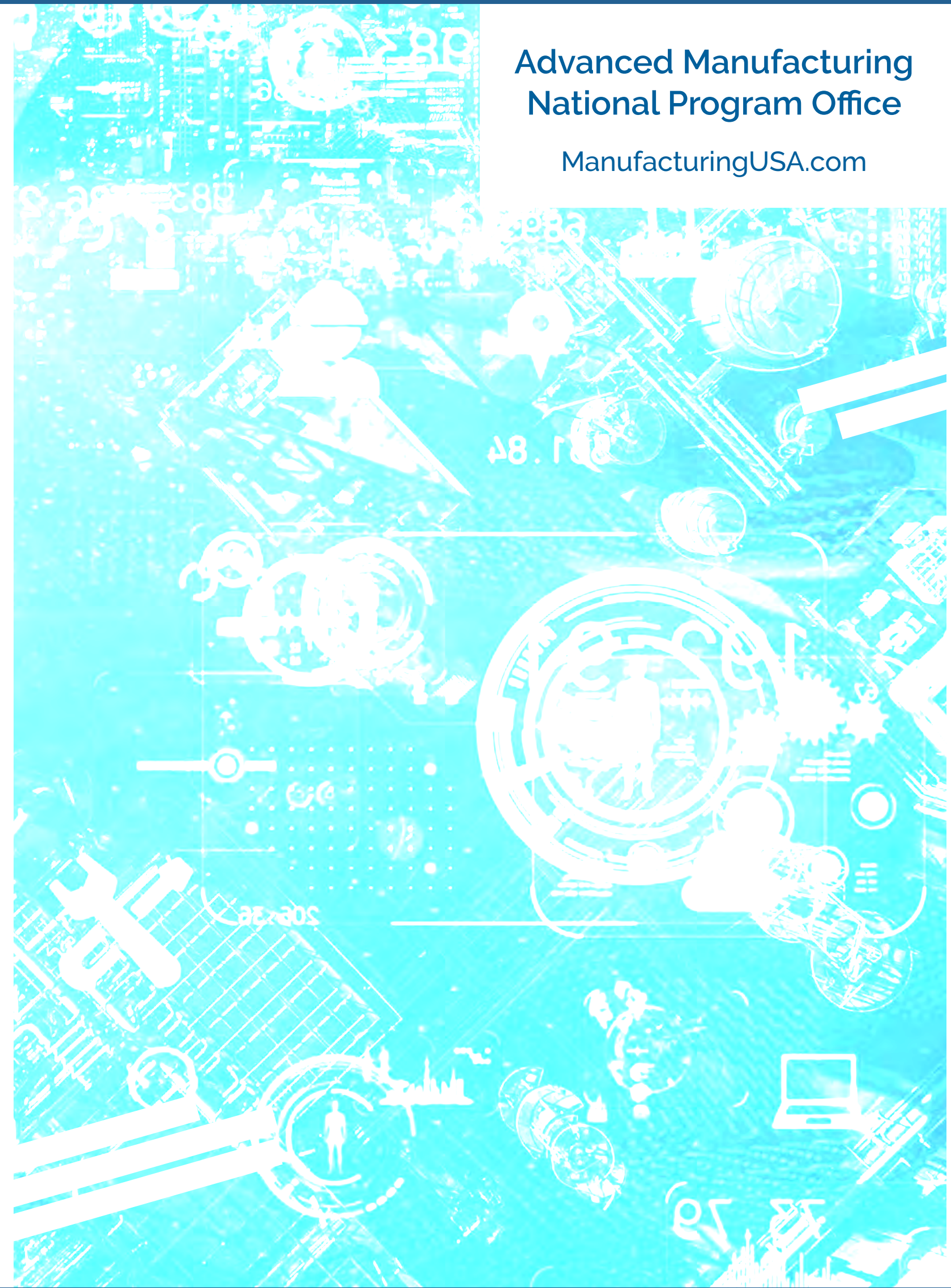

